\title{
Combustion Safety Simplified Test Protocol Field Study
}

L. Brand, D. Cautley, D. Bohac, P. Francisco, L. Shen, and S. Gloss Partnership for Advanced Residential Retrofit and NorthernSTAR

November 2015 


\section{NOTICE}

This report was prepared as an account of work sponsored by an agency of the United States government. Neither the United States government nor any agency thereof, nor any of their employees, subcontractors, or affiliated partners makes any warranty, express or implied, or assumes any legal liability or responsibility for the accuracy, completeness, or usefulness of any information, apparatus, product, or process disclosed, or represents that its use would not infringe privately owned rights. Reference herein to any specific commercial product, process, or service by trade name, trademark, manufacturer, or otherwise does not necessarily constitute or imply its endorsement, recommendation, or favoring by the United States government or any agency thereof. The views and opinions of authors expressed herein do not necessarily state or reflect those of the United States government or any agency thereof.

Available electronically at SciTech Connect http:/www.osti.gov/scitech

Available for a processing fee to U.S. Department of Energy and its contractors, in paper, from:

U.S. Department of Energy

Office of Scientific and Technical Information

P.O. Box 62

Oak Ridge, TN 37831-0062

OSTI http://www.osti.gov

Phone: 865.576 .8401

Fax: 865.576.5728

Email: reports@osti.gov

Available for sale to the public, in paper, from:

U.S. Department of Commerce

National Technical Information Service

5301 Shawnee Road

Alexandria, VA 22312

NTIS http://www.ntis.gov

Phone: 800.553 .6847 or 703.605 .6000

Fax: 703.605.6900

Email: orders@ntis.gov 


\title{
Combustion Safety Simplified Test Protocol Field Study
}

\author{
Prepared for: \\ The National Renewable Energy Laboratory \\ On behalf of the U.S. Department of Energy's Building America Program \\ Office of Energy Efficiency and Renewable Energy \\ 15013 Denver West Parkway \\ Golden, CO 80401 \\ NREL Contract No. DE-AC36-08GO28308
}

Prepared by:

L. Brand, D. Cautley, D. Bohac, P. Francisco, L. Shen, and S. Gloss

Partnership for Advanced Residential Retrofit and NorthernSTAR

Gas Technology Institute

1700 S. Mt. Prospect Road

Des Plaines, IL 60018

NREL Technical Monitor: Stacey Rothgeb

Prepared under Subcontract No. KNDJ-0-40346-05

November 2015 
The work presented in this report does not represent performance of any product relative to regulated minimum efficiency requirements.

The laboratory and/or field sites used for this work are not certified rating test facilities. The conditions and methods under which products were characterized for this work differ from standard rating conditions, as described.

Because the methods and conditions differ, the reported results are not comparable to rated product performance and should only be used to estimate performance under the measured conditions. 


\section{Contents}

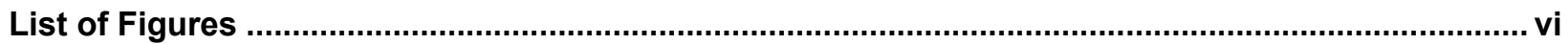

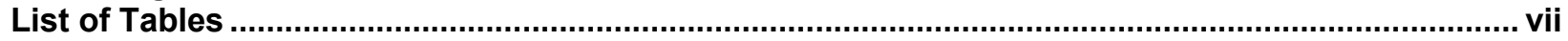

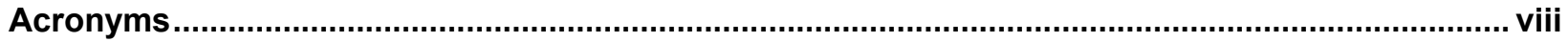

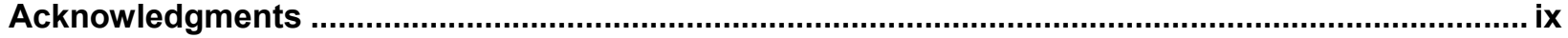

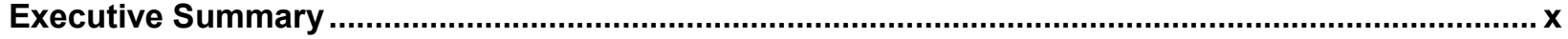

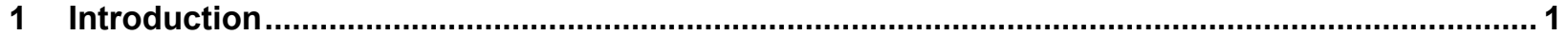

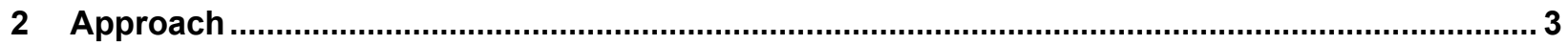

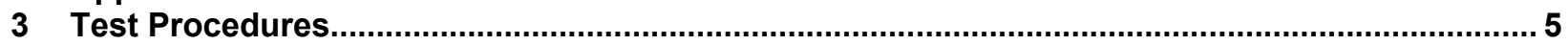

3.1 Test Procedures in Effect at the Time of Project Initiation .................................................. 12

3.1.1 National Fire Protection Agency 54-2012 (National Fuel Gas Code) .......................... 12

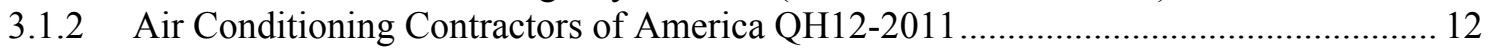

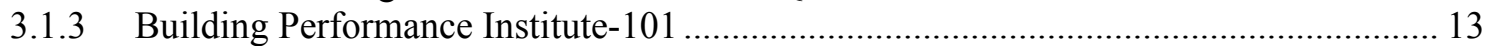

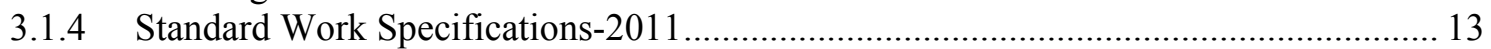

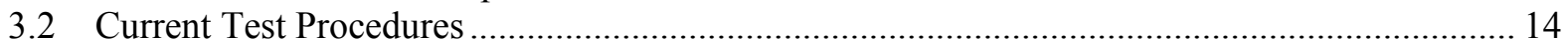

3.2.1 National Fire Protection Agency w2qA 54-2015 (National Fuel Gas Code)................. 14

3.2.2 Air Conditioning Contractors of America QH12-2014 ............................................... 14

3.2.3 Building Performance Institute-1200-2015 ............................................................. 15

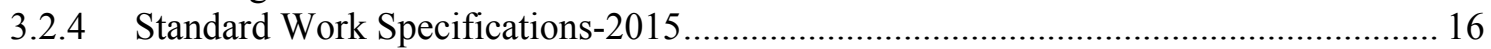

3.3 Overall Alignment and Partnership for Advanced Residential Retrofit/NorthernSTAR

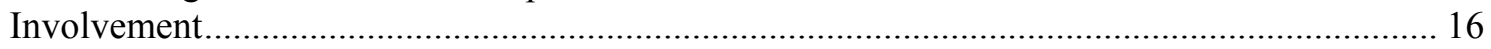

4 Field Data Collection and Analysis

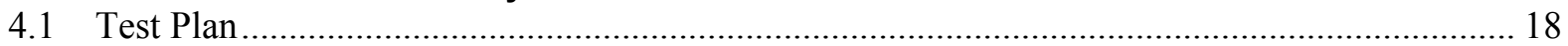

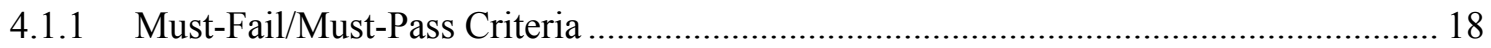

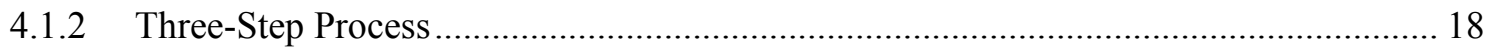

4.2 Field-Test Site Screening and Selection-Sampling Strategy ........................................... 19

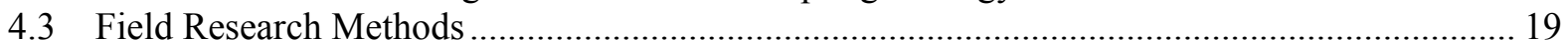

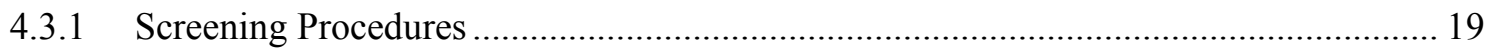

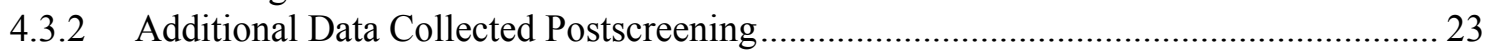

4.3.3 Short-Term Testing and Inspection Methods ........................................................ 24

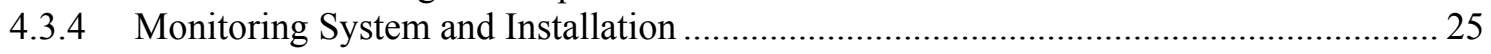

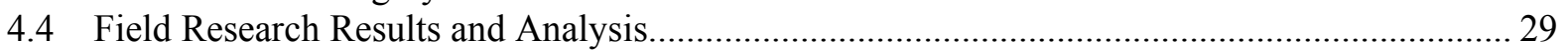

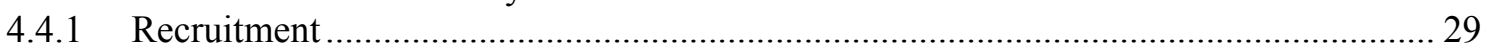

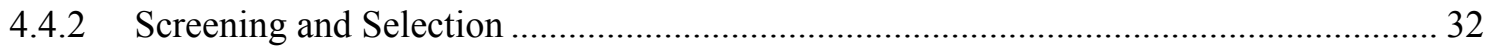

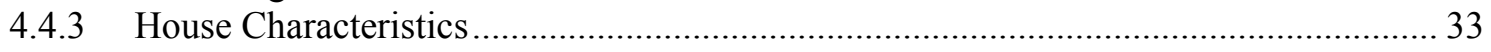

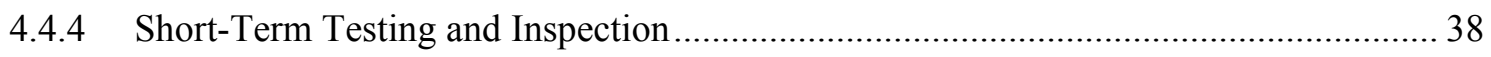

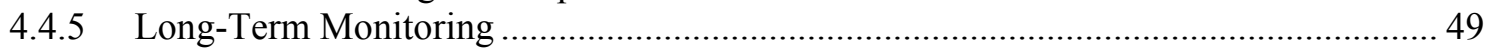

5 Survey Results from State Weatherization Agencies on Combustion Safety Field Data

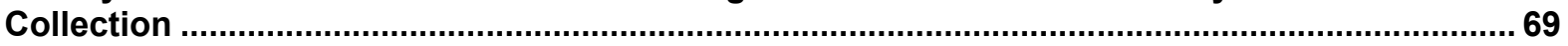

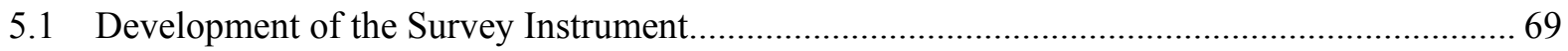

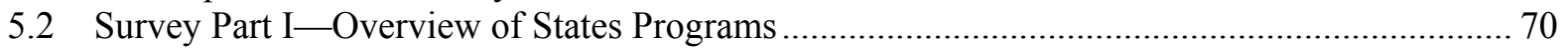

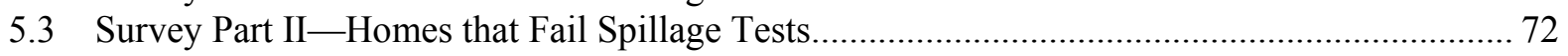

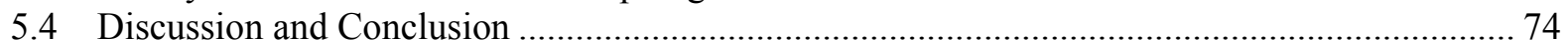

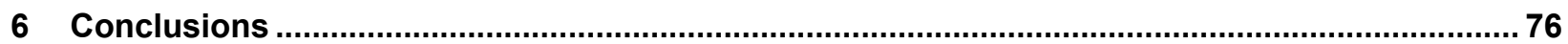

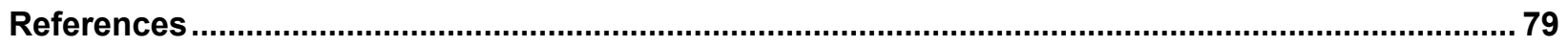

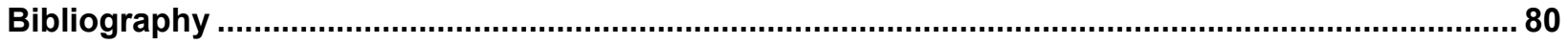

Appendix A. Overview of Short-Term Testing Protocol........................................................... 81

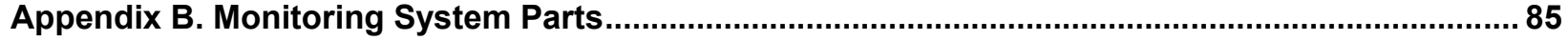

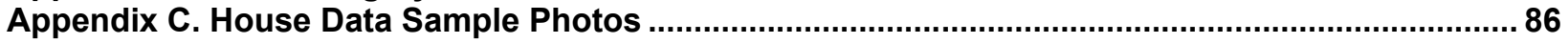

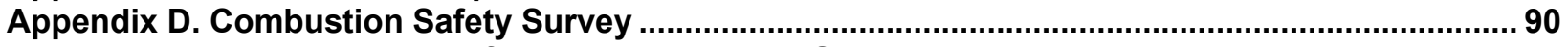

Appendix E Logistic Model Definition and Detailed Output ........................................................... 92 


\section{List of Figures}

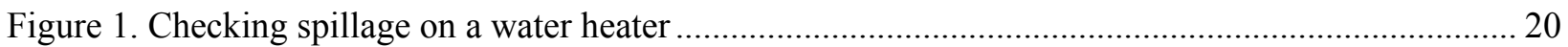

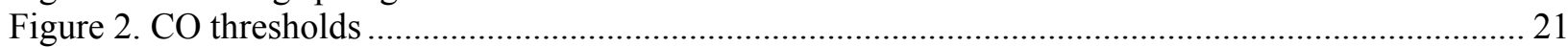

Figure 3. Field-test site selection flowchart ........................................................................ 23

Figure 4. Schematic view of monitoring system sensor placement at water heater................................ 27

Figure 5. Monitoring system main circuit board and valves (yellow tops) in enclosure, cover removed .. 28

Figure 6. Water heater draft hood with copper tube for $\mathrm{CO}_{2}$ sampling and thermocouple temperature wire showing

Figure 7. Custom wireless sensor module (black box) with pressure sensing tube placed in dryer exhaust

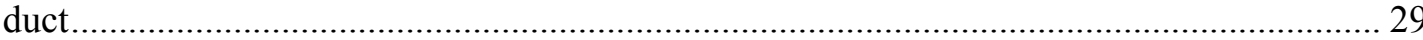

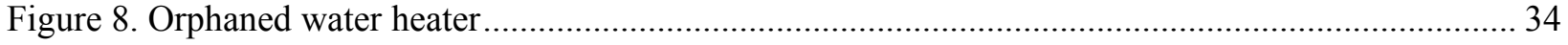

Figure 9. Common vented water heater ..................................................................................... 34

Figure 10. House MN 01 exhaust fan house depressurization (in $\mathrm{Pa}$ ) .................................................... 41

Figure 11. House MN 02 exhaust fan house depressurization (in $\mathrm{Pa}$ ) .................................................... 41

Figure 12. House MN 03 exhaust fan house depressurization (in $\mathrm{Pa}$ ) ................................................. 42

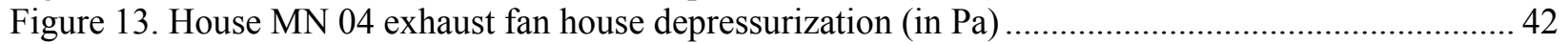

Figure 14. House MN 05 exhaust fan house depressurization (in $\mathrm{Pa}$ ) ................................................... 43

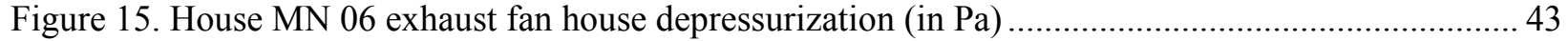

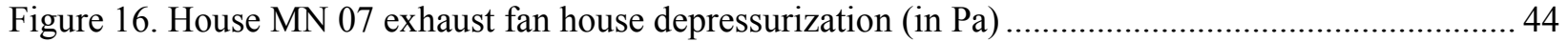

Figure 17. House MN 08 exhaust fan house depressurization (in $\mathrm{Pa}$ ) ................................................... 44

Figure 18. House MN 09 exhaust fan house depressurization (in $\mathrm{Pa}$ ) .................................................... 45

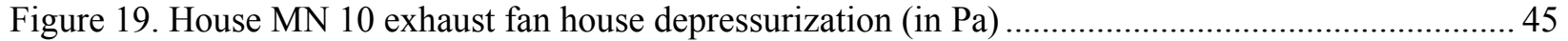

Figure 20. House WI 01 exhaust fan house depressurization (in $\mathrm{Pa}$ ) ................................................... 46

Figure 21. Comparison of the BPI protocol with the STP for measuring CAZ depressurization (in Pa) ... 47

Figure 22. Comparison of the comprehensive protocol with the STP for measuring CAZ depressurization

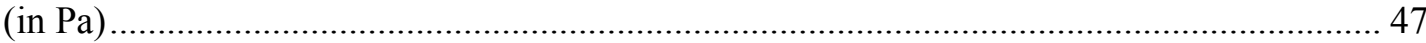

Figure 23. Comparison of the modified protocol with the STP for measuring CAZ depressurization (in

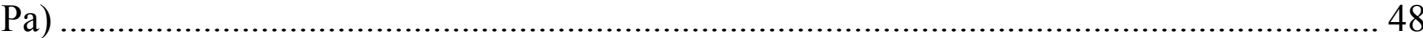

Figure 24. Comparison of the comprehensive protocol with the BPI protocol for measuring CAZ

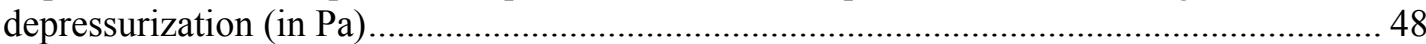

Figure 25. Average number of water heater burner cycles per day, by house ......................................... 51

Figure 26. Water heater burner runtime distribution, by house ........................................................... 51

Figure 27. Conditions during characteristic water heater burner cycle, House MN 01. Time shown in hours, minutes, and seconds. A brief increase in $\mathrm{CO}_{2}$ concentration at the start of the cycle is evidence of spillage, but the four spillage temperatures in the bottom panel show no

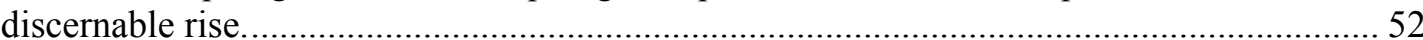

Figure 28. Fan runtime and CAZ door closed time, by house ............................................................ 54

Figure 29. Conditions during long-lasting spillage episode, House WI 01. Time shown in hours, minutes, and seconds. A sustained elevation of $\mathrm{CO}_{2}$ concentration and obvious rise in all four spillage temperatures (bottom panel) provide evidence of prolonged spillage. .................................. 56

Figure 30. Number of water heater cycles lasting at least as long as time displayed, in 2-minute bins. Cycles with spillage are differentiated by color.................................................................. 57

Figure 31. Logistic model fits for probability of spillage at selected outdoor temperatures and by time into

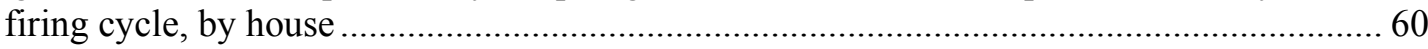

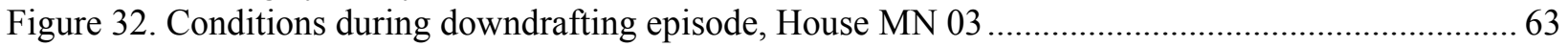

Unless otherwise noted, all figures were created by the Partnership for Advanced Residential Retrofit and NorthernSTAR. 


\section{List of Tables}

Table 1. Combustion Safety Testing Requirements from Multiple Standards in 2012 and 2015............... 6

Table 2. Combustion Appliance Safety Test Procedures Differences and Similarities ............................. 7

Table 3. Range of Building Types for the Four Climates ...................................................................... 19

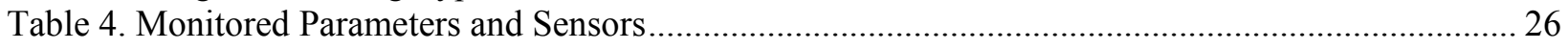

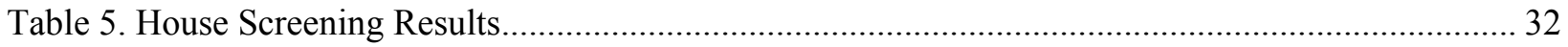

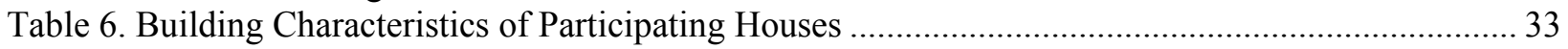

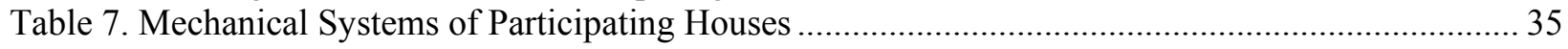

Table 8. Combustion Vent Configuration: Orphaned Water Heaters ..................................................... 35

Table 9. Combustion Vent Connector Configuration: Common Vented Water Heaters ............................ 36

Table 10. Common Vent Configuration: Common Vented Water Heaters …........................................... 36

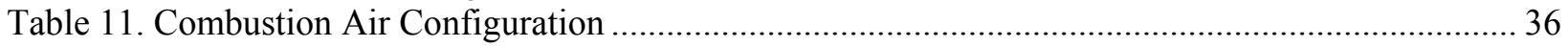

Table 12. Clothes Dryer and Kitchen Exhaust Fan Characteristics ....................................................... 38

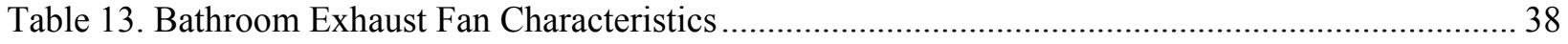

Table 14. Scheduled Visits of Screening and Short-Term Testing Visits................................................ 39

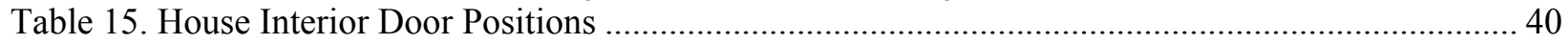

Table 16. Comparison of CAZ Pressure Measurements from Four WC Protocols for Participating Houses,

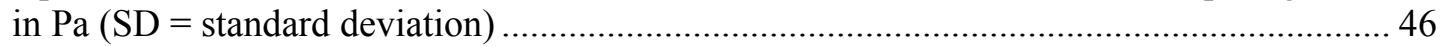

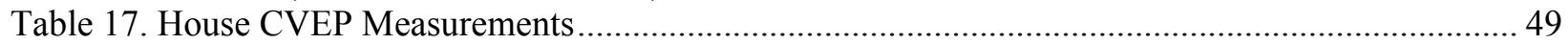

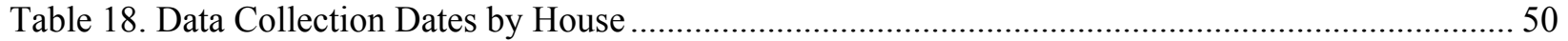

Table 19. Summary of Air Handlers, Exhaust Devices, and CAZ Door Monitoring ............................... 53

Table 20. Water Heater Spillage Time by House …............................................................................. 57

Table 21. Summary of Coefficients (odds ratio) from Logistic Regression Predictors for Spillage (Model

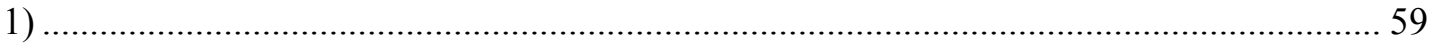

Table 22. Summary of Coefficients (odds ratio) from Logistic Regression Predictors (binary indicators of device operation) for Water Heater Spillage (Model 2) .........................................................5

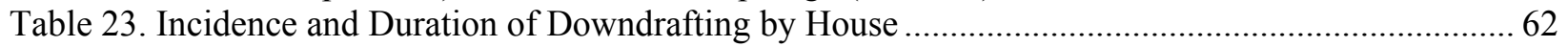

Table 24. Incidence and Duration of Downdrafting Episodes Coinciding with Water Heater Burner

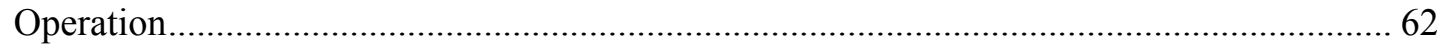

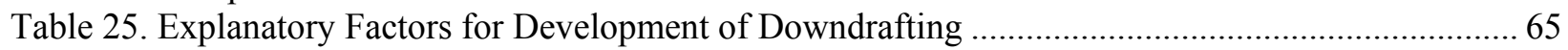

Table 26. Observed CO Concentrations in CAZ Airspace by House ..................................................... 67

Unless otherwise noted, all tables were created by the Partnership for Advanced Residential Retrofit and NorthernSTAR. 


\section{Acronyms}

ACCA

ANSI

BPI

CAZ

CEE

$\mathrm{CO}$

$\mathrm{CO}_{2}$

CVEP

DOE

LIWAP

NFGC

NFPA

NREL

PARR

RESNET

STP

SWS

WAP

WC

Wx
Air Conditioning Contractors of America

American National Standards Institute

Building Performance Institute

Combustion Appliance Zone

Center for Energy and Environment

Carbon Monoxide

Carbon Dioxide

Cold Vent Establishment Pressure

U.S. Department of Energy

Low Income Weatherization Assistance Program

National Fuel Gas Code

National Fire Protection Association

National Renewable Energy Laboratory

Partnership for Advanced Residential Retrofit

Residential Energy Services Network

Simplified Test Procedure

Standard Work Specifications

Weatherization Assistance Program

Worst Case

Weatherization Retrofit 


\section{Acknowledgments}

The authors would like to thank several key contributors to this significant effort. From the Minnesota Center for Energy and the Environment: Alex Haynor for his help installing the monitoring equipment in all the Minnesota locations, Kirk Kolehma for conducting the screening visits for the Minnesota houses and performing the short-term tests at all 11 monitored houses, and Jim Fitzgerald who provided guidance on test protocols from his vast experience and performed the appliance combustion vent and air sizing analysis.

The researchers thank the survey participants who provided responses from Alaska, Arkansas, Colorado, Idaho, Illinois, Kansas, Minnesota, Missouri, New Hampshire, New Jersey, New Mexico, New York, Oregon, Texas, Virginia, Washington State, and Washington, D.C. The authors also thank all the weatherization agency professionals in the many states who looked for homes to participate in this study as well as those who responded to the project survey. The National Association for State Community Services Programs' assistance in getting the word out is gratefully acknowledged. The authors thank the staff of Lawrence Berkeley National Laboratory for their valuable contributions to the combustion safety research done by the Partnership for Advanced Residential Retrofit and NorthernSTAR teams during the past several years. A special thanks to the homeowners of the 11 participating homes for their patience and for the invaluable field data used in this project.

Finally the authors offer a special thanks to Merry Sweeney from GTI who built this report with submissions from the many contributors in record time. 


\section{Executive Summary}

Combustion safety testing is an important step in the process of upgrading homes for energy efficiency. Field practitioners use several approaches based on published standards. Researchers have indicated that the test procedures in use are complex to implement in the field and provide too many false positives - i.e., too many failures that do not relate to long-term problems in the home. Failures often mean that money is diverted from energy-efficiency measures - or upgrades may not be made at all - if the program does not include remediation of safety issues. In this report the U.S. Department of Energy's Building America research teams Partnership for Advanced Residential Retrofit and NorthernSTAR provide a simplified test procedure (STP) that is easier to implement and should produce fewer false positives. The report includes a survey of state weatherization agencies on combustion safety issues, details of a field data collection instrumentation package, summary of data collected over 7 months, data analysis, and results.

The project provides several key results. State weatherization agencies do not generally track combustion safety failures. The data from those that do suggest limited actual evidence that combustion safety failures due to spillage from nondryer exhaust are common and that only a very small number of homes are subject to the failures.

Based on sequential application of the tests in the field, the STP identifies problem houses as effectively as the worst-case procedures.

The project team collected field data over a period of 7 months on 11 houses that indicated failures under the STP. Of these, 2 houses that demonstrated prolonged and excessive spillage were also the only 2 with venting systems that were out of compliance with the National Fuel Gas Code. The remaining homes experienced spillage that only occasionally extended beyond the first minute of operation. Combustion zone depressurization, outdoor temperature, and operation of individual fans all provide statistically significant predictors of the low level of spillage observed in these houses.

The authors concluded that vent system inspection should be the primary element of any combustion safety evaluation, and auditors need appropriate training to recognize vent system deficiencies. Carbon monoxide monitoring is an important part of the test and should also be included. The STP is an improvement over the worst-case approaches, but it still overpredicts the occurrence of problem houses. More work is needed to establish a more-predictive short-term test method.

These results are based on the 17 states that responded to the survey and the 11 houses instrumented in the project over 7 months. Technology transfer has already begun in the form of contributing many of the recommendations in the STP to the Building Performance Institute1200 standard that was published in the spring of 2015. 


\section{Introduction}

Performing energy-efficiency upgrades in existing homes requires a number of steps to achieve the best performance and ensure continued occupant safety. The weatherization agency or home performance contractor will ensure safe operation at test-in before the work is done and again at test-out to confirm that the upgrades applied did not impact the safety of the home. Combustion safety is one of the elements evaluated by the agency or contractor.

Combustion safety is the general term for evaluating gas-fired water heaters, boilers, and furnaces for safe operation. Several approaches are used to:

- Inspect vents and heat exchangers for corrosion or cracking

- Assess whether the vent is installed according to code

- Measure draft hood spillage time

- Evaluate the carbon monoxide (CO) in both the appliance flue and in the occupied space.

This report focuses on combustion safety test procedures in high-performance houses.

High-performance homes follow the "seal tight and ventilate right" approach to air sealing before thermal envelope and equipment upgrades are applied. Sealing tight reduces the infiltration load on the heating and cooling system, but it also reduced the availability of combustion air. Unless appropriately sized combustion air openings are installed according to code, exhaust fans tend to depressurize the house, further reduce the availability of combustion air, and impede the formation of normal draft in vent systems. These fans are generally range hood exhausts, standard gas or electric clothes dryers, and, to a lesser extent, bath fans and unbalanced whole-house ventilation fans. Air handler blowers can and do create depressurization when they serve unbalanced areas such as bedrooms with supply but no return ducting (unless a transfer grille is used), when passing through space that does not reside fully within the pressure envelope (unconditioned space), and in some cases simply if the ductwork is not well sealed. Wood-burning fireplaces (which are beyond the scope of this study) may also have an impact on house depressurization levels.

Field practitioners use several combustion safety test procedures, which are generally based on the training of the inspector. The Building Performance Institute (BPI), Residential Energy Services Network (RESNET), and the National Fuel Gas Code (NFGC) all provide combustion safety test procedures. Traditionally, the more commonly used procedures create worst-case (WC) conditions: draft hood spillage time is assessed when all exhaust fans are operating on high speed and all operable doors are adjusted such that the greatest negative pressure is developed near the gas appliance being tested. The inspector flags homes that fail the WC test; these homes may not be eligible for an energy-efficiency upgrade. Although the testing standards have recently moved away from WC conditions, few field data remain to correlate the test result to the actual combustion safety incidents in the home. In fact, the general assumption is that the combustion safety test is too severe and results in many false positives that are not supported by the actual operation of the house (Rapp et al. 2012; Cautley et al. 2012). The greatest needs are: 
- Hard data about field failures

- A simplified test procedure (STP) that is more predictive than the commonly used procedures of failure under real operating conditions in occupied homes

- Data from the field to verify the effectiveness of the proposed test procedure.

The U.S. Department of Energy's (DOE's) Building America research team Partnership for Advanced Residential Retrofit (PARR) addressed combustion safety in a measure guideline: Combustion Safety for Natural Draft Appliances Using Indoor Air (Brand 2014). NorthernSTAR produced a measure guideline: Combustion Safety for Natural Draft Appliances through Appliance Zone Isolation (Fitzgerald and Bohac 2014). These guidelines are based on current codes and standards and building performance audit techniques that weatherization teams, gas utility inspectors, and building performance contractors use in the field.

Improving the ability to identify combustion appliance hazards will allow DOE and Building America to conduct more home efficiency upgrades and make progress toward achieving the goal of 30\% energy reduction in existing homes according to the 2009 International Energy Conservation Code standard. 


\section{Approach}

The approach to this project was to:

- Support an STP based on the field experience of the PARR and NorthernSTAR Building America teams. Specifically, the proposed STP is expected to:

○ Include a setup for depressurization testing with prescribed door positions.

- Include the impact of leaky ducts in setting up depressurization testing (as part of evaluating the impact of the air handler operation).

- Include the impacts of the dryer, range hood, whole-building ventilation system, and largest fan.

- Operate the largest fans at lower rates.

$\circ$ Use spillage test times that depend on the appliance and the season when the testing is being conducted.

- Test for CO level in the appliance flue that exceeds the American National Standards Institute (ANSI) certification threshold limit for the type of appliance.

- Avoid draft pressure testing and failure criteria based on draft pressure.

$\circ$ Avoid the requirement that the technician drill a hole in the vent system.

- Measure the house depressurization levels produced by a severe condition (must fail) and a less severe (must pass) condition in the field.

- Collect and analyze continuous field data from homes that fail the most severe condition and pass the less severe condition. Use the field data to correlate the proposed test with conditions occurring in the houses.

- In parallel, survey state weatherization agencies to gather data about the frequency and severity of combustion safety failures and the approach to remediation.

- Participate in the 2015 update of the BPI-1200-S "Standard Practice for Basic Analysis of Buildings" to apply the concepts from this project.

The scope of this project was limited to combustion safety for houses in which the appliances were installed within the pressure boundary of the space (includes basements unless isolated) that take air for combustion and dilution from inside the pressure boundary or from a combination of inside and outside the pressure boundary.

This study also focused on nondryer exhausts and door positioning. Dryers and air handlers commonly operate at the same time as other combustion appliances, so combustion safety failures due to dryers or air handler operation were considered to be serious issues that should be addressed. Homes that failed due to either dryer or air handler operation were excluded from the study. However, failures due to all exhausts running at their highest flows and specific positioning of interior doors were considered less likely to all occur simultaneously and with other combustion appliance operation; therefore, this was the primary target scenario for this project. 
The following research questions were to be answered in this project:

1. Does the STP accurately predict combustion safety hazards as determined by long-term monitoring? Does it predict hazards more accurately than the conventional protocol used by weatherization agencies?

2. Is the STP practical for field implementation, and can it be improved?

3. What is the incidence of spillage and combustion safety failures based on feedback from weatherization agencies and other field experience? 


\section{Test Procedures}

Combustion safety test procedures for existing buildings were highly varied at the time that the overall effort to simplify combustion safety testing started in earlier projects. Procedures that were simple were also inadequate for the range of conditions encountered in existing homes. Procedures that considered all the most vital potential problems were too complex. Even for metrics that were covered by multiple procedures, the values at which passage or failure was indicated were inconsistent.

These standards have been substantially aligned, in part due to the contributions of PARR team members. This process has not always been simple or without controversy. However, at this time many (though not all) the simplifications proposed by the PARR and NorthernSTAR teams have been incorporated into these standards.

This section discusses four sources for combustion safety guidelines:

- NFPA 54 (the National Fuel Gas Code [NFGC])

- Air Conditioning Contractors of America (ACCA) Standard QH12

- BPI Standards 101 and 1200

- The National Renewable Energy Laboratory's (NREL's) Standard Work Specifications (SWS) (NREL 2013).

The section is divided into several parts: the standards as of PARR/NorthernSTAR project initiation, the standards today, and the involvement of PARR/NorthernSTAR team members in the evolution of these standards. Other standards, including derivatives implemented by specific programs, are not included Table 1 shows the various key requirements incorporated into each of these standards in 2012 and 2015. Table 2 shows the primary differences and similarities between combustion appliance safety test procedures.

In Table 1, definitions of column headings are as follows:

- Org/Std-Yr: the organization, standard, and standard publication date

- Req.?: whether or not the organization requires that the testing be done

- Focus appliances: which appliances are covered by the standard

- Combustion appliance zone (CAZ) door: whether the standard includes evaluation of the impact of the position of the door to the combustion appliance zone (Test) or has it in a specific position throughout (e.g., Closed)

- Other doors: whether the standard includes evaluation of the impact of positioning of other interior doors (Test each), does not require any evaluation (No), or specifies door positioning without further evaluation (Default)

- Air Handler: whether the standard sets maximum depressurization limits that indicate failure of the appliance regardless of actual spillage or draft problems

- Spillage: allowable time to last spillage

- Draft: whether a separate test for draft is conducted. 
Table 1. Combustion Safety Testing Requirements from Multiple Standards in 2012 and 2015

\begin{tabular}{|c|c|c|c|c|c|c|c|c|}
\hline $\begin{array}{c}\text { Org/ } \\
\text { Std-Yr }\end{array}$ & Req.? & Focus Appliances & $\begin{array}{l}\text { CAZ } \\
\text { Door }\end{array}$ & $\begin{array}{l}\text { Other } \\
\text { Doors }\end{array}$ & $\begin{array}{c}\text { Air } \\
\text { Handler }^{\mathrm{a}}\end{array}$ & Limits & Spillage & Draft \\
\hline \multicolumn{9}{|c|}{ Requirements as of 2012} \\
\hline NFPA/NFGC-2012 & No & Existing furnaces and boilers & Closed & No & No & No & $5 \mathrm{~min}$ & No \\
\hline ACCA/QH12-2011 & Yes & Existing appliances & Test & Test each & No & No & $5 \mathrm{~min}$ & No \\
\hline BPI/101-2011 & Yes & Existing appliances & Test & Test each & Yes & Yes & $1 \mathrm{~min}$ & Yes \\
\hline NREL/SWS-2011 & Yes & Existing appliances & Test & Test each & Yes & Yes & $2 \mathrm{~min}$ & No \\
\hline \multicolumn{9}{|c|}{ Requirements as of 2015} \\
\hline NFPA/NFGC-2015 & No & Existing appliances & Test & No & Yes & No & $5 \mathrm{~min}$ & No \\
\hline ACCA/QH12-2014 & Yes & Existing appliances & Test & Test each & Yes & No & $5 \min$ & No \\
\hline BPI/101-2015 & Yes & Existing appliances & Test & Default & Yes & No & 2 or $5 \min ^{c}$ & No \\
\hline NREL/SWS-2015 & Yes & Existing appliances & Test & Default & Yes & No & 2 or $5 \min ^{c}$ & No \\
\hline
\end{tabular}


Table 2. Combustion Appliance Safety Test Procedures Differences and Similarities

\begin{tabular}{|c|c|c|c|c|}
\hline & $\begin{array}{c}\text { ACCA } \\
\text { (ACCA QH12 2014) }\end{array}$ & $\begin{array}{l}\text { NFGC } 2015 \text { Annex G } \\
\text { (NFPA 2015) }\end{array}$ & $\begin{array}{c}\text { BPI } \\
(B P I-1200-2015) \\
\end{array}$ & STP \\
\hline $\begin{array}{l}\text { Occupant and Inspector } \\
\text { Safety } \\
\text { Note: A CO alarm must } \\
\text { sound within the } \\
\text { following three } \\
\text { concentrations and time } \\
\text { windows to meet } \\
\text { Underwriters } \\
\text { Laboratories standards: } \\
\text { - } 60-240 \text { min for } 70 \\
\text { ppm } \\
\text { - No less than } 10 \text { min } \\
\text { for } 150 \text { ppm } \\
\text { - } 4-15 \text { min for } 400 \text { ppm }\end{array}$ & $\begin{array}{l}\text { - If ambient CO levels of } 9 \text { ppm } \\
\text { are detected for more than } 15 \\
\text { min, the auditor shall have the } \\
\text { discretion to stop all CO and } \\
\text { depressurization testing. } \\
\text { - If ambient CO levels of } 25 \\
\text { ppm are detected, the auditor } \\
\text { shall stop all CO and } \\
\text { depressurization testing. }\end{array}$ & $\begin{array}{l}\text { - If ambient CO is } 70 \text { ppm or } \\
\text { greater, evacuate and call } \\
911 . \\
\text { - If ambient CO is } 30-70 \\
\text { ppm, the inspector should } \\
\text { recommend all CO sources } \\
\text { be turned off and windows } \\
\text { and doors opened. } \\
\text { - } 30 \text { ppm or lower, the } \\
\text { inspection can continue. } \\
\text { - Combustible gas of } 20 \% \\
\text { lower explosive limit or } \\
\text { higher, evacuate and call } \\
\text { 911. } \\
\text { - Combustible gas below } 20 \% \\
\text { lower explosive limit, } \\
\text { inspection can continue. }\end{array}$ & $\begin{array}{l}\text { If ambient CO is } 70 \text { ppm or greater, } \\
\text { evacuate and notify appropriate } \\
\text { emergency services. } \\
\text { - If ambient CO is } 36-69 \text { ppm, the } \\
\text { inspector should recommend all } \\
\text { CO sources be turned off and } \\
\text { windows and doors opened. } \\
\text { - If ambient CO is 9-35 ppm, the } \\
\text { inspector should advise occupants } \\
\text { of the reading and recommend } \\
\text { checking possible sources and } \\
\text { opening windows and doors. } \\
\text { - Combustible gas greater than } 10 \% \\
\text { lower explosive limit, evacuate and } \\
\text { notify appropriate emergency } \\
\text { services. }\end{array}$ & No specific requirement \\
\hline $\begin{array}{l}\text { Detection of Gas Leaks } \\
\text { from Piping or Fittings }\end{array}$ & $\begin{array}{l}\text { - Check all exposed gas piping } \\
\text { in the building for leaks with } \\
\text { the appropriate gas detector } \\
\text { capable of measuring } 20 \mathrm{ppm} \text {. } \\
\text { - Confirm leaks with leak- } \\
\text { detection fluid. } \\
\text { - Mark the locations of leaks } \\
\text { with a clearly visible tag and } \\
\text { notify the owner. }\end{array}$ & $\begin{array}{l}\text { - Check leaks with } \\
\text { noncorrosive leak detection } \\
\text { fluid or } \\
\text { - Check leaks with } \\
\text { combustible gas detector } \\
\text { confirmed with } \\
\text { noncorrosive leak detection } \\
\text { fluid. }\end{array}$ & $\begin{array}{l}\text { - Test according to NFGC Ch. } 8 \text { and } \\
\text { Annex C where called for by local } \\
\text { jurisdiction or } \\
\text { - Check gas piping for leaks with } \\
\text { combustible gas detector confirmed } \\
\text { with noncorrosive leak detection } \\
\text { fluid. }\end{array}$ & No specific requirement \\
\hline
\end{tabular}




\begin{tabular}{|c|c|c|c|c|}
\hline & $\begin{array}{c}\text { ACCA } \\
\text { (ACCA QH12 2014) }\end{array}$ & $\begin{array}{c}\text { NFGC } 2015 \text { Annex G } \\
\text { (NFPA 2015) }\end{array}$ & $\begin{array}{c}\text { BPI } \\
(B P I-1200-2015) \\
\end{array}$ & STP \\
\hline $\begin{array}{l}\text { Inspection of Appliance } \\
\text { Condition while Off }\end{array}$ & $\begin{array}{l}\text { Document whether the } \\
\text { combustion appliance venting } \\
\text { system shows evidence of the } \\
\text { following: } \\
\text { - Blockages } \\
\text { - Soot } \\
\text { - Corrosion or oxidation } \\
\text { - Improper support, slope, } \\
\text { and/or termination }\end{array}$ & $\begin{array}{l}\text { - Verify vent systems are } \\
\text { compliant with NFGC } \\
\text { chapters } 11 \text { and } 12 \text {. Size and } \\
\text { installation for other than } \\
\text { natural draft and Category I } \\
\text { appliances should be in } \\
\text { compliance with the } \\
\text { manufacturer's instructions. } \\
\text { - Inspect for damage, } \\
\text { blockages, restrictions, } \\
\text { leakage and corrosion. } \\
\text { - Ensure plastic venting } \\
\text { systems are free of sagging } \\
\text { and are sloped upward. } \\
\text { - Inspect internal components. }\end{array}$ & $\begin{array}{l}\text { Inspect vent system to ensure that } \\
\text { the materials and horizontal pitch } \\
\text { meet the manufacturers' } \\
\text { specifications. } \\
\text { - Inspected for blockages, } \\
\text { restrictions, leakage, and corrosion. } \\
\text { - Inspect visible sections of } \\
\text { combustion chamber and wiring. }\end{array}$ & No specific requirement \\
\hline $\begin{array}{l}\text { General Appliance } \\
\text { Operation }\end{array}$ & $\begin{array}{l}\text { Document whether the } \\
\text { combustion appliance venting } \\
\text { system shows insufficient } \\
\text { performance for the following: } \\
\text { - Blockages } \\
\text { - Soot } \\
\text { - Corrosion or oxidation } \\
\text { - Improper support, slope, } \\
\text { and/or termination } \\
\text { - Insufficient draft }\end{array}$ & $\begin{array}{l}\text { Check proper ignition and } \\
\text { ensure safety features are } \\
\text { functioning properly. } \\
\text { - Visually check flame } \\
\text { appearance and ensure main } \\
\text { gas burner is burning } \\
\text { properly. } \\
\text { - Verify appliance shuts off } \\
\text { properly. }\end{array}$ & No specific requirement & No specific requirement \\
\hline
\end{tabular}




\begin{tabular}{|c|c|c|c|c|}
\hline & $\begin{array}{c}\text { ACCA } \\
\text { (ACCA QH12 2014) }\end{array}$ & $\begin{array}{l}\text { NFGC } 2015 \text { Annex G } \\
\text { (NFPA 2015) }\end{array}$ & $\begin{array}{c}\text { BPI } \\
(\text { BPI-1200-2015) } \\
\end{array}$ & STP \\
\hline Baseline Testing & No specific requirement & No specific requirement & $\begin{array}{l}\text { - Place all appliances in CAZ on } \\
\text { standby mode. } \\
\text { - Close fireplace dampers and doors } \\
\text { and ensure that they are fully } \\
\text { extinguished. } \\
\text { - Close all exterior doors and } \\
\text { windows. } \\
\text { - Close interior doors between CAZ } \\
\text { and rest of house. } \\
\text { - Close interior doors to all rooms } \\
\text { except for rooms with an exhaust } \\
\text { fan, central forced-air system } \\
\text { return. } \\
\text { - Turn off mechanical forced-air } \\
\text { heating and cooling systems. }\end{array}$ & No specific requirement \\
\hline
\end{tabular}




\begin{tabular}{|c|c|c|c|c|}
\hline & $\begin{array}{c}\text { ACCA } \\
(\mathrm{ACCA} \text { QH12 2014) }\end{array}$ & $\begin{array}{l}\text { NFGC } 2015 \text { Annex G } \\
\text { (NFPA 2015) }\end{array}$ & $\begin{array}{c}\text { BPI } \\
\text { (BPI-1200-2015) }\end{array}$ & STP \\
\hline $\begin{array}{l}\text { Preparing for WC } \\
\text { Testing }\end{array}$ & $\begin{array}{l}\text { - Close all exterior windows, } \\
\text { doors, and attic hatches. } \\
\text { - Ensure that drain traps are } \\
\text { filled with water. } \\
\text { - Turn on all indoor fans: } \\
\text { bathroom exhaust, range hood, } \\
\text { clothes dryer, powered attic } \\
\text { fans (with the exception of a } \\
\text { whole-house exhaust fan). } \\
\text { - Turn on the air handler if the } \\
\text { pressure differential in the } \\
\text { CAZ becomes more negative } \\
\text { with reference to the outdoors. } \\
\text { - Open or close interior doors to } \\
\text { the CAZ, rooms with exhaust } \\
\text { fans, or other interior rooms to } \\
\text { achieve the highest pressure } \\
\text { differential in the CAZ with } \\
\text { reference to the outdoors. } \\
\text { - Makeup air systems, } \\
\text { combustion air ducting, and } \\
\text { ventilation systems are to } \\
\text { remain as is. } \\
\text { - Ensure fireplace damper is } \\
\text { closed or a simulator is } \\
\text { operating in the fireplace with } \\
\text { the damper open. } \\
\text { Ensure the vent or flue is at } \\
\text { room temperature. }\end{array}$ & $\begin{array}{l}\text { - Close all exterior building } \\
\text { doors and windows. } \\
\text { - Close all interior doors } \\
\text { between the CAZ and the } \\
\text { rest of the house. } \\
\text { - Turn on exhaust fans } \\
\text { (clothes dryer, range hoods, } \\
\text { and bath exhaust, all at } \\
\text { maximum speed). } \\
\text { - Close fireplace damper and } \\
\text { close doors, if present. }\end{array}$ & $\begin{array}{l}\text { - Turn on all exhaust to highest } \\
\text { speed setting (clothes dryer-check } \\
\text { and clean dryer filter and check for } \\
\text { blockages at the external vent } \\
\text { damper, range hoods, and other } \\
\text { exhaust fans). } \\
\text { Turn on central forced-air system } \\
\text { blowers-if it makes the CAZ } \\
\text { more depressurized leave on, } \\
\text { otherwise turn off. } \\
\text { - Open interior CAZ doors-if it } \\
\text { makes the CAZ more depressurized } \\
\text { leave open, otherwise close. }\end{array}$ & $\begin{array}{l}\text { - Close all exterior doors, } \\
\text { windows, and fireplace dampers. } \\
\text { - Open all interior doors, and } \\
\text { leave open all combustion air } \\
\text { openings to the outdoors. } \\
\text { - In homes with central air } \\
\text { handlers: close the door to any } \\
\text { room that does not have either a } \\
\text { return air duct or an exhaust fan. } \\
\text { - Close the nearest door to the } \\
\text { combustion appliances to } \\
\text { separate them from the rest of } \\
\text { the house. } \\
\text { - Do not turn off whole-building } \\
\text { ventilation systems operating } \\
\text { continuously. Disable any } \\
\text { ventilation systems controlled } \\
\text { for intermittent operation. } \\
\text { - Do not disable any interlocked } \\
\text { appliance makeup air systems. } \\
\text { - Turn on any clothes dryer } \\
\text { vented to the outside and kitchen } \\
\text { ventilation to the max operating } \\
\text { speed. } \\
\text { - If the next-largest exhaust fan is } \\
\text { a higher-speed operating exhaust } \\
\text { ventilation system, turn it to the } \\
\text { higher speed. Otherwise turn on } \\
\text { the next-largest exhaust fan. } \\
\text { makes CAZ more depressurized } \\
\text { leave on, otherwise turn off. }\end{array}$ \\
\hline
\end{tabular}




\begin{tabular}{|c|c|c|c|c|}
\hline & $\begin{array}{c}\text { ACCA } \\
\text { (ACCA QH12 2014) }\end{array}$ & $\begin{array}{c}\text { NFGC } 2015 \text { Annex G } \\
\text { (NFPA 2015) }\end{array}$ & $\begin{array}{c}\text { BPI } \\
\text { (BPI-1200-2015) } \\
\end{array}$ & STP \\
\hline WC Testing & $\begin{array}{l}\text { Place the lowest Btu input } \\
\text { appliance being tested into } \\
\text { operation first and adjust the } \\
\text { thermostat so the appliance } \\
\text { operates continuously. } \\
\text { - Test for spillage after } 5 \text { min of } \\
\text { operation using a match, } \\
\text { candle, or smoke. } \\
\text { - If a draft is established within } \\
5 \text { min the combustion } \\
\text { appliance passes, otherwise } \\
\text { the combustion appliance fails } \\
\text { the test. } \\
\text { - For additional fossil fuel } \\
\text { appliances in the same room, } \\
\text { turn on the next appliance } \\
\text { being tested so it operates at } \\
\text { the full input while the } \\
\text { previous appliance continues } \\
\text { to operate. } \\
\text { - Repeat testing for each } \\
\text { additional appliance. } \\
\text { - Or follow the } \\
\text { methodology/procedure per } \\
\text { the Authority having } \\
\text { Jurisdiction. }\end{array}$ & $\begin{array}{l}\text { - Turn on appliance being } \\
\text { inspected for continuous } \\
\text { operation. } \\
\text { - Verify all the appliances } \\
\text { within the CAZ are on } \\
\text { standby mode and ready to } \\
\text { be turned on. } \\
\text { - After } 5 \text { min check for } \\
\text { spillage using smoke pen. } \\
\text { - Immediately after smoke } \\
\text { pen test turn on all other } \\
\text { appliances within the CAZ } \\
\text { to their maximum inputs and } \\
\text { repeat spillage test. } \\
\text { - Shut down all appliances to } \\
\text { standby mode, wait } 15 \text { min. } \\
\text { - Repeat steps for each } \\
\text { appliance being inspected. } \\
\text { - Additional inspections: } \\
\text { determine if appliance } \\
\text { venting is impacted by other } \\
\text { door and air handler settings } \\
\text { - There is also a list of } \\
\text { appliance specific } \\
\text { inspections. }\end{array}$ & $\begin{array}{l}\text { - Turn on appliance with the lowest } \\
\text { Btu capacity for continuous } \\
\text { operation. } \\
\text { - Measure spillage and CO in cold } \\
\text { vent (except domestic water } \\
\text { heaters) } \\
\text { - Test for spillage after burner has } \\
\text { been on for } 5 \text { min. } \\
\text { - Measure CO of undiluted flue gas } \\
\text { at } 5 \text { min of burner operation. } \\
\text { - Measure spillage and CO in } \\
\text { domestic water heater and warm } \\
\text { vents } \\
\text { - Test for spillage at } 2 \text { min of burner } \\
\text { operation. } \\
\text { - Measure CO of undiluted flue gas } \\
\text { taken at } 5 \text { min of main burner } \\
\text { operation. } \\
\text { - Follow instructions for WC testing } \\
\text { of multiple combustion appliances } \\
\text { sharing a chimney and/or venting } \\
\text { system. } \\
\text { - Test combustion appliances in } \\
\text { order from lowest Btu to highest. } \\
\text { - } 2 \text { above methods to be used. } \\
\text { - After spillage has been completed } \\
\text { for the } 1^{\text {st }} \text { appliance place the next- } \\
\text { smallest Btu appliance into } \\
\text { operation leaving the } 1^{\text {st }} \text { operating. } \\
\text { appliance has been operating for } 2 \\
\text { min. } \\
\text { appliances sharing the same } \\
\text { chimney and/or vent system. } \\
\text { - Test the } 2^{\text {nd }} \text { appliance immediately } \\
\text { aptiance once the } 2^{\text {nd }} \\
\text { - }\end{array}$ & $\begin{array}{l}\text { - Place the appliance being } \\
\text { inspected in operation. The } \\
\text { lowest-capacity appliance } \\
\text { should be tested first. Follow } \\
\text { lighting instructions for each } \\
\text { appliance. } \\
\text { - If the appliance being tested is a } \\
\text { draft-hood-equipped furnace, } \\
\text { turn all thermostats to heating } \\
\text { mode so the appliance will } \\
\text { operate continuously. } \\
\text { - Test for spillage at the draft } \\
\text { hood relief opening using a } \\
\text { smoke pen at the following } \\
\text { times: } \\
\text { o For furnaces in heating } \\
\text { season and water heaters, test } \\
\text { at } 3 \text { min. } \\
\text { o For furnaces out of heating } \\
\text { season, test at } 5 \text { min. } \\
\text { - Measure CO in the appliance } \\
\text { flue } \\
\text { - Turn on all other fuel gas } \\
\text { appliances within the CAZ, if } \\
\text { the appliances are furnaces or } \\
\text { boilers they should be set to } \\
\text { continuous operation. } \\
\text { continue onto next-lowest Btu. }\end{array}$ \\
\hline
\end{tabular}




\subsection{Test Procedures in Effect at the Time of Project Initiation}

\subsubsection{National Fire Protection Agency 54-2012 (National Fuel Gas Code)}

NFPA 54 (also known as ANSI Z223.1) has been in use for years and has undergone periodic updates. Appendix G of the 2012 edition recommended — but did not require - a procedure for assessing the combustion safety of existing furnaces and boilers. It was not intended to cover water heaters.

This standard considered the impact of exhaust devices such as dryers and exhaust fans. Doors between the CAZ and the remainder of the house were closed.

Other door positions were not considered. Any impact on pressures due to air handler operation was also not considered. This includes pressure impacts of duct leakage and from insufficient return air pathways in homes with central returns.

Spillage in atmospherically vented appliances was assessed at 5 minutes of burner operation. This timing is consistent with measurements that are intended to be conducted on newly installed appliances with cold vents. (NFPA 54 covers installation of new appliances.)

Draft was measured as part of this procedure. Also, no limits were specified for maximum depressurization of the CAZ.

\subsubsection{Air Conditioning Contractors of America QH12-2011}

ACCA, in cooperation with the Residential Energy Services Network, published its first audit standard for existing residential buildings in 2011. This standard, referred to as QH12, included requirements for combustion safety testing. Unlike NFPA 54, QH12 required that the testing be conducted. It also covered water heaters, furnaces, and boilers.

Compliance with the combustion safety testing requirements of QH12-2011 could be achieved through multiple means. Several test procedures from other organizations were referenced. Additionally, QH12-2011 provided a test method in an appendix. Because the test procedures from other organizations were allowable, it is not possible to state that QH12-2011 necessarily required a specific setup or set of tests. The following discussion focuses on the contents of Appendix A of QH12-2011. Because compliance with other standards was allowed, any differences between QH12-2011 and these standards were also permissible as long as the other procedure was followed in its entirety.

As with all the standards discussed in this section, QH12-2011 considered the impact of intentional exhausts, including exhaust fans and dryers.

QH12-2011 also considered the impact of interior door positioning. Each interior door, including the one to the CAZ, was supposed to be positioned to produce the greatest negative pressure in the $\mathrm{CAZ}$ whether that position was open or closed (as determined by testing).

The air handler was to be turned on at the same time as all exhaust fans for the QH12-2011 procedure. Whether the air handler pressurized or depressurized the CAZ was not considered. This means that door closure impacts would be identified, but if the air handler positively 
pressurized the CAZ (e.g., supply leaks in a basement) a problem from, say, a dryer, could have been masked.

Spillage was to be tested at 5 minutes of burner operation. This is consistent with NFPA 54. In an effort to ensure that the flue was in "cold-vent" conditions, QH12-2011 specified that the auditor should ensure that the flue was at room temperature.

No tests for draft or limits for maximum depressurization were included in this procedure.

The primary differences between combustion safety procedures in QH12-2011 and NFPA 542012 were that QH12 included the operation of the air handler fan, requirement for testing, and allowing other procedures to be used.

\subsubsection{Building Performance Institute-101}

BPI-101 was the Building Analyst standard. It has since been superseded by BPI-1200-2015. BPI-101 required that combustion safety testing be conducted. It also covered water heaters, furnaces, and boilers.

As with all the standards discussed in this section, BPI-101 considered the impacts of intentional exhausts, including exhaust fans and dryers.

BPI-101 considered the impact of interior door positioning. Each interior door, including the one to the CAZ, was supposed to be positioned to produce the greatest negative pressure in the CAZ whether that position was open or closed (as determined by testing).

In BPI-101 the air handler was to be turned on separately from other exhaust fans. This means that door closure impacts and the direct impact of the air handler on the CAZ were considered.

Spillage was to be tested at 1 minute of burner operation. Draft in the flue was to be measured; passage failure was based on comparing the draft pressure to values in a table that depended on outdoor temperature. BPI-101 also included limits for maximum depressurization.

The draft measurement and maximum depressurization limits provided additional failure criteria relative to NFPA 54-2012 and ACCA QH12-2011. The separate operation of the air handler differentiated BPI-101 as a standard that would fully consider the effects of the air handler on the CAZ.

\subsubsection{Standard Work Specifications-2011}

The SWS were developed by NREL. As a federally developed document, the standards of other organizations were frequently referenced instead of developing independent procedures. Initially, the SWS specifically referred to BPI-101. Eventually that was changed, and many of the requirements for which tests needed to be performed were explicitly laid out when the SWS was first finalized.

The SWS did not provide extensive details for how to do testing. It stated that depressurization testing should include the effects of doors, duct leakage, air handler operation, and door position, implying the same set of requirements as BPI-101. 
The SWS had requirements for spillage and maximum depressurization limits but no requirement to measure draft. Spillage was based on 2 minutes, putting the SWS between BPI-101 and the requirements of NFPA 54-2012 and ACCA QH12-2011. Depressurization limits were inconsistent within the SWS but were closely aligned with BPI-101.

\subsection{Current Test Procedures}

This section describes the states of the above standards after their most recent revisions. Many of these changes are in line with the recommendations of the PARR/NorthernSTAR STP. Specific recommendations of this STP include:

- Not testing for draft

- Not failing units solely because they exceed the maximum depressurization limits

- Positioning doors based on supply registers, return grilles, and exhaust fans rather than from door-by-door pressure testing

- Spillage assessed based on a "warm-vent/cold-vent" decision tree

- Operating large exhaust fans at lower flow rates.

\subsubsection{National Fire Protection Agency w2qA 54-2015 (National Fuel Gas Code)}

NFPA 54 has had some significant updates to Appendix G. It now covers water heaters, though such testing is still only recommended, not required.

In this edition the position of the door between the CAZ and the remainder of the house is now considered. Positions of other interior doors are still not considered.

A major change in this edition is that the impact on pressures due to air handler operation is now considered. Air handler operation has multiple potential impacts, and accounting for these impacts is a significant improvement. One of these, the impacts due to interior door closures, however, is not considered in the current edition of the code.

Spillage in atmospherically vented appliances is still assessed at 5 minutes of burner operation. There continue to be no measurement of draft or limits for maximum depressurization of the CAZ.

\subsubsection{Air Conditioning Contractors of America QH12-2014}

ACCA updated its QH12 standard in 2014. Specific references to other organizations' standards were removed, though discretion was given to the Authority Having Jurisdiction to choose another procedure.

Exhaust fans and the impact of interior door positioning are unchanged from the previous version. Each interior door, including the one to the CAZ, is supposed to be positioned to produce the greatest negative pressure in the CAZ whether that position was open or closed (as determined by testing). 
The air handler is to be turned on separately from other fans to determine whether it pressurizes or depressurizes the CAZ. This is a major advancement of QH12 and was one reason other organizations' methods were removed for the 2014 edition.

Spillage continues to be assessed at 5 minutes of burner operation. The language about ensuring that the flue was in "cold-vent" conditions was also retained.

There continue to be no measurement of draft or limits for maximum depressurization of the CAZ.

\subsubsection{Building Performance Institute-1200-2015}

BPI-1200-2015 was published as an ANSI standard in spring 2015. BPI-1200 requires that combustion safety testing be conducted. It continues to cover water heaters, furnaces, and boilers.

As with all the standards discussed in this section, BPI-1200 considers the impact of intentional exhausts, including exhaust fans and dryers.

The impact of interior door positioning is considered by BPI-1200 but not through a one-by-one door evaluation as before. The procedure that has been adopted is very similar to that in the STP proposed by PARR and NorthernSTAR. Doors to rooms that contain exhaust fans or return grilles are left open. Doors to rooms with only supply registers are closed.

In BPI-1200 the air handler continues to be turned on separately from other exhaust fans. This means that door closure impacts and the direct impact of the air handler on the CAZ are considered.

In BPI-1200, spillage testing now takes a multipath approach. Specifically, the amount of time allowed for spillage to stop depends on whether the appliance is in "cold-vent" or "warm-vent" mode. Water heaters are assumed to be in warm-vent mode at all times, because water heaters fire throughout the year. Furnaces are assumed to be in warm-vent mode if the thermostat is set to "HEAT" and in cold-vent mode if the thermostat is set to any other setting. Even though flues may be cold even if the appliance is in "warm-vent" mode, the thinking was that expecting auditors to accurately measure flue temperatures or to wait long enough to make sure the vent is cold is not reasonable.

For spillage, appliances in "warm-vent" mode are to be tested at 2 minutes of burner operation. This is longer than the 1-minute period in BPI-101, but shorter than the test period for NFPA 54 or ACCA QH12. Appliances in "cold-vent" mode are to be tested at 5 minutes of burner operation, which is aligned with NFPA 54 and ACCA QH12. Both aim to have appliances tested in "cold-vent" mode.

Draft in the flue no longer needs to be measured. BPI-1200 also removed limits for maximum depressurization. 


\subsubsection{Standard Work Specifications-2015}

The SWS undergo periodic maintenance. The maintenance committee met in April 2014 to address comments submitted through public review. However, many of the comments about combustion safety were postponed until all the standards that were discussed above were revised. These revisions were completed after BPI-1200-2015 was published. The committee subsequently drafted changes to the combustion safety section of the SWS to bring it into alignment with BPI-1200-2015. As of this writing these changes had not yet been formally published; however, the committee has agreed upon the changes to be made.

\subsection{Overall Alignment and Partnership for Advanced Residential Retrofit/NorthernSTAR Involvement}

Table 1 shows that the standards have been substantially aligned. As of 2012, there were differences about whether testing was required, door positioning, operation of the air handler, allowable time to last spillage, draft testing, and maximum depressurization limits. In 2015, the only areas of real difference are in whether testing is required (all except NFPA 54 require it) and positioning of interior doors. Spillage also is somewhat different; NFPA 54 and ACCA QH12 use cold-vent limits and BPI-1200 and the SWS use a two-path approach. Otherwise, the procedures are all effectively the same. The only major recommendation from the STP that has not been adopted in any of these standards is to operate large exhaust fans at lower flow rates.

Removing draft testing and maximum depressurization limits and simplifying interior door positioning that is in BPI-1200-2015 and the SWS are consistent with the proposed STP from $\mathrm{PARR} /$ NorthernSTAR. The two-path spillage testing requirements of 2 minutes for warm-vent mode and 5 minutes for cold-vent mode also appear in the STP. Thus, even while the Building America project was underway, some organizations were adopting the recommendations of the project.

Although not discussed previously, $\mathrm{CO}$ limits have also been brought into alignment and are consistent with the Building America project. BPI-1200-2015 was permitted to use the table of CO limits used in NFPA 54-2015, and these appear in the published standard. ACCA QH12 refers to the NFPA 54-2015 table. Therefore, all these organizations are using the same CO limits for flue gases. However, requirements continue to differ for various levels of ambient (e.g., indoor air) $\mathrm{CO}$.

PARR team members have been involved in some capacity with each of these standards and the resulting alignment.

- Paul Francisco provided public review comments to both NFPA 54 and ACCA QH12 during their revision processes. In both cases, comments on original drafts included recommendations to require air handlers to be operated separately from other fans to assess their impact on CAZ pressures. In both cases, these comments were accepted and contributed to both standards.

- Paul Francisco and Larry Brand were members of BPI Working Group-7, which was convened to make recommendations to the BPI-1200 committee about combustion safety testing. Paul Francisco was the originator of the "warm-vent/cold-vent" two-path strategy. 
- Paul Francisco is also on the maintenance committee for the SWS and drafted the changes to align the SWS with BPI-1200.

NorthernSTAR team members have also been involved in some capacity with each of these standards and the resulting alignment.

- Rebecca Olson has served as chair of the BPI Standards Technical Committee since 2013. She helped guide the adoption of the new BPI-1200--Standard Practice for Basic Analysis of Buildings and was one of the major drivers of Working Group-7.

- Jim Fitzgerald was on the BPI-1200 Working Group-7, and the BPI Standards Technical Committee from the beginning through comment resolution and voting on BPI-1200. 


\section{Field Data Collection and Analysis}

\subsection{Test Plan}

\subsubsection{Must-Fail/Must-Pass Criteria}

The project objectives were to identify (1) if homes that passed the STP had a very low probability of developing spillage events, and (2) how many homes that failed the STP were safe, as defined by having no significant spillage events. Consequently, houses selected for the project would be those that failed a stringent combustion safety test but might pass under less stringent conditions. The following must-fail/must-pass criteria were defined:

- For the must-fail criterion, the house was placed in the conditions specified by the STP. The steps required to meet these conditions were:

- Close the door nearest to the combustion appliance that separates the appliance from the main body of the house.

- Close the interior doors of all rooms except for rooms with an exhaust fan and rooms with a central forced-air system return.

- Turn on the clothes dryer.

○ Turn on the kitchen exhaust fan to its highest speed.

- Turn on the next largest capacity exhaust fan.

- Check that the air handler fan on (if it depressurizes the CAZ).

- Water heaters failed this test if spillage continued for more than 2 minutes after the burner was activated. Space heating systems failed if spillage continued for more than 5 minutes. The house conditions for the must-pass criterion were the same as for the mustfail conditions, with the following exceptions:

- Switch the kitchen exhaust fan to its lowest speed (if available).

- Turn off all other exhaust fans.

- The spillage time requirements for the must-pass conditions were the same as those for the must-fail conditions.

\subsubsection{Three-Step Process}

A three-step process was followed to identify candidate houses, select those of interest, and collect data over a heating, shoulder, and cooling season.

1. Screening. This step was used to identify houses that met the must-fail/must-pass criteria. These tests typically took 1.5-2 hours to perform. Houses that passed this requirement moved on to the second step.

2. Short-term testing. Houses in this step underwent a full day of evaluation to:

A. Confirm the findings from the first step.

B. Ensure that the combustion appliances were installed and operating correctly. 
C. Record detailed pressure, temperature, spillage, and performance data. Houses that passed the requirements in this step moved on to the last step.

3. Long-term monitoring. Houses that passed the initial steps were monitored over 3 to 6 months to determine the circumstances under which combustion safety events occurred. A full instrumentation package was installed in each house and data were downloaded remotely. Each homeowner signed a site participation agreement.

\subsection{Field-Test Site Screening and Selection-Sampling Strategy}

Sample size for this test was initially determined by the cost of monitoring and data analysis. It was originally proposed that in each location/climate up to 100 houses would be screened to select 6 to 10 qualified houses for the long-term study. Locations were selected to obtain extremes in temperature and a range of building types. The project plan was for NorthernSTAR to test and instrument 10 houses in Minnesota (cold climate) and 6 houses in Phoenix, Arizona (hot climate). PARR was to test and instrument 6 houses in southern Illinois (moderate climate) and 6 houses in Atlanta, Georgia (mixed climate). Table 3 shows the mix of expected building construction types. The columns are sorted with highest frequency at the top. Because of the difficulty finding houses that met the criteria, only 11 houses were qualified — all in cold northern climates. See Section 4.4.

Table 3. Range of Building Types for the Four Climates

\begin{tabular}{|c|c|c|c|c|}
\hline & $\begin{array}{c}\text { Minnesota } \\
\text { (Minneapolis) }\end{array}$ & $\begin{array}{l}\text { Southern } \\
\text { Illinois }\end{array}$ & $\begin{array}{c}\text { Arizona } \\
\text { (Phoenix) }\end{array}$ & $\begin{array}{r}\text { Georgia } \\
\text { (Atlanta) }\end{array}$ \\
\hline \multirow{3}{*}{ Building Type } & Basement & Basement & Slab & Basement \\
\hline & Crawl space & Slab & Crawl space & Slab \\
\hline & & Crawl space & Basement & \\
\hline \multirow{3}{*}{$\begin{array}{l}\text { Possible Appliance } \\
\text { Location }\end{array}$} & Basement & Basement & Attic & Basement \\
\hline & Inside closet & Inside closet & Inside closet & Attic \\
\hline & & Crawl space & Basement & \\
\hline
\end{tabular}

${ }^{\mathrm{a}}$ www.census.gov/construction/chars/completed.html

\subsection{Field Research Methods}

\subsubsection{Screening Procedures}

The screening procedure was used to identify houses for short-term testing and long-term monitoring. Building technicians performed the must-fail/must-pass screening tests. A NorthernSTAR building technician conducted most of the tests on houses in Minnesota, which were located in the Twin Cities metropolitan area. PARR and NorthernSTAR staff trained local weatherization building technicians to conduct the tests on houses in their area. Sections A through $\mathrm{E}$ describe the screening test procedures. To be included in the monitoring section of the study, a house had to fail the Section C spillage test when set up according to the must-fail conditions in Sections A and B. Those conditions were equivalent to those specified for the STP. The house also needed to pass the spillage requirement for the must-pass conditions specified by Section D. 


\section{A. Set Up Depressurization Conditions}

1. Close all exterior doors, windows, and fireplace dampers. Open all interior doors. Leave open all combustion air openings to the outdoors.

2. Close the door to any room with a supply register that does not have either an exhaust fan or a central air handler return air duct (independent of a transfer grille, jumper duct, or other mechanism for providing a return air pathway).

3. Close the nearest operable door to the combustion appliances to separate them from the rest of the house.

4. Do not turn off a whole-building ventilation system that is operating continuously. Disable supply or balanced ventilation systems that are controlled for intermittent operation. Do not turn on whole-house (summer) exhaust fans.

5. Do not disable any interlocked appliance makeup air systems.

6. Turn on any clothes dryers that are vented to the outside.

\section{B. Set Up Must-Fail Test Conditions}

1. Turn on any kitchen exhaust ventilation systems and operate at maximum speed.

2. If the next-largest exhaust fan is a higher speed of an operating exhaust ventilation system, turn it to the higher speed. If not, turn on the next-largest exhaust fan.

3. Turn on the air handler fan and measure the indoor-to-outdoor pressure difference. If the air handler operation depressurizes the CAZ relative to the outdoors, leave the air handler on. If not, turn off the air handler.

\section{Perform Must-Fail Combustion Safety Spillage and Carbon Monoxide Tests}

1. Place the appliance being inspected in operation. Test the lowest-capacity appliance first. Follow the lighting instructions for each appliance. If the appliance being tested is a draft-hood-equipped furnace, turn all thermostats to heating mode so the appliance will operate continuously.

2. Use smoke to test for spillage at the draft hood relief opening of the appliance being tested. The test duration is specified by:

A. For furnaces in heating season and water heaters, test at 2 minutes and 5 minutes. Use the 2-minute result for pass/fail decisions.

B. For furnaces out of heating season, test at 5 minutes.

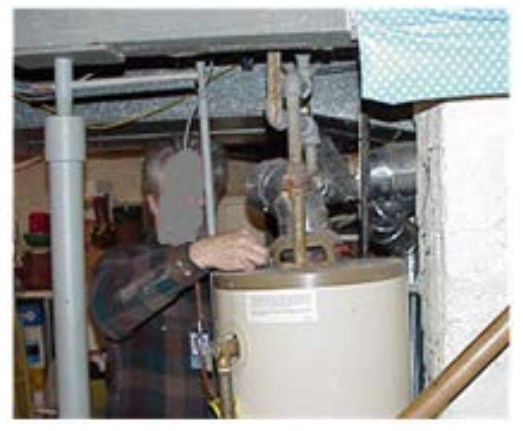

Figure 1. Checking spillage on a water heater 
(Excerpted from NFGC (NFPA 54) 2015 Annex G with permission from the American Gas Association)

\begin{tabular}{|l|l|}
\hline Appliance & Threshold Limit \\
\hline Central Furnace (all categories) & 400 ppmlair free2,3 \\
\hline Floor Furnace & $400 \mathrm{ppm}$ air free \\
\hline Gravity Furnace & $400 \mathrm{ppm}$ air free \\
\hline Wall Furnace (BIV) & $200 \mathrm{ppm}$ air free \\
\hline Wall Furnace (Direct Vent) & $400 \mathrm{ppm}$ air free \\
\hline Water Heater & $200 \mathrm{ppm}$ air free \\
\hline
\end{tabular}

1 Parts per million

2 Air free emission levels are based on a mathematical equation (involving carbon monoxide and oxygen or carbon dioxide readings) to convert an actual diluted flue gas carbon monoxide testing sample to an undiluted air free flue gas carbon monoxide level utilized in the appliance certification standards. For natural gas or propane, using as-measured $\mathrm{CO}$ ppm and $\mathrm{O} 2$ percentage:

$$
C O_{A F p p m}=\left(\frac{20.9}{20.9-O_{2}}\right) \times C O_{p p m}
$$

Where:

COAFppm $=$ Carbon monoxide, air-free ppm

COppm $=$ As-measured combustion gas carbon monoxide ppm

$\mathrm{O} 2=$ Percentage of oxygen in combustion gas, as a percentage

3 An alternate method of calculating the $\mathrm{CO}$ air free when access to an oxygen meter is not available:

$$
\mathrm{CO}_{\mathrm{AFpm}}=\left(\frac{\mathrm{UCO}_{2}}{\mathrm{CO}_{2}}\right) \times C O
$$

Where:

$\mathrm{UCO} 2=$ Ultimate concentration of carbon dioxide for the fuel being burned in percent for natural gas (12.2 percent) and propane (14.0 percent) $\mathrm{CO} 2=$ Measured concentration of carbon dioxide in combustion products in percent $\mathrm{CO}=$ Measured concentration of carbon monoxide in combustion products in percent

Figure 2. CO thresholds

3. Measure CO levels in the appliance flue. These levels should not exceed the ANSI certification requirement for the type of appliance (see Figure 2). If the appliance fails this test:

A. Record the failure.

B. Notify the homeowner that the appliance should be evaluated by a qualified service technician.

C. Exclude this house from the study. This test may be repeated after the appliance is serviced. 
4. Turn on all other fuel gas appliances within the same room. If the other appliances are furnaces or boilers, they should be set to operate continuously. Furnace fans should be running.

5. Use smoke to test for spillage at the draft hood relief opening of the appliance being tested.

6. Turn off all combustion appliances and set up the next appliance for testing.

7. If any combustion appliance fails the spillage tests when operating alone or with another appliance, record the failures and continue to the next section. If all appliances pass the spillage tests, return the house to original conditions. This house does not qualify for the monitoring section of the project.

\section{Set Up Must-Pass Conditions and Perform Spillage Test}

1. Repeat the depressurization conditions with the kitchen fan set to low speed and the next largest exhaust fan kept off.

2. Return to depressurization conditions created in Set Up Depressurization Conditions: Step 1.

3. Turn on any kitchen exhaust ventilation system and operate it at the lowest speed.

4. Turn off the next-largest exhaust fan, if one is present.

5. Turn on the air handler fan and measure the indoor-to-outdoor pressure difference. If air handler operation further depressurizes the CAZ relative to the outdoors, leave the air handler on. Otherwise turn off the air handler.

6. Use smoke to test for spillage at the draft hood relief opening of the appliance being tested.

7. If the combustion appliance fails spillage, this house does not qualify for the monitoring section of the project, and the homeowner should be notified that remediation is necessary. If the combustion appliance passes the spillage criteria, this house qualifies for monitoring.

\section{E. Return the Site to Its Original Condition}

1. Return doors, windows, exhaust fans, fireplace dampers, and all fuel-gas-burning appliances to their previous conditions of use before leaving the site. 


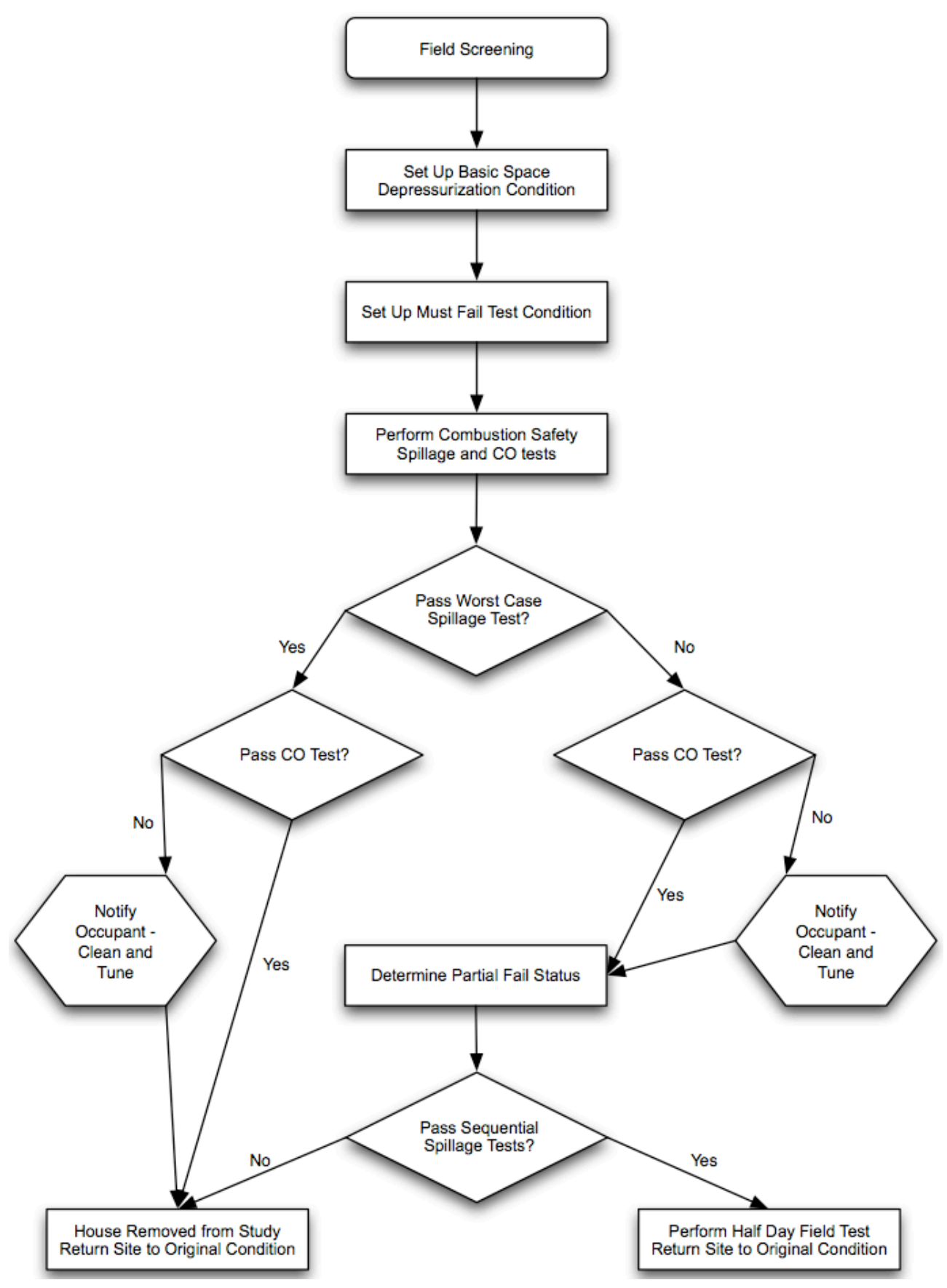

Figure 3. Field-test site selection flowchart

\subsubsection{Additional Data Collected Postscreening}

If a house met the screening criteria, the technician collected additional site data to help determine compliance with current combustion safety codes and guidelines and to see if the house was suitable for further study. The following information was collected for each candidate house that was selected for further study: 
1. Natural gas input and output capacities from appliance labels

2. Location of each appliance and source of combustion air (sealed mechanical closet open to the outdoors, basement with no combustion air from outdoors, garage, etc.)

3. Area of intentional combustion air openings to the outdoors, size, and types of grilles or louvers in doors and for outside openings, as well as the duct length and diameter (if a duct is used)

4. Volume of the room where each appliance is installed (except for rooms outside the pressure boundary); basements are inside the pressure boundary

5. Vent system configuration, including data about vent connector and common vent (or chimney) diameters and lengths

6. Blower door house envelope air leakage test results

7. Duct leakage results (if test was performed)

8. List of all exhaust fans including attic exhaust fans (at roof), kitchen exhaust fans, ventilation fans, bathroom ventilation fans, and dryers. The location and measured and/or rated fan air flow rate should be noted and a photo taken of the name plate or the make and model if possible.

9. Floor area and ceiling heights for the NFGC Standard Method if combustion air was from indoors only or from both indoors and outdoors

10. Measured baseline and induced depressurization under the must-fail condition (see Section 2.3.1)

11. Pass/fail results of the appliance spillage tests under must-pass and must-fail conditions. The project team reviewed the above information from candidate houses and then evaluated the screening information to determine if the houses met the screening criteria to be selected for the study.

\subsubsection{Short-Term Testing and Inspection Methods}

For houses that passed the field-test screening, project staff conducted more extensive short-term tests, which achieved two objectives:

- Confirmed that the house met the criteria for long-term monitoring

- Provided the data needed to evaluate options for an STP.

For the short-term test procedure, the project staff did not conduct a comprehensive safety test (e.g., gas leak detection). Instead, the tests focused on combustion venting performance and documenting conditions related to venting performance. Additional sections of the PARR and NorthernSTAR Measure Guideline combustion safety test procedures were conducted as time allowed and as deemed necessary after a brief visual inspection of the equipment. A detailed protocol for screening and selecting and the short-term and long-term tests was developed and communicated to the weatherization teams that participated in the project. Appendix A includes an overview of the short-term testing protocol for this project. 
Safe work practices were followed to protect the health of the project staff and occupants. If the results of this inspection identified a baseline house CO level that exceeded the $35 \mathrm{ppm}$ NREL SWS Limit (https://sws.nrel.gov/spec/202011), the homeowner was notified and the inspection stopped until the situation was corrected.

Houses were included in the long-term monitoring section of the study if they failed the must-fail test and passed the must-pass test. While monitoring the system installation, the must-fail/mustpass test was performed using the 2-minute criteria as a check of the repeatability of the tests. Two houses did not pass this retest. For the project, the screening visit test results were used to qualify the houses to be included in the study.

\subsubsection{Monitoring System and Installation}

The project team designed and assembled a monitoring system specifically for the project. The system generally made use of commercially available sensors selected for suitability across the ranges and conditions expected (Table 4). Appendix B includes more information about system components. 
Table 4. Monitored Parameters and Sensors

\begin{tabular}{|c|c|c|}
\hline Measurement & Sensor Used & Use of This Measurement \\
\hline $\begin{array}{c}\text { Temperature in Water Heater (or Furnace) } \\
\text { Flue }\end{array}$ & Type K thermocouple & $\begin{array}{l}\text { Determination of water heater (or } \\
\text { furnace) burner firing status }\end{array}$ \\
\hline $\begin{array}{c}\text { Temperature in Water Heater (or Furnace) } \\
\text { Vent }\end{array}$ & Type K thermocouple & Detection of downdrafting \\
\hline $\begin{array}{l}\text { Temperature at Four Locations Around } \\
\text { Water Heater (or Furnace) Draft Hood }\end{array}$ & Type K thermocouple & $\begin{array}{l}\text { Temperature in combustion products } \\
\text { spillage zone }\end{array}$ \\
\hline $\begin{array}{c}\text { Temperatures in CAZ (High and Low } \\
\text { Positions) and Outdoors }\end{array}$ & Type K thermocouple & \\
\hline $\begin{array}{c}\text { Pressure Difference, Water Heater (or } \\
\text { Furnace) Vent to CAZ }\end{array}$ & $\begin{array}{c}\text { Differential pressure transducer, } \\
\text { digital output }\end{array}$ & $\begin{array}{l}\text { Determination of normal operating } \\
\text { conditions, detection of downdrafting }\end{array}$ \\
\hline Pressure Difference, Outdoors to $\mathrm{CAZ}^{\mathrm{a}}$ & $\begin{array}{c}\text { Differential pressure transducer, } \\
\text { digital output }\end{array}$ & $\begin{array}{c}\text { Characterization of CAZ operating } \\
\text { conditions }\end{array}$ \\
\hline Current Draw of Air Handler & $\begin{array}{c}\text { 20A current transducer, analog } \\
\text { output }\end{array}$ & Air handler fan operating status \\
\hline Pressure Induced by Fan Operation ${ }^{\text {b }}$ & Custom wireless sensor module & Exhaust fan operating status \\
\hline $\begin{array}{c}\text { Carbon Dioxide }\left(\mathrm{CO}_{2}\right) \text { Concentration above } \\
\text { Water Heater (or Furnace) Draft Hood } \\
\mathrm{CO}_{2} \text { Concentration in CAZ away from } \\
\text { Appliances }\end{array}$ & $\begin{array}{c}\text { Nondispersive infrared } \mathrm{CO}_{2} \\
\text { sensor, analog output } \\
\text { Same }\end{array}$ & $\begin{array}{l}\text { Detection of combustion products } \\
\text { spillage } \\
\text { Background } \mathrm{CO}_{2} \text { level }\end{array}$ \\
\hline CO near Ceiling in CAZ & Electrochemical sensor & Detection of elevated CO levels \\
\hline
\end{tabular}

${ }^{a}$ The CAZ pressure difference used in this report is outdoor pressure with respect to CAZ pressure, and CAZ depressurization appears as a positive value.

${ }^{\mathrm{b}}$ Wired current sensors and wireless pressure sensing modules were used to monitor clothes dryers and other exhaust devices, depending on accessibility for wiring. 
The locations of the sensors associated with the water heaters are shown in Figure 4.

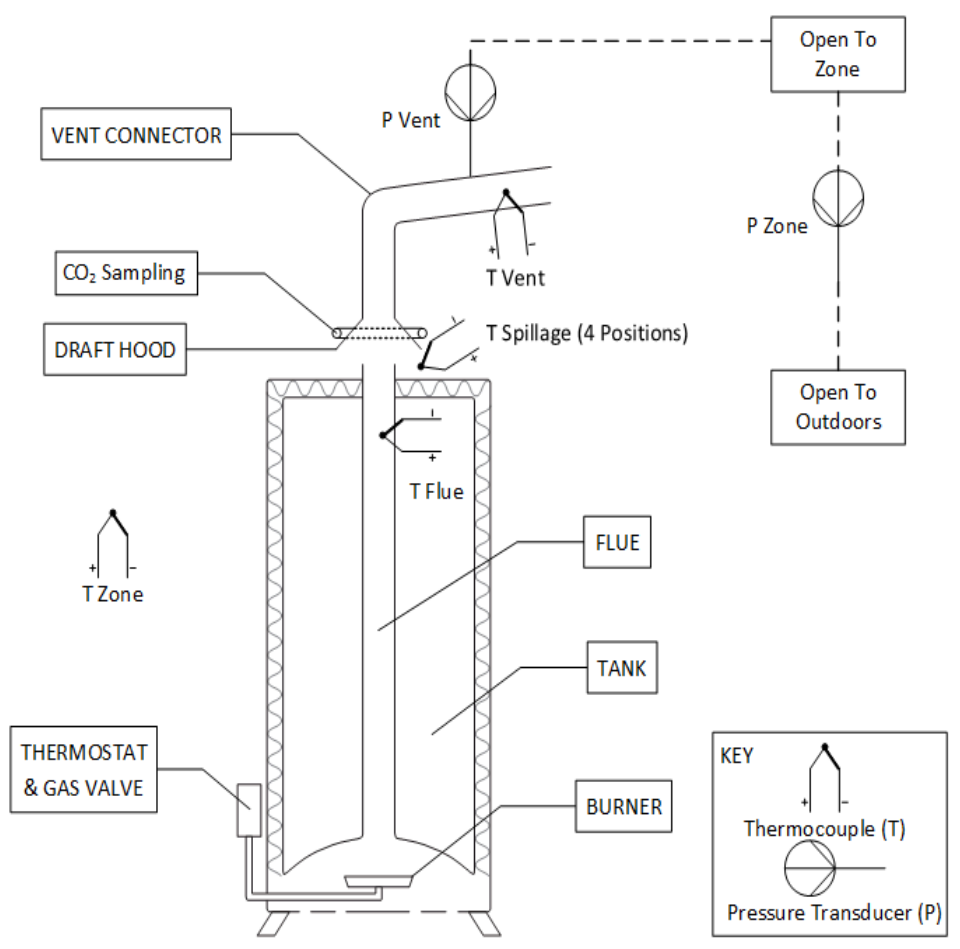

Figure 4. Schematic view of monitoring system sensor placement at water heater

A single sensor was used to measure pressure. It was mounted in the main system enclosure, with valves that allowed sequential measurement of differential pressures and a periodic rezeroing. Rezeroing reduces the effects of drift over time and with varying temperature, common in pressure measurement in the range of a few Pascals. The pressure measurement valving array was operated on a 3-second cycle, with a 1-second allowance for signal settling after the valves were reset and 2 seconds of data collection at each measurement location. The digital-output pressure sensor was queried 25 times during each second of measurement (though even this was not adequate to filter out significant wind-induced noise, as discussed later). Fractional-inch plastic tubing carried pressure signals from the measurement locations to the enclosure.

Similarly, a single $\mathrm{CO}_{2}$ sensor was mounted in the enclosure, and a pump drew samples sequentially from each measurement location through a set of valves. The concentration of $\mathrm{CO}_{2}$ around the appliances compared to room level was used as the primary metric to identify spillage. A common sensor allowed more accurate measurement of differences in concentration, independent of absolute sensor accuracy. The initial design placed the $\mathrm{CO}_{2}$ sampling pumps inside the main system enclosures, but comments from homeowners led to a decision to place them in separate noise-reducing enclosures that were mounted near the main system. $\mathrm{CO}_{2}$ valving was operated on a 20 -second cycle, with a 10 -second purge period followed by 10 seconds of data collection at each sampling point. The $\mathrm{CO}_{2}$ sensor output was captured once each second during active measurement. 
The team used thermocouples for all temperature sensors, based on their durability and ability to withstand the temperature ranges expected. Spillage temperature probes were mounted at four positions spaced around the circumference of the water heater draft hood, about $1 / 4 \mathrm{in}$. below the edge and $1 / 4$ in. beyond the circumference of the lower edge of the draft hood, where combustion spillage products would be expected to heat them. The thermocouples were constructed of 24gauge wire. The response time for moving air was a few seconds.

The system was based around a Beaglebone Black single-board computer, which offers a lowcost, fully programmable platform that allows essentially unlimited measurement and control options. A micro secure digital card provided storage capacity for programs and data. A customprinted circuit board included a number of integrated circuits that provided amplification (of thermocouple and $\mathrm{CO}$ sensor output), analog-to-digital converters, and other components. The team ran custom software, written in Python, on the Beaglebone computers. All parameters were sampled once per second, except the oversampling of differential pressures as mentioned earlier. Data were recorded at 1-minute intervals when no burner was firing, and at 1-second intervals when a burner was firing (and for a cooldown period of 2 to 3 minutes after firing). To preserve pump life, $\mathrm{CO}_{2}$ data were collected for the first 15 minutes of every burner cycle; additional background readings were taken every 4 hours if no burner operation was detected.

The computer, printed circuit board, wiring connections, valves for pressure signals, and $\mathrm{CO}_{2}$ sampling were mounted in an $8-\times 16-\times 4$-in. enclosure with mounting hardware to permit attachment to framing or other surfaces (Figure 5 and Figure 6). Figure 5 shows the wiring connectors along the lower edge of the circuit board and the $\mathrm{CO}_{2}$ sampling pump in a separate gray box below the right side of the enclosure. The uninterruptible power supply backup power unit is also shown.

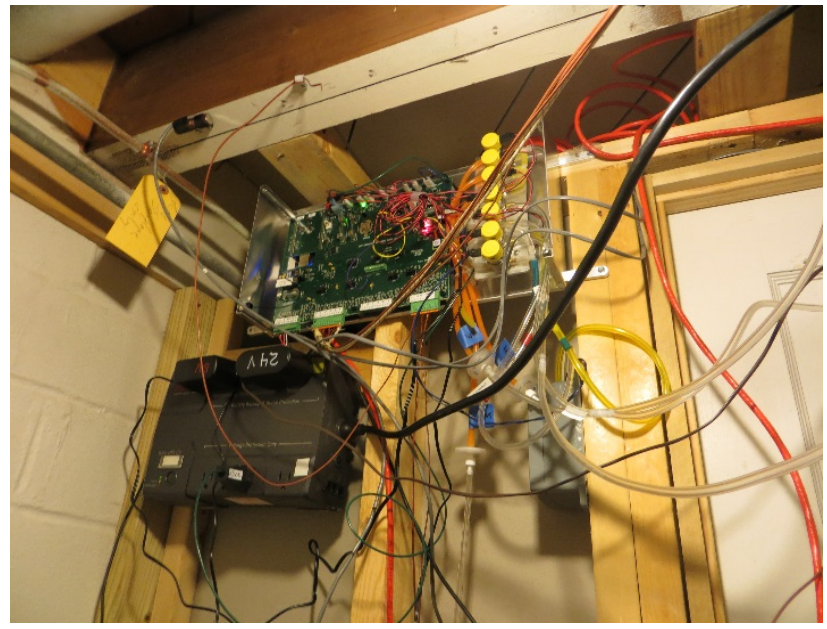

Figure 5. Monitoring system main circuit board and valves (yellow tops) in enclosure, cover removed

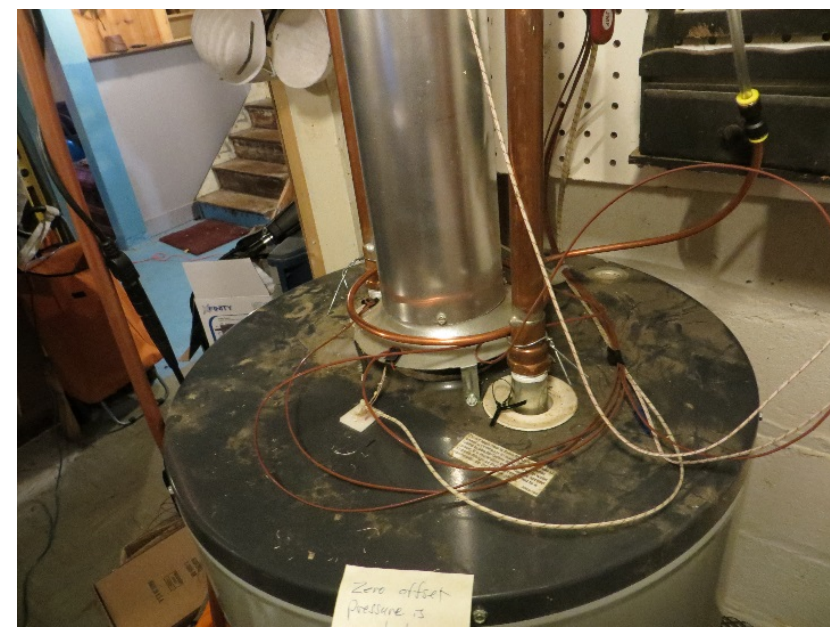

Figure 6. Water heater draft hood with copper tube for $\mathrm{CO}_{2}$ sampling and thermocouple temperature wire showing

The project team developed a wireless sensor module specifically for the project. The module is based around a commercially available ZigBee wireless transceiver with onboard analog-todigital conversion capability. The module includes a pressure sensor and amplifier circuit and 
was designed to be placed near an exhaust fan, with a flexible tube placed within the fan housing or exhaust duct so the sensor would see an elevated (positive or negative) pressure when the device was operating. The modules were programmed to read and transmit a pressure signal at 15-second intervals and are operated by three AA batteries (Figure 7).

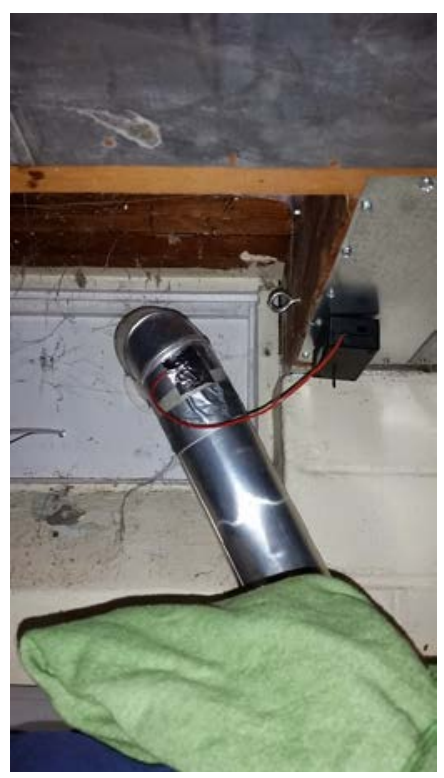

Figure 7. Custom wireless sensor module (black box) with pressure sensing tube placed in dryer exhaust duct

Communications for Internet-based remote data downloads were provided using one of the following:

- Direct cabled connection to a home Internet router

- Powerline carrier connection to a home internet router

- Wi-Fi link to a cellular modem; this was generally placed on an above-grade floor (a "Mi-Fi" arrangement).

\subsection{Field Research Results and Analysis}

\subsubsection{Recruitment}

Originally this project was designed to study the implications of a simplified combustion safety test protocol in four areas of the country (cold, moderate, hot-humid, and hot-dry) with different weather conditions and construction types. The initial target locations within these four climates were the Twin Cities Metro area of Minneapolis-St. Paul, Minnesota (cold climate); southern Illinois (moderate climate); Atlanta, Georgia (hot-humid climate); and Phoenix, Arizona (hot-dry climate). The project plan was for NorthernSTAR to test and instrument 10 houses in Minnesota and 6 houses in Phoenix, Arizona, and for PARR to test and instrument 6 houses in southern Illinois and 6 houses in Atlanta, Georgia.

In Minnesota contact with the state grantee for DOE's low-income weatherization assistance program (WAP) was made through NorthernSTAR team member Center for Energy and Environment (CEE). In Illinois contact with the state WAP grantee was made through PARR 
team member Indoor Climate Research \& Training (ICRT), which is also a WAP training center. For the other two locations contact was made with WAP training centers that ICRT located in each state. The training center in Phoenix was interested and willing to participate. The training center in Atlanta stated that a recently publicized incident made participation impossible at that time. Therefore, efforts were redirected to contacting the WAP training center in Little Rock, Arkansas, which in turn put ICRT in touch with the state WAP grantee.

Multiple states expressed concerns about the workflow and liability of the project. The extended monitoring period would require that retrofits be completed EXCEPT for addressing combustion safety issues, which could interrupt workflow. From a liability perspective, states were concerned that if an incident occurred in a home in which a combustion safety hazard had been identified they could be deemed culpable. These states were willing to collaborate on the project if the project team could show support from DOE's WAP. The small number of homes to be tested in each location was such that the workflow issue was deemed manageable.

ICRT approached DOE about the project, and DOE sent an email to target states encouraging their participation. In addition to the states previously mentioned, DOE recommended Mississippi as another hot-humid state that could be a promising partner. Therefore, the email was also sent to Mississippi and ICRT reached out to the state grantee.

Despite these efforts, finding eligible homes proved elusive. Therefore, additional contacts were made to expand the number of states seeking homes. ICRT reached out to WAP state managers or training centers in Texas, New Mexico, Idaho, Oregon, and Washington State. ICRT contacted Conservation Services Group, which administers utility programs in a number of states. All were willing to look for eligible homes. Conservation Services Group focused on New York. NorthernSTAR also contacted the WAP state manager in Wisconsin.

In the end, the team reached out to 13 states, and almost all expressed willingness to collaborate. However, more than 600 homes were reviewed for eligibility according to project requirements, and only about 10 were identified. These were almost entirely in Minnesota. Homes were often owned by friends and families of project team members and were not WAP clients. This led to the administration of a survey, discussed in Section 5. The details follow about each state that the project team contacted.

- Arizona: Agencies in Arizona expressed interest in the project; however, no houses could be recruited. The Phoenix area low-income housing stock typically has water heaters in the garages, and the heating systems are either gas packs or induced draft. These houses do not fit the project criteria. The agency suggested that we contact the Flagstaff WAP provider, which, because of the altitude, might be able to find houses that would qualify for the project but needed approval from the state of Arizona to proceed. Unfortunately, communications with the state grantee delayed approval until June 2015, and the timing and logistics ruled out proceeding with Arizona.

- Arkansas: The state WAP grantee required DOE approval to look for homes. The WAP reported reviewing several hundred homes throughout the state but was unable to locate any that met the project criteria. 
- Georgia. The WAP training center in Atlanta was interested but stated that a recent incident in the state made participation impossible.

- Idaho: The state WAP program was initially very optimistic that it could find homes that met the criteria. Once approached the WAP supported the project quickly and readily began reviewing homes. However, no homes that failed combustion safety testing met the project criteria.

- Illinois: Several agencies in southern Illinois were recruited to look for homes. Two agreed to review homes. However, no homes were located that fit the project requirements. Agencies reported that cases in which homes failed spillage were almost entirely due to air handler operation; dryers were the cause of others.

- Minnesota: Although discussion began in fall 2014, official permission from the state to the three WAP providers that had been recruited was delayed until February 2015. The agencies eventually provided three referrals. The project team scheduled these houses for screening tests.

A reason for the dearth of referrals from the WAP providers is likely related to the fact that a backdrafting water heater was their primary requirement for identification. The agencies singled out houses with orphaned water heaters as candidates. Any houses they worked on that required furnace replacement were not included in the search, because these needed immediate work. Because the mechanical contractor would be in the house at this time, remedial work was performed on the orphaned water heater as needed.

Because of the delays in the team's recruitment efforts with the WAP agencies, an approach was taken in fall 2014 to find participants through friends and family. CEE inquired among staff and partnering groups if their own houses or those of people they knew might fit the requirements. Fourteen candidates were identified from these efforts and screening tests were scheduled as they were identified.

- Mississippi: The state WAP grantee referred ICRT to a specific agency. This agency reviewed its files and found that very few homes in the last 3 years would have potentially been eligible. Eleven homes were identified as potential candidates but none qualified. In the end, Mississippi chose not to participate further.

- New Mexico: The WAP training center and state WAP grantee were both very interested in the project; however, no houses could be recruited. As with Arizona, the housing stock typically has water heaters in the garages, and the heating systems are either gas packs or induced draft. These houses do not fit the project criteria. One home was identified as a possible candidate due to spillage, but further discussions revealed that failure was due to air handler operation.

- Oregon: The state WAP grantee agreed to recruit homes for the project. However, no homes were located that fit the project requirements.

- Texas: The state WAP grantee indicated it would be agreeable. However, the program director stated that the housing stock probably would not meet the project criteria. 
- Washington: The WAP training center expressed willingness to approach the state agencies. However, the program has a heavy focus on all-electric homes, and no leads were generated.

- Wisconsin: Through friends and family efforts, a participant who is a staff person at Seventhwave was recruited in Madison, Wisconsin. Discussions also took place with the Wisconsin Weatherization Program, which chose not to participate in the project.

- Conservation Services Group (New York): This is the one substantial program that was contacted that was not a part of DOE's WAP program. As with most state WAP grantees, Conservation Services Group expressed a willingness to look for homes for the project, focusing on New York, but was unable to find suitable candidates.

\subsubsection{Screening and Selection}

From December 2014 to June 2015, 18 houses in Minnesota were identified as candidates for the study. Six were owned by CEE or Seventhwave staff. Eight were referrals by CEE staff or partners of CEE. Four were referred by local Low Income WAP (LIWAP) providers. Table 5 lists the houses that were screened in Minnesota and the results of the screening tests.

Table 5. House Screening Results

\begin{tabular}{|c|c|c|c|}
\hline Category & $\begin{array}{c}\text { Date } \\
\text { Evaluated }\end{array}$ & $\begin{array}{l}\text { Eligible/ } \\
\text { Ineligible }\end{array}$ & Reason Failed \\
\hline Friend & $12 / 1 / 2014$ & Ineligible & Venting issue \\
\hline Family & $12 / 3 / 2014$ & Eligible & \\
\hline Family & $12 / 5 / 2014$ & Eligible & \\
\hline Friend & $2 / 1 / 2015$ & Ineligible & $\begin{array}{l}\text { Did not meet must-pass criterion at time of } \\
\text { screening }\end{array}$ \\
\hline Family & $2 / 16 / 2015$ & Eligible & \\
\hline Family & $2 / 20 / 2015$ & Eligible & \\
\hline LIWAP & $2 / 28 / 2015$ & Ineligible & Did not meet must-fail criterion at time of screening \\
\hline LIWAP & $3 / 13 / 2015$ & Ineligible & Did not meet exhaust equipment requirements \\
\hline Family & $3 / 24 / 2015$ & Ineligible & Did not meet must-fail criterion at time of screening \\
\hline Friend & $3 / 29 / 2015$ & Ineligible & Did not meet must-fail criterion at time of screening \\
\hline Friend & $4 / 6 / 2015$ & Eligible & \\
\hline Friend & $4 / 6 / 2015$ & Eligible & \\
\hline LIWAP & $4 / 13 / 2015$ & Eligible & \\
\hline Friend & $4 / 28 / 2015$ & Ineligible & $\begin{array}{c}\text { Did not meet must-pass criterion at time of } \\
\text { screening }\end{array}$ \\
\hline Family & $4 / 30 / 2015$ & Eligible & \\
\hline Friend & $5 / 4 / 2015$ & Ineligible & Did not meet must-fail criterion at time of screening \\
\hline Friend & $5 / 5 / 2015$ & Eligible & \\
\hline LIWAP & $5 / 6 / 2015$ & Eligible & \\
\hline
\end{tabular}

The screening test took 1.5-2 hours and was performed by a CEE field technician. The screenings for the LIWAP houses were completed by a CEE field technician and LIWAP staff. These screenings were used as training for LIWAP staff members so they could perform the screenings themselves; however, too few LIWAP houses were available for the process to 
transition over to them. An eleventh house located in Madison, Wisconsin, was added to the project. It is owned and occupied by a Seventhwave staff person, and he performed the screening test on the house.

For all the houses that passed the screening criteria, the water heater was the combustion appliance that met the must-fail/must-pass spillage criteria and was instrumented for long-term monitoring. For the smoke test, a pass was given if the visible smoke was completely drawn into the draft hood.

Appendix $\mathrm{C}$ includes photos from the selected 11 homes.

\subsubsection{House Characteristics}

Table 6 summarizes the house characteristics. The houses are fairly representative of the older housing stock in the metropolitan area: smaller one-story ranches and story-and-a-half houses. Both styles include basements. None of the houses were overly tight. The envelope air leakage ranged from 3.9 to $11.1 \mathrm{ACH} 50$ with an average of $6.15 \mathrm{ACH} 50$. Six of the houses had exterior masonry flues; these all had metal liners.

Table 6. Building Characteristics of Participating Houses

\begin{tabular}{|c|c|c|c|c|c|c|}
\hline House & Type & $\begin{array}{c}\text { Air } \\
\text { Leakage } \\
\text { (CFM50/ } \\
\text { ACH50) }\end{array}$ & $\begin{array}{c}\text { Foundation } \\
\text { Type }\end{array}$ & $\begin{array}{l}\text { Floor } \\
\text { Area }\end{array}$ & $\begin{array}{l}\text { Type of } \\
\text { Flue }\end{array}$ & $\begin{array}{c}\text { Garage } \\
\text { Location }\end{array}$ \\
\hline MN01 & $\begin{array}{l}\text { Story-and-a- } \\
\text { half }\end{array}$ & $1,680 / 5.80$ & $\begin{array}{c}\text { Basement } \\
\text { (conditioned) }\end{array}$ & 2,174 & $\begin{array}{l}\text { Exterior } \\
\text { masonry }\end{array}$ & Attached \\
\hline MN02 & $\begin{array}{c}\text { Story-and-a- } \\
\text { half }\end{array}$ & $1,373 / 4.48$ & $\begin{array}{c}\text { Basement with } \\
\text { partial crawl } \\
\text { space } \\
\text { (conditioned) }\end{array}$ & 2,300 & $\begin{array}{l}\text { Interior } \\
\text { masonry }\end{array}$ & Detached \\
\hline MN03 & $\begin{array}{c}\text { Story-and-a- } \\
\text { half }\end{array}$ & $1,415 / 4.68$ & $\begin{array}{c}\text { Basement } \\
\text { (conditioned) }\end{array}$ & 2,269 & $\begin{array}{l}\text { Exterior } \\
\text { masonry }\end{array}$ & Detached \\
\hline MN04 & $\begin{array}{l}\text { Story-and-a- } \\
\text { half }\end{array}$ & $1,277 / 7.07$ & $\begin{array}{c}\text { Basement } \\
\text { (conditioned) }\end{array}$ & 1,354 & $\begin{array}{l}\text { Interior } \\
\text { masonry }\end{array}$ & Detached \\
\hline MN05 & $\begin{array}{l}\text { Story-and-a- } \\
\text { half }\end{array}$ & $2,370 / 7.25$ & $\begin{array}{l}\text { Basement with } \\
\text { partial crawl } \\
\text { space } \\
\text { (conditioned) }\end{array}$ & 2,453 & $\begin{array}{l}\text { Exterior } \\
\text { masonry }\end{array}$ & Detached \\
\hline MN06 & Ranch & $995 / 3.89$ & $\begin{array}{c}\text { Basement } \\
\text { (conditioned) }\end{array}$ & 1,920 & $\begin{array}{l}\text { Exterior } \\
\text { masonry }\end{array}$ & Detached \\
\hline MN07 & Ranch & $1,061 / 4.08$ & $\begin{array}{c}\text { Basement } \\
\text { (conditioned) }\end{array}$ & 1,950 & B-vent & Detached \\
\hline MN08 & $\begin{array}{l}\text { Story-and-a- } \\
\text { half }\end{array}$ & $2,633 / 11.14$ & $\begin{array}{c}\text { Basement } \\
\text { (conditioned) }\end{array}$ & 1,772 & $\begin{array}{l}\text { Exterior } \\
\text { masonry }\end{array}$ & Attached \\
\hline MN09 & $\begin{array}{l}\text { Story-and-a- } \\
\text { half }\end{array}$ & $2,279 / 6.51$ & $\begin{array}{c}\text { Basement } \\
\text { (conditioned) }\end{array}$ & 2,624 & $\begin{array}{l}\text { Interior } \\
\text { masonry }\end{array}$ & Attached \\
\hline
\end{tabular}




\begin{tabular}{|c|c|c|c|c|c|c|}
\hline House & Type & $\begin{array}{c}\text { Air } \\
\text { Leakage } \\
\text { (CFM50/ } \\
\text { ACH50) } \\
\end{array}$ & $\begin{array}{c}\text { Foundation } \\
\text { Type }\end{array}$ & $\begin{array}{l}\text { Floor } \\
\text { Area }\end{array}$ & $\begin{array}{l}\text { Type of } \\
\text { Flue }\end{array}$ & $\begin{array}{l}\text { Garage } \\
\text { Location }\end{array}$ \\
\hline MN10 & Ranch & $1,153 / 4.16$ & $\begin{array}{c}\text { Basement } \\
\text { (conditioned) }\end{array}$ & 2,080 & B-vent & Detached \\
\hline WI01 & $\begin{array}{l}\text { Story-and-a- } \\
\text { half }\end{array}$ & $3,009 / 8.55$ & $\begin{array}{c}\text { Basement } \\
\text { (conditioned) }\end{array}$ & 2,639 & $\begin{array}{l}\text { Exterior } \\
\text { masonry }\end{array}$ & Attached \\
\hline
\end{tabular}

All but one of the houses had forced-air heating systems. All the houses with central air conditioning had those systems connected in common with their forced-air heating systems. All the water heaters were natural draft, and 7 of the 11 houses had orphaned water heaters (water heaters that were common vented before the other appliances were removed from the vent). The furnaces on the common vented systems were either natural draft or induced draft. Figure 8 shows the combustion vent system of an orphaned water heater; Figure 9 shows a common vented water heater with the other vent exiting from the heating system.

Table 7 lists the components of the mechanical systems present in each house.

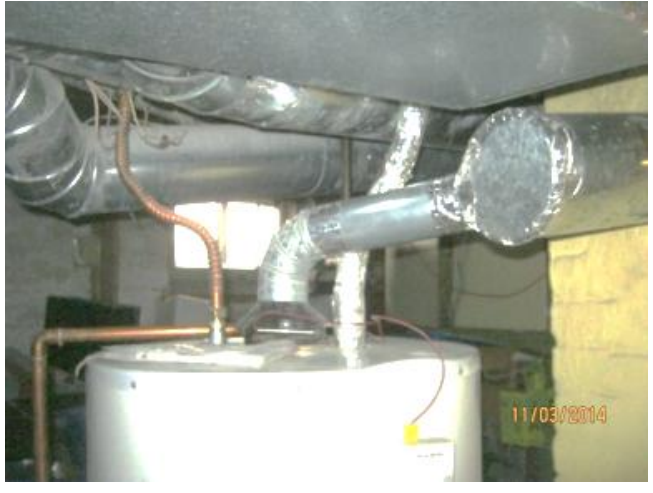

Figure 8. Orphaned water heater

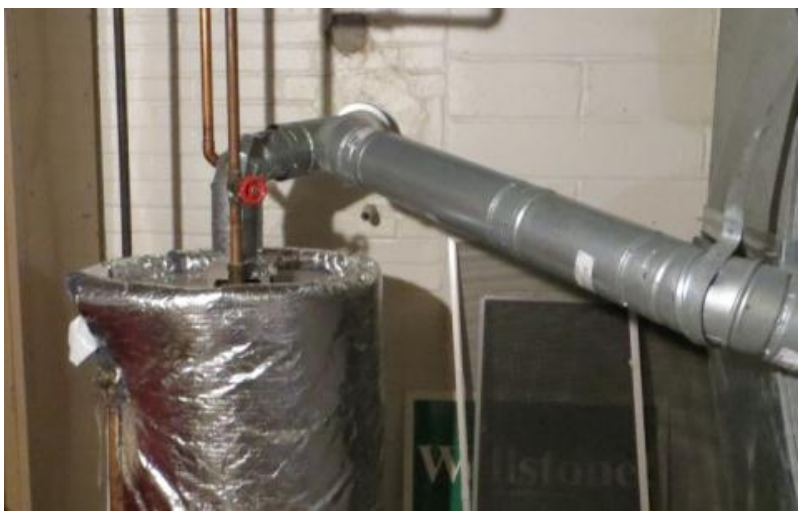

Figure 9. Common vented water heater

Testing was performed to measure the cold vent establishment pressure (CVEP). The CEVP is the highest level of CAZ depressurization for which the appliance can overcome a cold stack and establish a draft up the flue. This provides an appliance- and house-specific prediction of the level of CAZ depressurization necessary to cause depressurization-induced combustion gas spillage. Instead of a "generic" depressurization guideline for an appliance type (e.g., 5 Pa for natural draft appliances), the measured CVEP is specific to the appliance location, combustion vent configuration, and other factors that impact the ability of an appliance to draft properly under depressurization conditions (Table 8 through Table 11). For example, a water heater can more easily establish a draft when the vent connector runs straight up from the draft hood to the roof termination than when an elbow is attached to the draft hood followed by a 4-ft horizontal run before it connects to a vertical section. An appliance can more easily establish draft when the vertical section is closer to the draft hood. 
Table 7. Mechanical Systems of Participating Houses

\begin{tabular}{|c|c|c|c|c|c|}
\hline House & $\begin{array}{c}\text { Heating } \\
\text { System Type }\end{array}$ & $\begin{array}{c}\text { Water Heater } \\
\text { Type }\end{array}$ & $\begin{array}{c}\text { Water Heater } \\
\text { Venting }\end{array}$ & $\begin{array}{c}\text { Air } \\
\text { Conditioning }\end{array}$ & $\begin{array}{c}\text { Whole-House } \\
\text { Ventilation }\end{array}$ \\
\hline MN01 & $\begin{array}{l}\text { Hydronic, } \\
\text { direct vent }\end{array}$ & Natural draft & Orphaned & Window & ERV \\
\hline MN02 & $\begin{array}{l}\text { Forced air, } \\
\text { direct vent }\end{array}$ & Natural draft & Orphaned & Central & N/A \\
\hline MN03 & $\begin{array}{l}\text { Forced air, } \\
\text { induced draft }\end{array}$ & Natural draft & $\begin{array}{c}\text { Common } \\
\text { vented }\end{array}$ & Central & N/A \\
\hline MN04 & $\begin{array}{c}\text { Forced air, } \\
\text { natural }\end{array}$ & Natural draft & $\begin{array}{l}\text { Common } \\
\text { vented }\end{array}$ & Window & $\begin{array}{l}\text { Continuous } \\
\text { exhaust only }\end{array}$ \\
\hline MN05 & $\begin{array}{l}\text { Forced air, } \\
\text { induced draft }\end{array}$ & Natural draft & $\begin{array}{c}\text { Common } \\
\text { vented }\end{array}$ & Central & N/A \\
\hline MN06 & $\begin{array}{l}\text { Forced air, } \\
\text { direct vent }\end{array}$ & Natural draft & Orphaned & Central & $\mathrm{N} / \mathrm{A}$ \\
\hline MN07 & $\begin{array}{l}\text { Forced air, } \\
\text { direct vent }\end{array}$ & Natural draft & Orphaned & Central & $\mathrm{N} / \mathrm{A}$ \\
\hline MN08 & $\begin{array}{l}\text { Forced air, } \\
\text { induced draft }\end{array}$ & Natural draft & $\begin{array}{l}\text { Common } \\
\text { vented }\end{array}$ & Window & $\mathrm{N} / \mathrm{A}$ \\
\hline MN09 & $\begin{array}{l}\text { Forced air, } \\
\text { direct vent }\end{array}$ & Natural draft & Orphaned & Window & $\mathrm{N} / \mathrm{A}$ \\
\hline MN10 & $\begin{array}{l}\text { Forced air, } \\
\text { direct vent }\end{array}$ & Natural draft & Orphaned & Central & $\mathrm{N} / \mathrm{A}$ \\
\hline WI01 & $\begin{array}{l}\text { Forced air, } \\
\text { direct vent }\end{array}$ & Natural draft & Orphaned & Central & N/A \\
\hline
\end{tabular}

Table 8. Combustion Vent Configuration: Orphaned Water Heaters

\begin{tabular}{|c|c|c|c|c|c|c|c|c}
\hline House & $\begin{array}{c}\text { Input } \\
\text { (Btu/h) }\end{array}$ & $\begin{array}{c}\text { Diameter } \\
\text { (in.) }\end{array}$ & $\begin{array}{c}\text { Rise, } \\
\text { above } \\
\text { DD (ft) }\end{array}$ & $\begin{array}{c}\text { Vent } \\
\text { Height } \\
\text { (ft) }\end{array}$ & $\begin{array}{c}\text { Total } \\
\text { Lateral } \\
\text { (ft) }\end{array}$ & $\begin{array}{c}\text { All } \\
\text { Elbows } \\
\text { Offsets }\end{array}$ & $\begin{array}{c}\text { Table } \\
\text { Limit/ } \\
\text { Input }\end{array}$ & $\begin{array}{c}\text { Vent } \\
\text { Meets } \\
\text { Code }\end{array}$ \\
\hline MN 01 & 39,600 & 4 & 1.5 & 27 & 5 & 3 & $136 \%$ & Yes \\
MN 02 & 39,500 & 3 & 0.5 & 23 & 4 & 2.5 & $119 \%$ & Yes \\
\hline MN 06 & 28,000 & 4 & 1.0 & 20 & 2 & 3 & $248 \%$ & Yes \\
MN 07 & 37,000 & 4 & 1.5 & 18 & 4 & 2.5 & $238 \%$ & Yes \\
MN 09 & 40,000 & 4 & 0.3 & 20 & 1 & 1 & $217 \%$ & Yes \\
\hline MN 10 & 40,000 & 4 & 1.5 & 18 & 1 & 2 & $185 \%$ & Yes \\
\hline WI 01 & 38,000 & 3 & 0.3 & 25 & 20 & 6 & N/A & No \\
\hline
\end{tabular}

${ }^{\text {a }}$ Ratio of NFPA 54 vent maximum capacity with actual input rate. 
Table 9. Combustion Vent Connector Configuration: Common Vented Water Heaters

\begin{tabular}{|c|c|c|c|c|c|c|c|c|c|c|}
\hline House & $\begin{array}{c}\text { WH } \\
\text { Input } \\
\text { (Btu/h) }\end{array}$ & Туре & $\begin{array}{l}\text { Diam } \\
\text { (in.) }\end{array}$ & $\begin{array}{l}\text { Rise, } \\
\text { Total } \\
\text { (ft) }\end{array}$ & $\begin{array}{l}\text { Rise, } \\
\text { above } \\
\text { DD } \\
\text { (ft) }\end{array}$ & $\begin{array}{l}\text { Run } \\
\text { (ft) }\end{array}$ & $\begin{array}{c}90 \\
\text { Elbow }\end{array}$ & Saddle & $\begin{array}{l}\text { Table } \\
\text { Limit/ } \\
\text { Input }\end{array}$ & $\begin{array}{c}\text { Connector } \\
\text { Meets } \\
\text { Code }\end{array}$ \\
\hline $\begin{array}{c}\text { MN } \\
03\end{array}$ & 39,706 & SW & 4 & 1 & 0.5 & 4 & 2 & Wye & $138 \%$ & Yes \\
\hline $\begin{array}{c}\text { MN } \\
04\end{array}$ & 33,000 & SW & 3 & 2 & 0.5 & 6 & 4 & $\begin{array}{c}\text { Stacked } \\
\text { tee }\end{array}$ & $75 \%$ & No \\
\hline $\begin{array}{c}\text { MN } \\
05\end{array}$ & 40,000 & SW & 4 & 1 & 1 & 1 & 1 & $\begin{array}{c}\text { B-vent } \\
\text { Wye }\end{array}$ & $138 \%$ & Yes \\
\hline $\begin{array}{c}\text { MN } \\
08\end{array}$ & 40,000 & SW & 4 & 2 & 2 & 10 & 3 & $\begin{array}{c}\text { Stacked } \\
\text { tee }\end{array}$ & $137 \%$ & Yes \\
\hline
\end{tabular}

Table 10. Common Vent Configuration: Common Vented Water Heaters

\begin{tabular}{|c|c|c|c|c|c|c|c|c|c|c|}
\hline 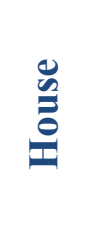 & 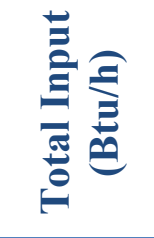 & 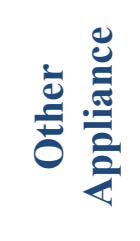 & $\sum_{0}^{0}$ & 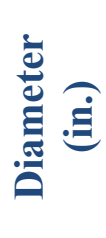 & 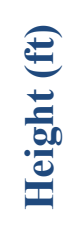 & 可 & 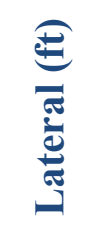 & हैं & 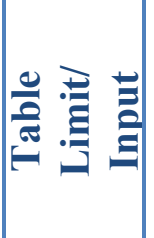 & 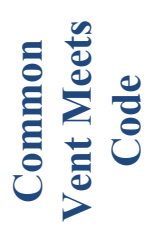 \\
\hline $\begin{array}{c}\text { MN } \\
03\end{array}$ & 105,706 & $\begin{array}{c}\text { ID } \\
\text { furnace }\end{array}$ & SW & 6 & 24 & Yes & 2 & Listed & $124 \%$ & Yes \\
\hline $\begin{array}{c}\text { MN } \\
04\end{array}$ & 128,000 & $\begin{array}{c}\text { Nat } \\
\text { furnace }\end{array}$ & SW & 5 & 30 & No & 0 & Listed & $105 \%$ & Yes \\
\hline $\begin{array}{c}\text { MN } \\
05\end{array}$ & 110,000 & $\begin{array}{c}\text { ID } \\
\text { furnace }\end{array}$ & SW & 4 & 24 & No & 1 & None & $106 \%$ & Yes \\
\hline $\begin{array}{c}\text { MN } \\
08\end{array}$ & 106,000 & $\begin{array}{c}\text { ID } \\
\text { furnace }\end{array}$ & $\begin{array}{c}\text { SW } \\
\text { offset }\end{array}$ & 5 & 26 & Yes & N/A & Listed & $113 \%$ & Yes \\
\hline
\end{tabular}

Table 11. Combustion Air Configuration

\begin{tabular}{|c|c|c|c|c|c|c|c|c|c|}
\hline \multirow[b]{2}{*}{ House } & \multicolumn{2}{|c|}{ CAZ Allowance } & \multicolumn{3}{|c|}{ Outdoor Air Allowance } & \multirow[b]{2}{*}{$\begin{array}{c}\text { Combined } \\
\text { Allowance } \\
(\text { Btu/h) }\end{array}$} & \multirow[b]{2}{*}{$\begin{array}{c}\text { Appl } \\
\text { Input } \\
\text { (Btu/h) }\end{array}$} & \multirow[b]{2}{*}{$\begin{array}{c}\% \text { of } \\
\text { Code } \\
\text { Req }\end{array}$} & \multirow[b]{2}{*}{$\begin{array}{l}\text { Meets } \\
\text { Code }\end{array}$} \\
\hline & $\begin{array}{c}\text { CAZ } \\
\text { Vol } \\
\left(\mathbf{f t}^{3}\right)\end{array}$ & $\begin{array}{c}\text { Allowed } \\
\text { Input } \\
\text { (Btu/h) }\end{array}$ & $\begin{array}{c}\text { Outdoor } \\
\text { Comb } \\
\text { Air } \\
\left.\text { (in. }^{2}\right)\end{array}$ & $\begin{array}{c}\text { Free } \\
\text { Air } \\
\left(\text { in. }{ }^{2}\right)\end{array}$ & $\begin{array}{c}\text { Allowed } \\
\text { Input } \\
\text { (Btu/h) }\end{array}$ & & & & \\
\hline $\begin{array}{c}\text { MN } \\
01\end{array}$ & 720 & 14,400 & 12.6 & 9.45 & 28,350 & 42,750 & 39,600 & $108 \%$ & Yes \\
\hline $\begin{array}{c}\text { MN } \\
02\end{array}$ & 5,460 & 109,200 & 19.6 & 14.7 & 44,100 & 153,300 & 40,000 & $383 \%$ & Yes \\
\hline $\begin{array}{c}\text { MN } \\
\mathbf{0 3}\end{array}$ & 11,040 & 220,800 & 19.6 & 14.7 & 44,100 & 264,900 & 40,000 & $662 \%$ & Yes \\
\hline $\begin{array}{c}\text { MN } \\
\text { 04 }\end{array}$ & 7,100 & 142,000 & 0 & 0 & 0 & 142,000 & 140,000 & $101 \%$ & Yes \\
\hline
\end{tabular}




\begin{tabular}{|c|c|c|c|c|c|c|c|c|c|}
\hline \multirow[b]{2}{*}{ House } & \multicolumn{2}{|c|}{ CAZ Allowance } & \multicolumn{3}{|c|}{ Outdoor Air Allowance } & \multirow[b]{2}{*}{$\begin{array}{c}\text { Combined } \\
\text { Allowance } \\
(\text { Btu/h) }\end{array}$} & \multirow[b]{2}{*}{$\begin{array}{c}\text { Appl } \\
\text { Input } \\
\text { (Btu/h) }\end{array}$} & \multirow[b]{2}{*}{$\begin{array}{c}\% \text { of } \\
\text { Code } \\
\text { Req }\end{array}$} & \multirow[b]{2}{*}{$\begin{array}{l}\text { Meets } \\
\text { Code }\end{array}$} \\
\hline & $\begin{array}{c}\text { CAZ } \\
\text { Vol } \\
\left(\mathbf{f t}^{3}\right)\end{array}$ & $\begin{array}{c}\text { Allowed } \\
\text { Input } \\
\text { (Btu/h) }\end{array}$ & $\begin{array}{c}\text { Outdoor } \\
\text { Comb } \\
\text { Air } \\
\text { (in. }^{2} \text { ) } \\
\end{array}$ & $\begin{array}{c}\text { Free } \\
\text { Air } \\
\text { (in. }^{2} \text { ) }\end{array}$ & $\begin{array}{c}\text { Allowed } \\
\text { Input } \\
\text { (Btu/h) }\end{array}$ & & & & \\
\hline $\begin{array}{c}\text { MN } \\
05\end{array}$ & 6,720 & 134,400 & 19.6 & 14.7 & 44,100 & 178,500 & 110,000 & $162 \%$ & Yes \\
\hline $\begin{array}{c}\text { MN } \\
06\end{array}$ & 210 & 4,200 & 0 & 0 & 0 & 4,200 & 28,000 & $15 \%$ & No \\
\hline $\begin{array}{c}\text { MN } \\
07\end{array}$ & 1,260 & 25,200 & 19.6 & 14.7 & 44,100 & 69,300 & 40,000 & $173 \%$ & Yes \\
\hline $\begin{array}{c}\text { MN } \\
08\end{array}$ & 6,200 & 124,000 & 19.6 & 14.7 & 44,100 & 168,100 & 106,000 & $159 \%$ & Yes \\
\hline $\begin{array}{c}\text { MN } \\
09\end{array}$ & 960 & 19,200 & 19.6 & 14.7 & 44,100 & 63,300 & 40,000 & $158 \%$ & Yes \\
\hline $\begin{array}{c}\text { MN } \\
10\end{array}$ & 7,500 & 150,000 & 19.8 & 14.85 & 44,550 & 194,550 & 40,000 & $486 \%$ & Yes \\
\hline $\begin{array}{l}\text { WI } \\
01\end{array}$ & 6,662 & 133,240 & 0 & 0 & 0 & 133,240 & 38,000 & $351 \%$ & Yes \\
\hline
\end{tabular}

The CVEP test procedure is described in Appendix A. In brief, a blower door creates a level of depressurization that is expected to generate backdrafting, the appliance is fired, and the blower door flow is gradually reduced until the appliance drafts properly. A reversal of positive to negative vent pressure is often used to indicate when draft is established. This test has not been used extensively in the laboratory or in the field. Additional experience is necessary to better understand the repeatability of the results and usefulness for predicting combustion spillage issues. Table 17 (in Section 4.4.4) lists the outdoor test conditions, the measured CVEP, and the measured CAZ depressurization using the simplified protocol. The CVEP varied widely with a low value of $-1.7 \mathrm{~Pa}$ and high of $-7.4 \mathrm{~Pa}$. Some of the variation could be due to greater uncertainty for windy conditions when brief wind gusts can "trip" a backdrafting situation into positive venting. However, the CVEP ranged from $-2.6 \mathrm{~Pa}$ to $6 \mathrm{~Pa}$ for the four houses tested when the wind speed was lower than $10 \mathrm{mph}$. This suggests that the appliance vent configuration and other factors have a significant impact on the resistance to depressurization induced spillage and that a single value for a depressurization guideline for safe venting may incorrectly identify a large fraction of passes or failures.

Because the selection criteria required that these houses failed spillage for the simplified depressurization conditions, the measured depressurization for the simplified protocol is expected to be larger than the CVEP. That was true for 7 of the 10 houses and for 2 of the other 3 houses the depressurization was within 1.1 Pa of the CVEP. Further work is necessary to better understand the test repeatability, protocol changes to improve repeatability, and vent system or other factors that influence the CVEP.

The exhaust appliances in the houses were the clothes dryer (located in the basement), an exhaust fan (typically multispeed), and at least one bathroom exhaust fan. Table 12 and Table 13 show the flow rates of the exhaust fans located in each house. Exhaust flow rates were directly measured using a flow hood whenever possible. Otherwise they were deduced from pressure 
measurements. Houses MN 07 and MN 10 had a bathroom ceiling exhaust fan configured to run continuously as a whole-house ventilation system with a flow rate of 30 CFM and 72 CFM, respectively. A third house (MN 04) had a kitchen fan that ran continuously at a low speed with a flow rate of $30 \mathrm{CFM}$.

Table 12. Clothes Dryer and Kitchen Exhaust Fan Characteristics

\begin{tabular}{l|c|c|c|c}
\hline \multirow{2}{*}{ House } & \multicolumn{2}{|c|}{$\begin{array}{c}\text { Clothes Dryer } \\
\text { Kitchen Exhaust Fan }\end{array}$} \\
\cline { 2 - 5 } & Location & $\begin{array}{c}\text { Flow Rate } \\
\text { (CFM) }\end{array}$ & Type & $\begin{array}{c}\text { Flow Rate } \\
\text { (CFM) }\end{array}$ \\
\hline MN 01 & Basement & 125 & Through wall & $230 / 80$ \\
MN 02 & Basement & 95 & Roof termination & $159 / \mathrm{N} / \mathrm{A}$ \\
\hline MN 03 & Basement & 135 & Roof termination & $183 / 93$ \\
MN 04 & Basement & 130 & Through wall & $272 / \mathrm{N} / \mathrm{A}$ \\
MN 05 & Basement & 175 & Through wall & $261 / 202$ \\
MN 06 & Basement & 87 & Through wall & $270 / 95$ \\
MN 07 & Basement & 87 & Roof termination & $167 / 122$ \\
MN 08 & Basement & 84 & Roof termination & $250 / 178$ \\
\hline MN 09 & Basement & 154 & Roof termination & $276 / 220$ \\
MN 10 & Basement & 86 & Roof termination & $121 / 20$ \\
WI 01 & Basement & 90 & N/A & N/A \\
\hline
\end{tabular}

Table 13. Bathroom Exhaust Fan Characteristics

\begin{tabular}{l|c|c|c|c}
\hline \multirow{2}{*}{ House } & \multicolumn{4}{|c}{ Bathroom Exhaust Fan(s) } \\
\cline { 2 - 5 } & \multirow{2}{*}{ One } & \multicolumn{2}{c}{ Two } \\
\cline { 2 - 5 } & Exhausted to: & $\begin{array}{c}\text { Flow Rate } \\
\text { (CFM) }\end{array}$ & Exhausted to: & $\begin{array}{c}\text { Flow Rate } \\
\text { (CFM) }\end{array}$ \\
\hline MN 01 & Through wall & 30 & Through wall & 21 \\
MN 02 & Roof termination & 70 & Through wall & 20 \\
MN 03 & Through wall & 65 & Noof termination & 50 \\
MN 04 & Roof termination & 44 & N/A & N/A \\
MN 05 & Roof termination & 39 & Roof termination & 68 \\
MN 06 & Through wall & 62 & Through wall & 26 \\
MN 07 & Roof termination & 108 & N/A & N/A \\
MN 08 & Roof termination & 59 & Through wall & 33 \\
MN 09 & Roof termination & 62 & N/A & N/A \\
\hline MN 10 & Roof termination & 130 & 46 & \multicolumn{3}{|c}{} \\
WI 01 & Through wall & &
\end{tabular}

\subsubsection{Short-Term Testing and Inspection}

For the 11 houses that met the screening criteria, short-term testing was scheduled on the same day that instrumentation was installed in the houses (Table 14). In some cases it was also repeated after monitoring equipment was added. This work was done by a two-person team, one to perform the short-term testing and the other to do the instrument installation. The work took a 
full day to complete, including data collection. The short-term testing took place during both winter and spring, from the middle of February 2015 to the middle of May 2015.

Table 14. Scheduled Visits of Screening and Short-Term Testing Visits

\begin{tabular}{|c|c|c}
\hline House & Screening Date & Short-Term Testing Date \\
\hline MN 01 & $12 / 3 / 2014$ & $2 / 15 / 2015$ \\
MN 02 & $12 / 5 / 2014$ & $2 / 16 / 2015$ \\
MN 03 & $2 / 16 / 2015$ & $2 / 23 / 2015$ \\
MN 04 & $2 / 20 / 2015$ & $2 / 27 / 2015$ \\
MN 05 & $4 / 6 / 2015$ & $4 / 9 / 2015$ \\
MN 06 & $4 / 6 / 2015$ & $4 / 17 / 2015$ \\
MN 07 & $4 / 13 / 2015$ & $4 / 24 / 2015$ \\
MN 08 & $4 / 30 / 2015$ & $5 / 7 / 2015$ \\
MN 09 & $5 / 5 / 2015$ & $5 / 12 / 2015$ \\
MN 10 & $5 / 6 / 2015$ & $5 / 19 / 2015$ \\
WI 01 & $3 / 25 / 2015$ & $4 / 4 / 2015$ \\
\hline
\end{tabular}

In performing the pressure measurements for the short-term testing, interior door positions were concerns, particularly with forced-air systems. Table 15 provides the door positions for each participating house. 
Table 15. House Interior Door Positions

\begin{tabular}{|c|c|c|c|c|}
\hline House & CAZ Door Location & $\begin{array}{l}\text { CAZ Door } \\
\text { Position BPI }\end{array}$ & $\begin{array}{l}\text { Additional Doors Closed }^{\mathrm{a}} \text { : } \\
\text { BPI }\end{array}$ & $\begin{array}{c}\text { Additional Doors Closed }{ }^{\mathrm{b}} \text { : } \\
\text { Pressure }\end{array}$ \\
\hline MN 01 & Mechanical room & Open & $\begin{array}{l}2-2^{\text {nd }}-\text { floor bedrooms, } 1^{\text {st }}- \\
\text { floor bedroom, } 1^{\text {st }} \text {-floor } \\
\text { bath, basement office }\end{array}$ & $\begin{array}{c}2-2^{\text {nd }} \text {-floor bedrooms, } 1^{\text {st }} \text {-floor } \\
\text { bedroom, } 1^{\text {st }} \text {-floor bath, } \\
\text { basement office }\end{array}$ \\
\hline MN 02 & Top of basement stairs & Open & $\begin{array}{l}2^{\text {nd }} \text { floor, main-floor office, } \\
\text { basement bedroom }\end{array}$ & $\begin{array}{c}2^{\text {nd }} \text { floor, main-floor office, } \\
\text { basement bedroom }\end{array}$ \\
\hline MN 03 & N/A & $\mathrm{N} / \mathrm{A}$ & None & $\begin{array}{c}2^{\text {nd }} \text { floor, } 2 \text { main-floor bedrooms, } \\
\text { hall to bedrooms }\end{array}$ \\
\hline MN 04 & $\mathrm{~N} / \mathrm{A}$ & $\mathrm{N} / \mathrm{A}$ & $2-2^{\text {nd }}$-floor bedrooms & $2-2^{\text {nd }}$-floor bedrooms \\
\hline MN 05 & Top of basement stairs & Open & Main-floor bath & Main-floor bath, main-floor hall \\
\hline MN 06 & Mechanical room & Open & None & 2 main-floor bedrooms \\
\hline MN 07 & Utility room & Closed & None & None \\
\hline MN 08 & Top of basement stairs & Open & Main-floor bath & $\begin{array}{l}\text { Main-floor bath, 2nd floor, } \\
2 \text { main-floor bedrooms }\end{array}$ \\
\hline MN 09 & Utility room & Open & None & $\begin{array}{c}2 \text { basement bedrooms, } \\
\text { basement bath }\end{array}$ \\
\hline MN 10 & Top of basement stairs & Closed & Master bedroom & Master bedroom \\
\hline WI 01 & Top of basement stairs & Closed & Bonus room, $2^{\text {nd }}$-floor bath & $\begin{array}{l}\text { Bonus room, } 2^{\text {nd }} \text {-floor bath, } \\
2^{\text {nd }} \text {-floor east bedroom }\end{array}$ \\
\hline
\end{tabular}

${ }^{\text {a }}$ Interior doors closed based on BPI protocol.

${ }^{\mathrm{b}}$ Interior doors closed based on assessment of pressure difference across door. 
Figure 10 through Figure 20 show the house depressurization that resulted from exhaust fan operation for each house operating individually and in concert. The error bars indicate the uncertainty of the change in house pressure due to wind-driven variations in the measured pressure. The uncertainties were computed using the square root of the sum of the squares of the standard deviations of the 1-second measurements for the baseline and fan-on periods. The uncertainties were minimized by using outdoor pressure references at all four sides of the houses and a weighted average of three 30 -second baseline and three 30 -second fan-on periods. See Appendix A for further details.

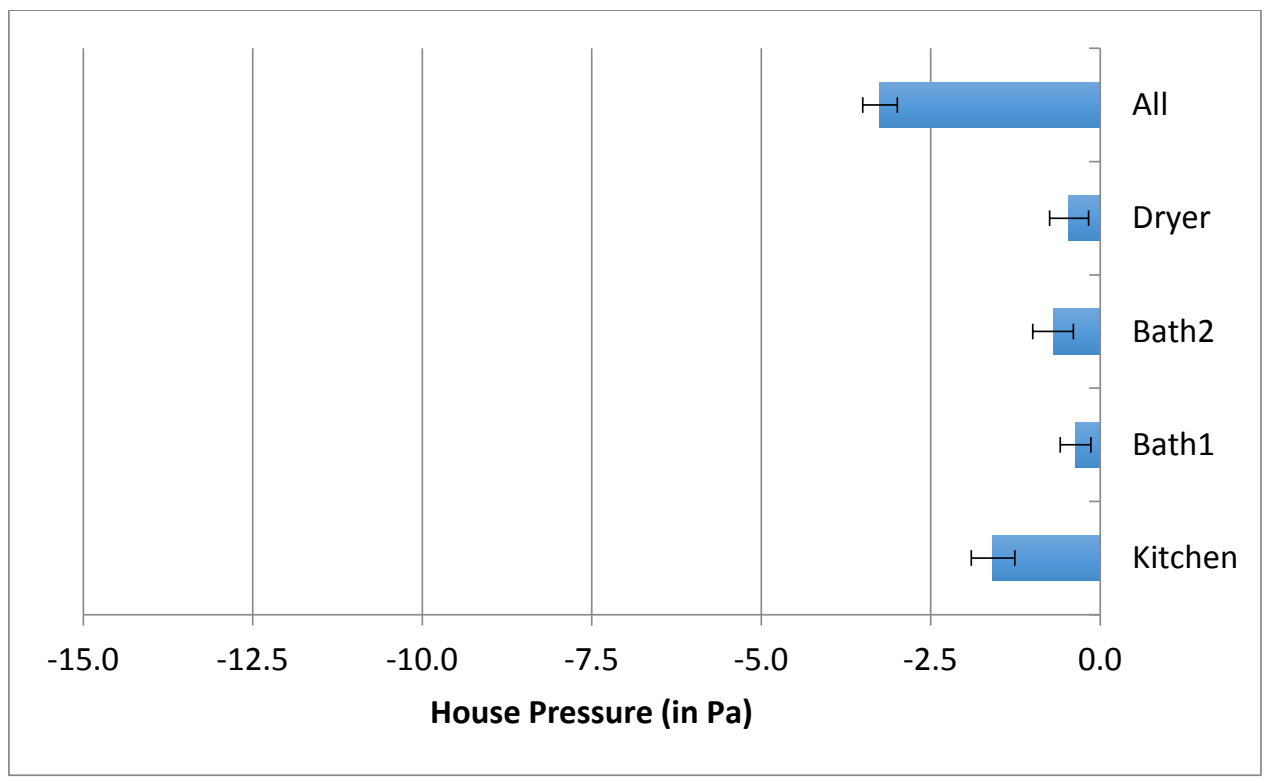

Figure 10. House MN 01 exhaust fan house depressurization (in $\mathrm{Pa}$ )

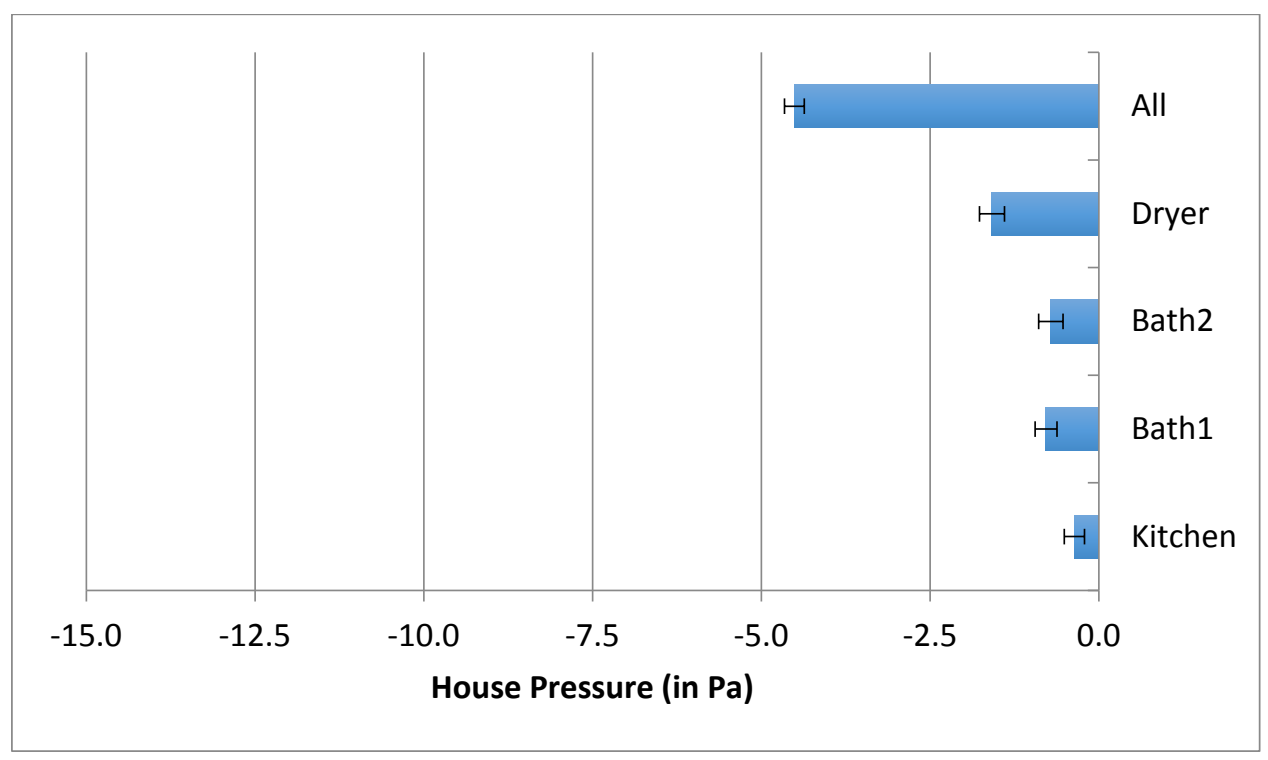

Figure 11. House MN 02 exhaust fan house depressurization (in $\mathrm{Pa}$ ) 


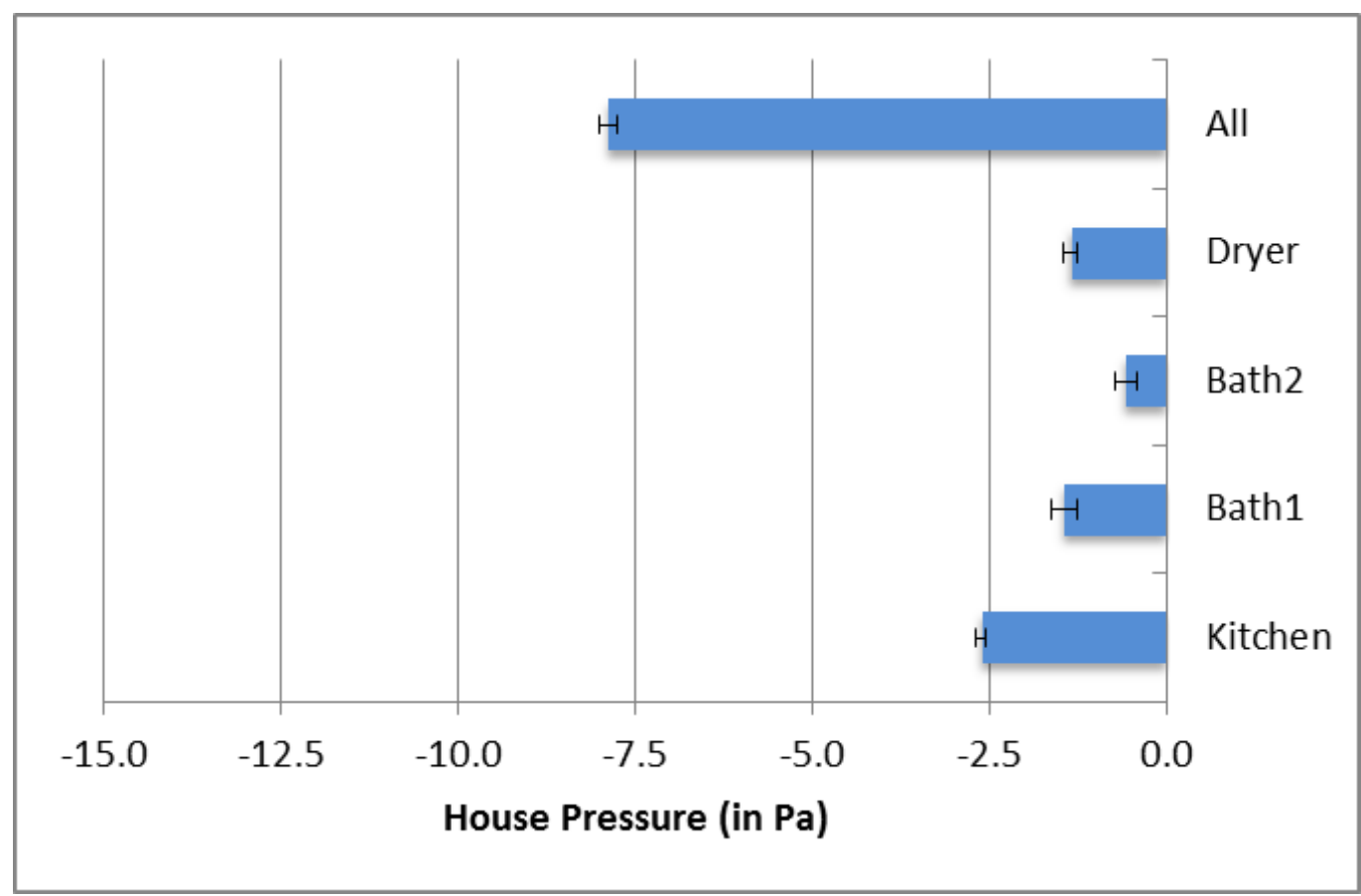

Figure 12. House MN 03 exhaust fan house depressurization (in $\mathrm{Pa}$ )

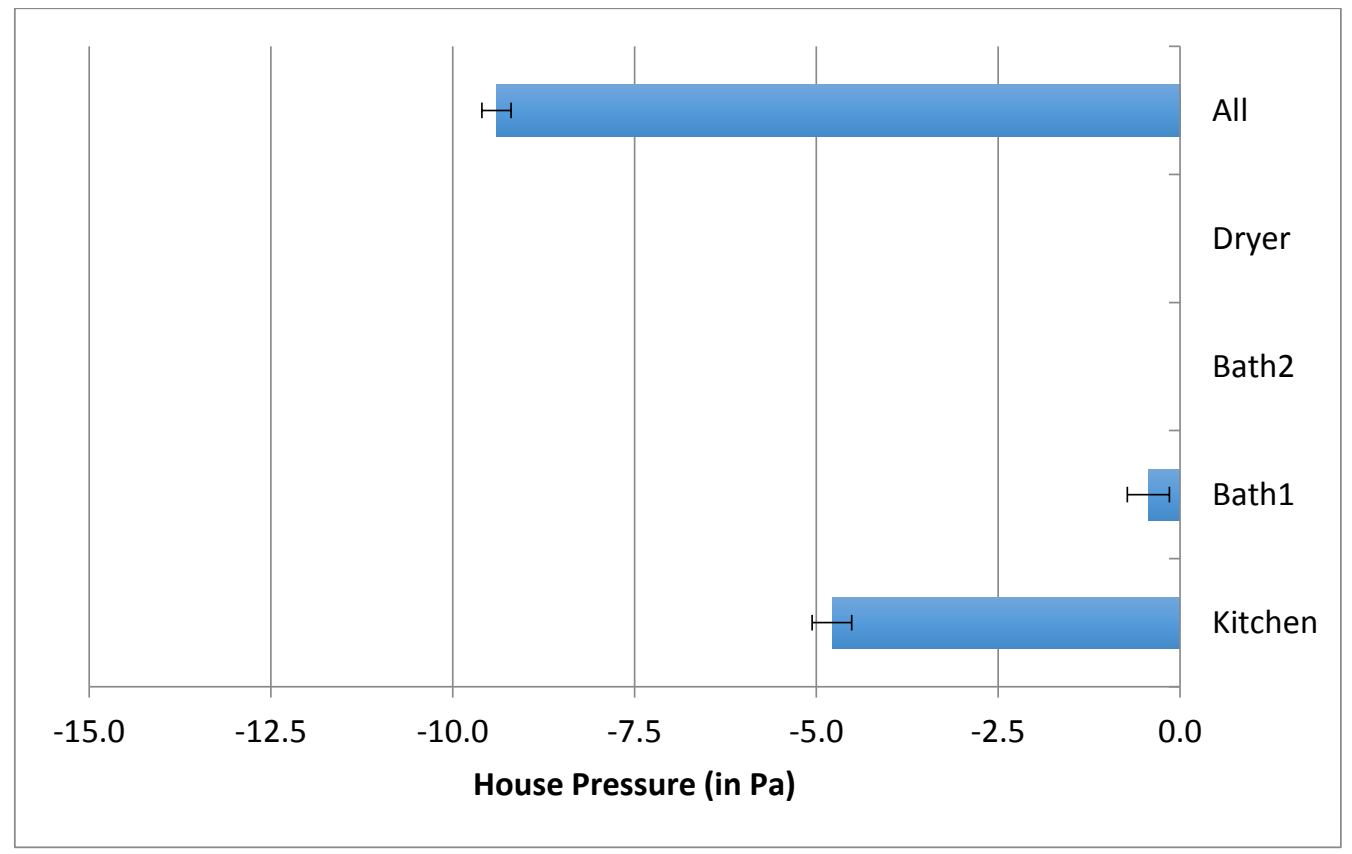

Figure 13. House MN 04 exhaust fan house depressurization (in $\mathrm{Pa}$ ) 


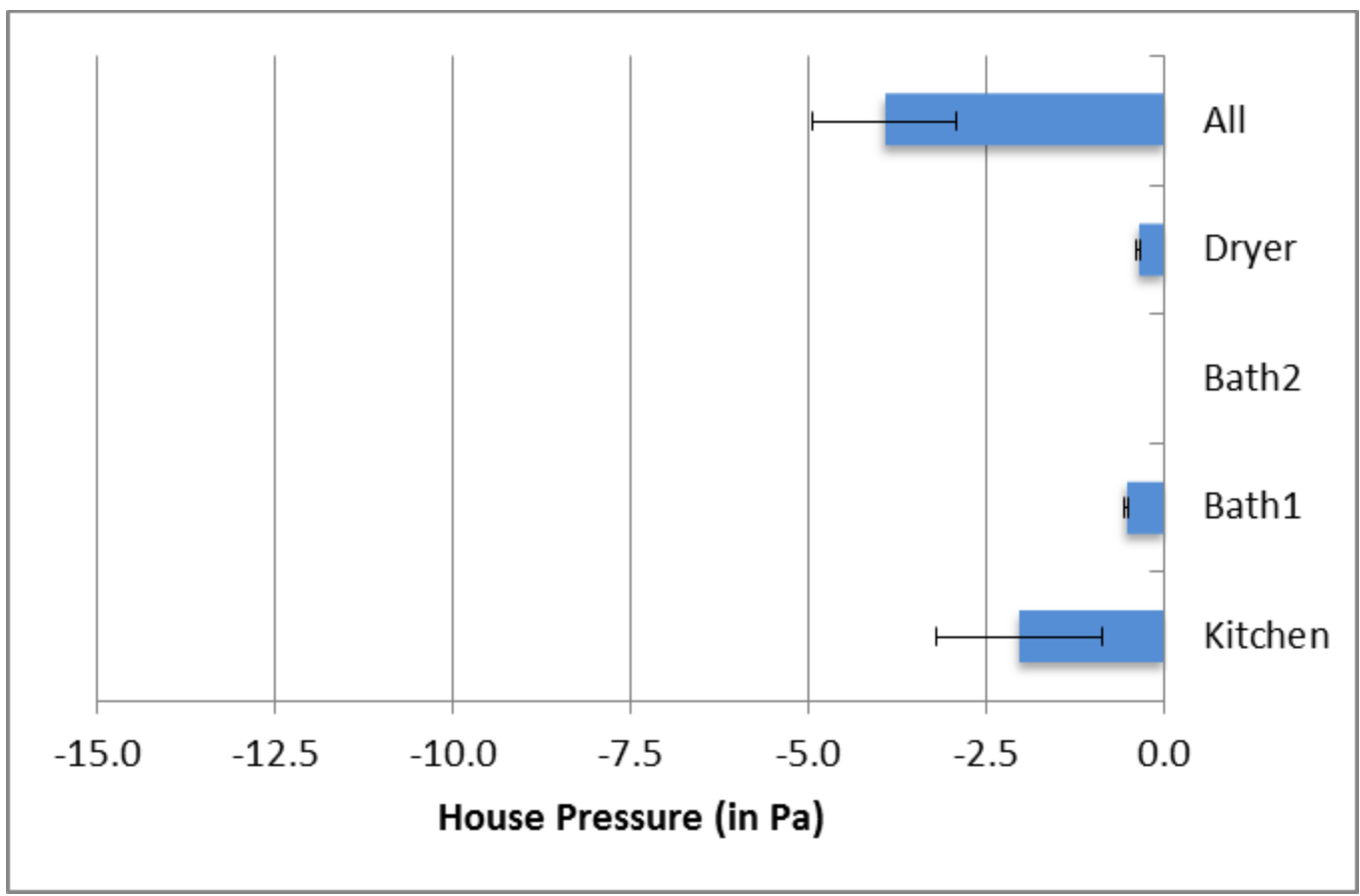

Figure 14. House MN 05 exhaust fan house depressurization (in $\mathrm{Pa}$ )

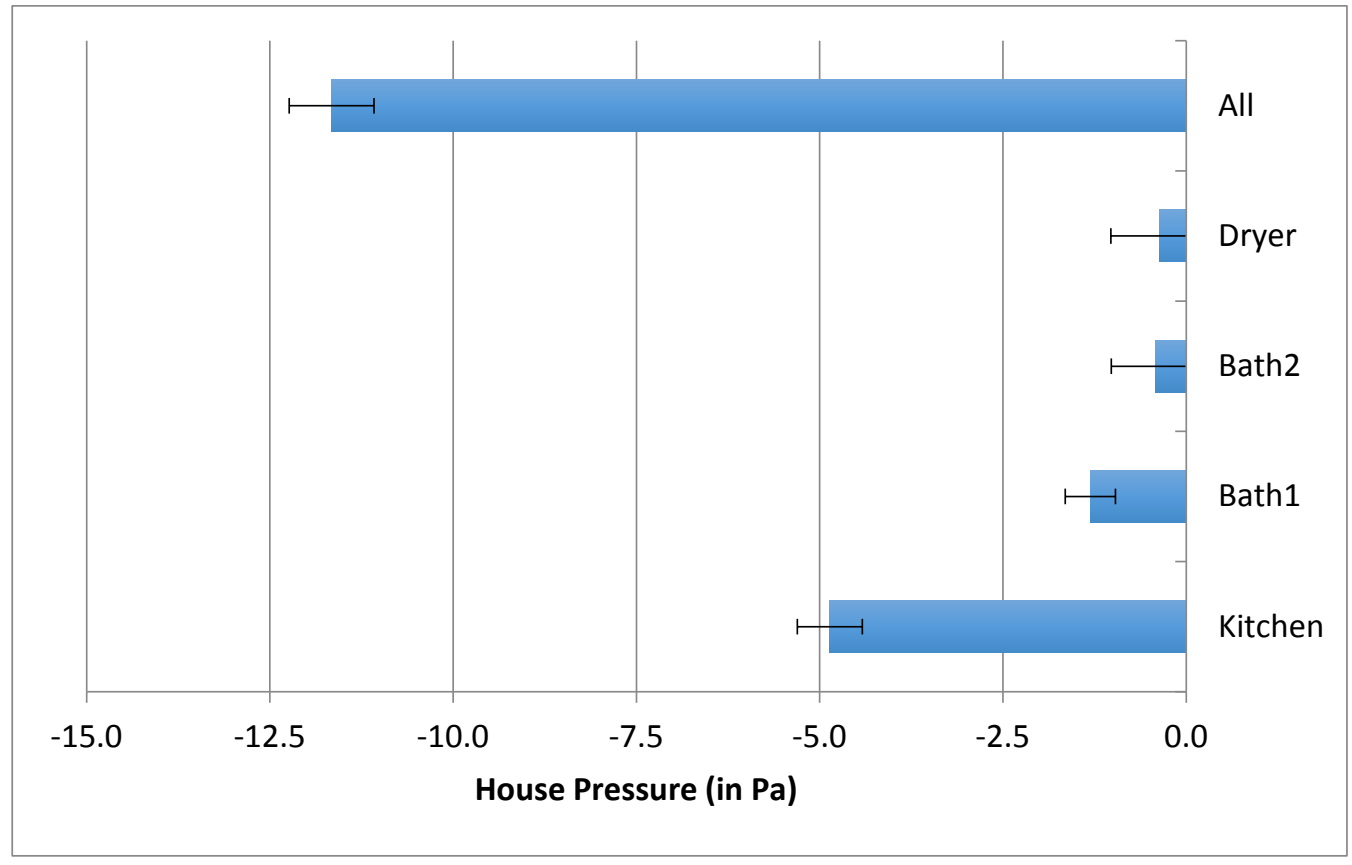

Figure 15. House MN 06 exhaust fan house depressurization (in Pa) 


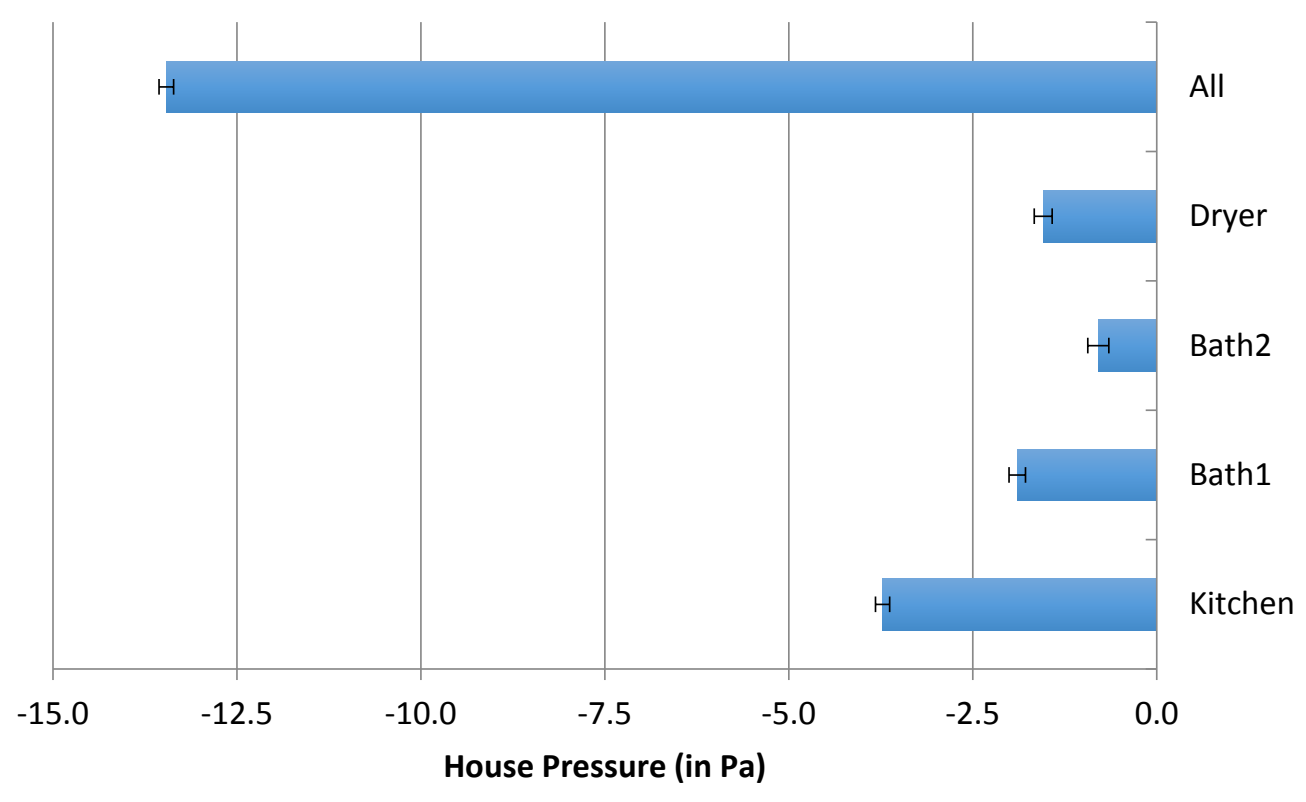

Figure 16. House MN 07 exhaust fan house depressurization (in Pa)

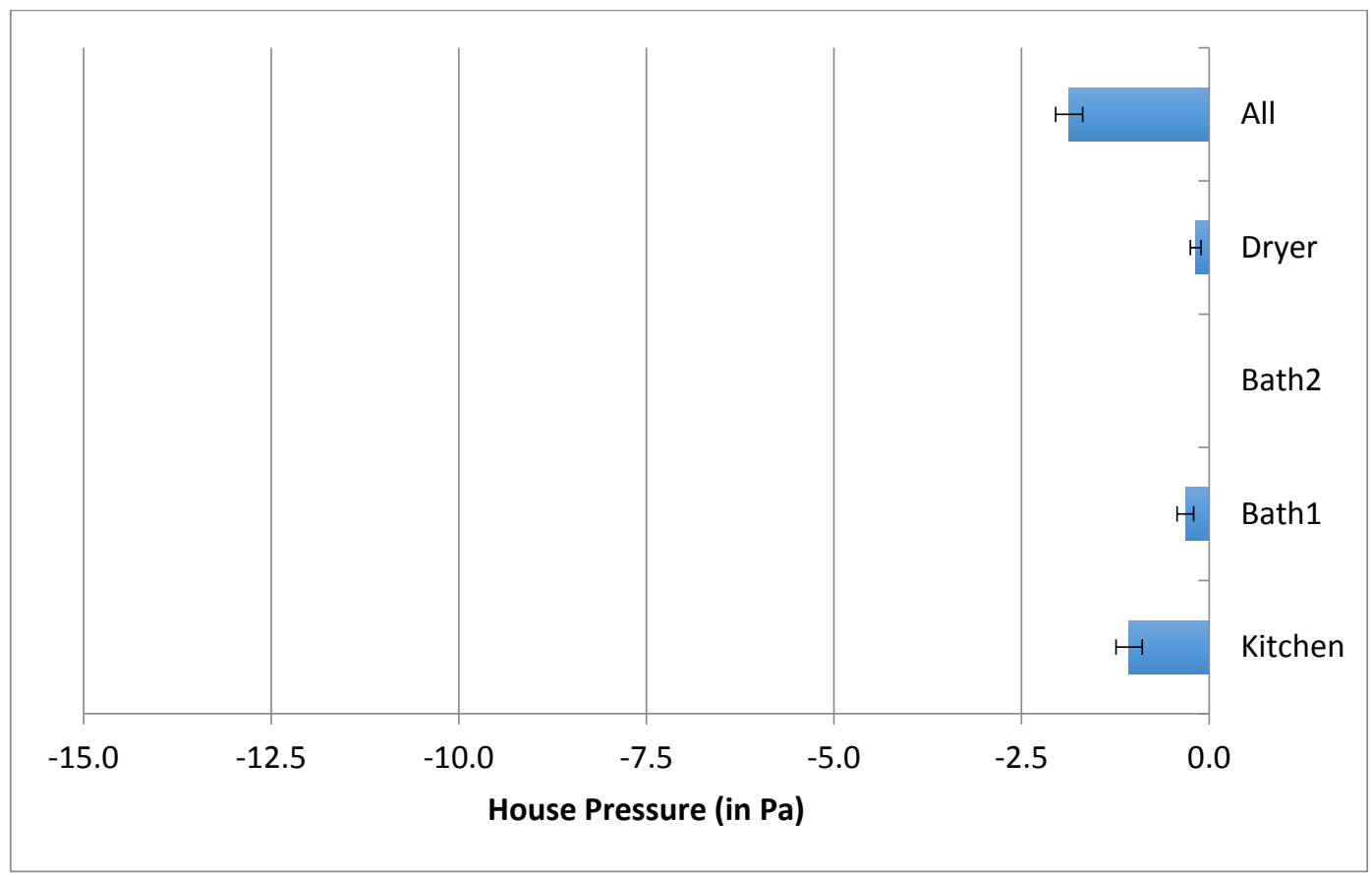

Figure 17. House MN 08 exhaust fan house depressurization (in $\mathrm{Pa}$ ) 


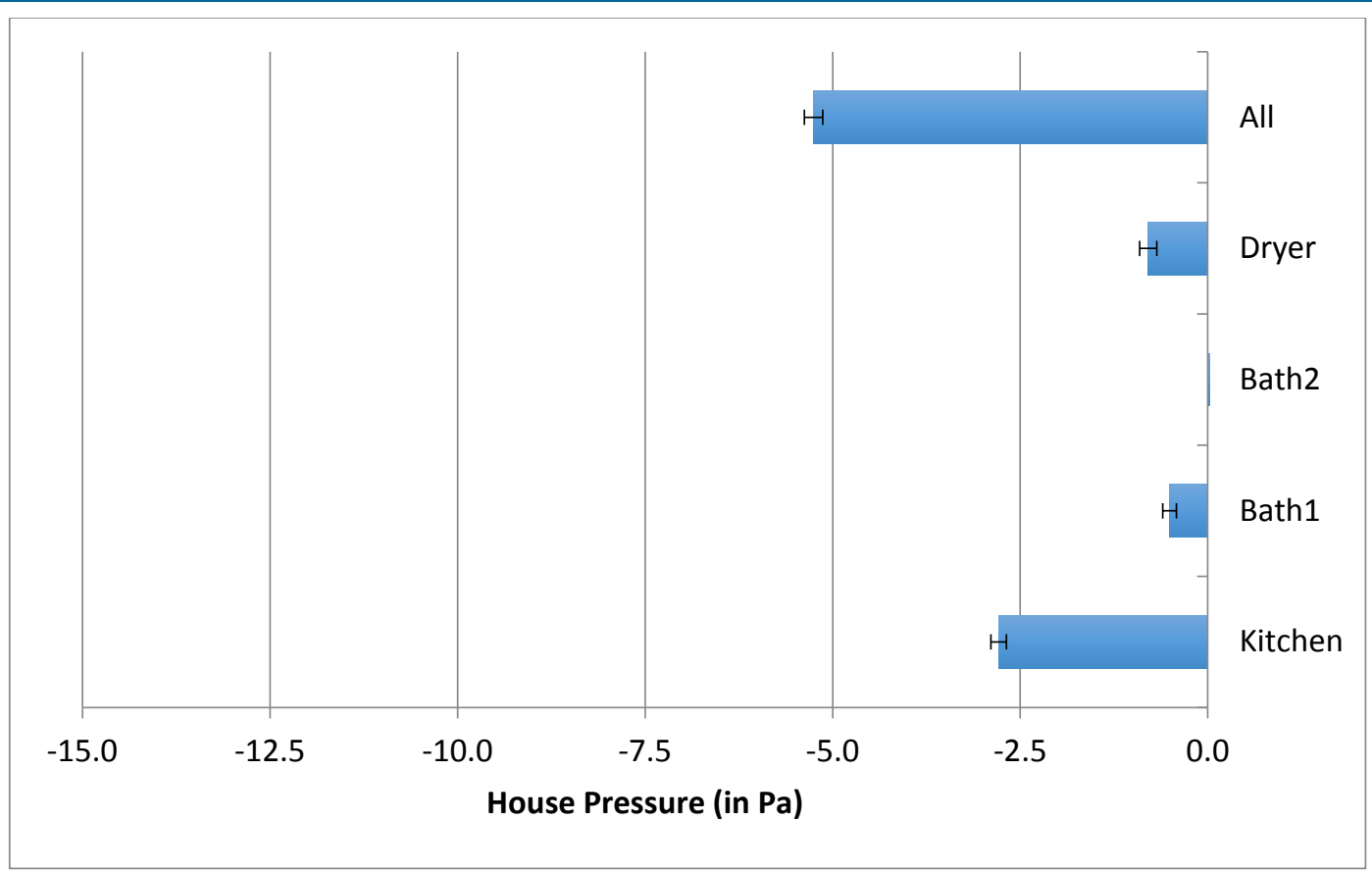

Figure 18. House MN 09 exhaust fan house depressurization (in $\mathrm{Pa}$ )

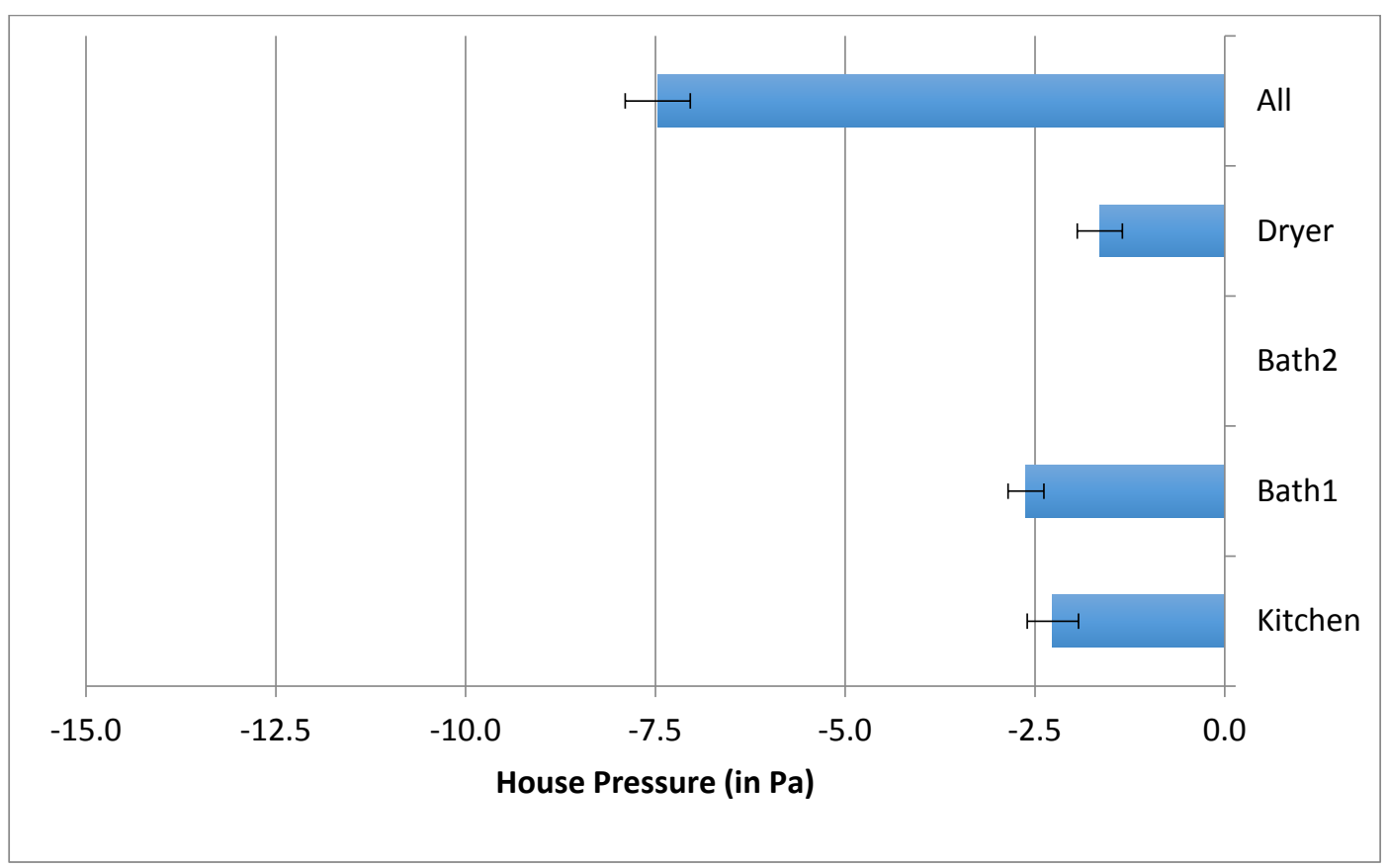

Figure 19. House MN 10 exhaust fan house depressurization (in $\mathrm{Pa}$ ) 


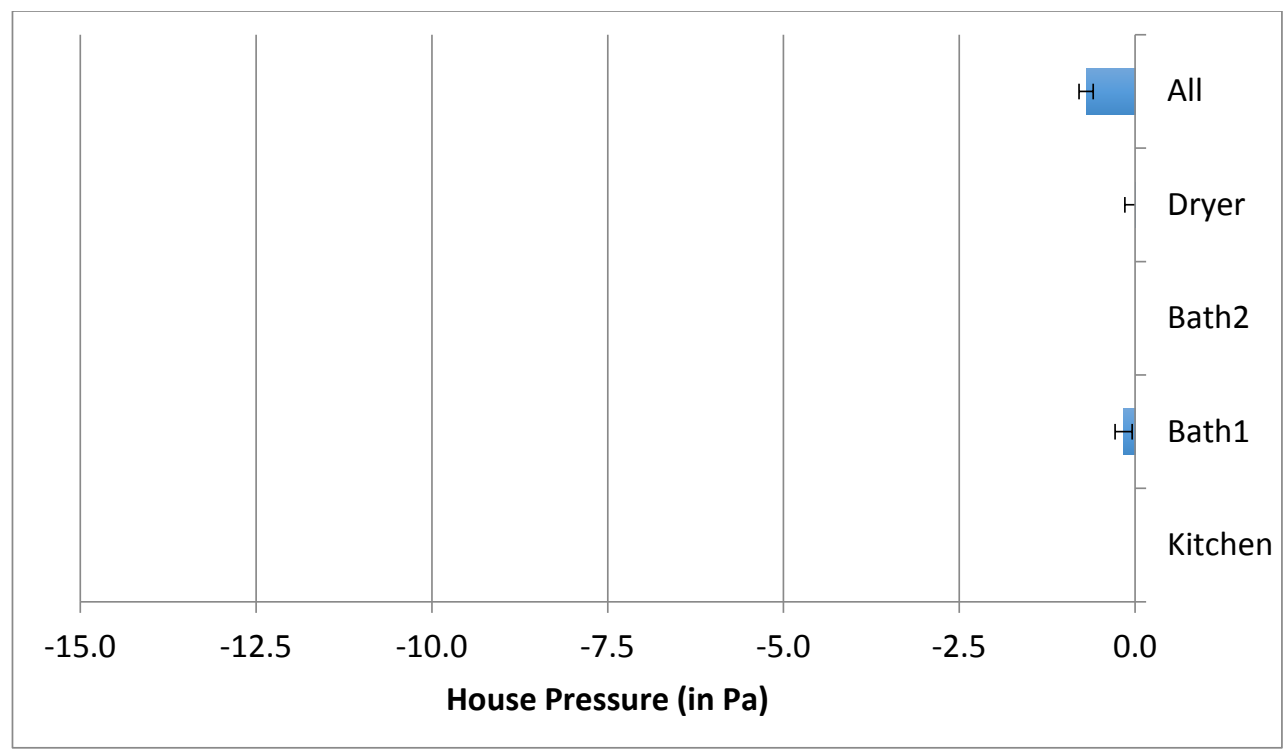

Figure 20. House WI 01 exhaust fan house depressurization (in Pa)

Four WC test protocols were performed and pressure measurements were taken to compare the protocols:

- The BPI protocol

- A comprehensive protocol that modifies the BPI protocol by determining the interior door positions based on pressure

- The STP proposed by this project

- A modified STP again with the interior door positions based on pressure.

Table 16 shows the CAZ pressure measurements recorded for each protocol for 10 of the participating houses. The pressure measurements for house MN 10 could not be performed by the time of the writing of this report.

Table 16. Comparison of CAZ Pressure Measurements from Four WC Protocols for Participating Houses, in $\mathrm{Pa}$ (SD = standard deviation)

\begin{tabular}{|c|c|c|c|c|c|c|c|c|}
\hline \multirow{2}{*}{ House } & \multicolumn{2}{|c|}{ BPI } & \multicolumn{2}{|c|}{ Comprehensive } & \multicolumn{2}{|c|}{ STP } & \multicolumn{2}{|c|}{ Modified STP } \\
\hline & $\Delta \mathbf{P}$ & SD & $\Delta \mathbf{P}$ & SD & $\Delta \mathbf{P}$ & SD & $\Delta \mathbf{P}$ & SD \\
\hline MN 01 & -4.0 & 0.1 & -4.0 & 0.1 & -3.6 & 0.2 & -3.8 & 0.2 \\
\hline MN 02 & -5.4 & 0.2 & -5.4 & 0.2 & -4.1 & 0.1 & -4.1 & 0.2 \\
\hline MN 03 & -7.8 & 0.1 & -7.8 & 0.1 & -6.8 & 0.2 & -6.7 & 0.0 \\
\hline MN 04 & -9.7 & 0.1 & -9.8 & 0.4 & -10.0 & 0.3 & -9.8 & 0.5 \\
\hline MN 05 & -3.7 & 0.1 & -5.0 & 0.1 & -3.5 & 0.1 & -5.0 & 0.3 \\
\hline MN 06 & -13.1 & 0.4 & -13.7 & 0.7 & -10.1 & 0.4 & -10.1 & 0.3 \\
\hline MN 07 & -13.4 & 0.1 & -13.4 & 0.1 & -11.1 & 0.1 & -11.1 & 0.1 \\
\hline MN 08 & -2.6 & 0.1 & -2.3 & 0.1 & -2.1 & 0.1 & -2.3 & 0.1 \\
\hline MN 09 & -4.7 & 0.2 & -5.2 & 0.1 & -5.0 & 0.1 & -5.1 & 0.2 \\
\hline WI 01 & -1.6 & 0.2 & -1.9 & 0.1 & -1.7 & 0.1 & -1.9 & 0.1 \\
\hline
\end{tabular}


To look at the effectiveness of the STP, the pressure measurements from the STP were plotted separately versus the BPI, comprehensive, and modified STP protocols, respectively. These are shown in Figure 21 through Figure 23.

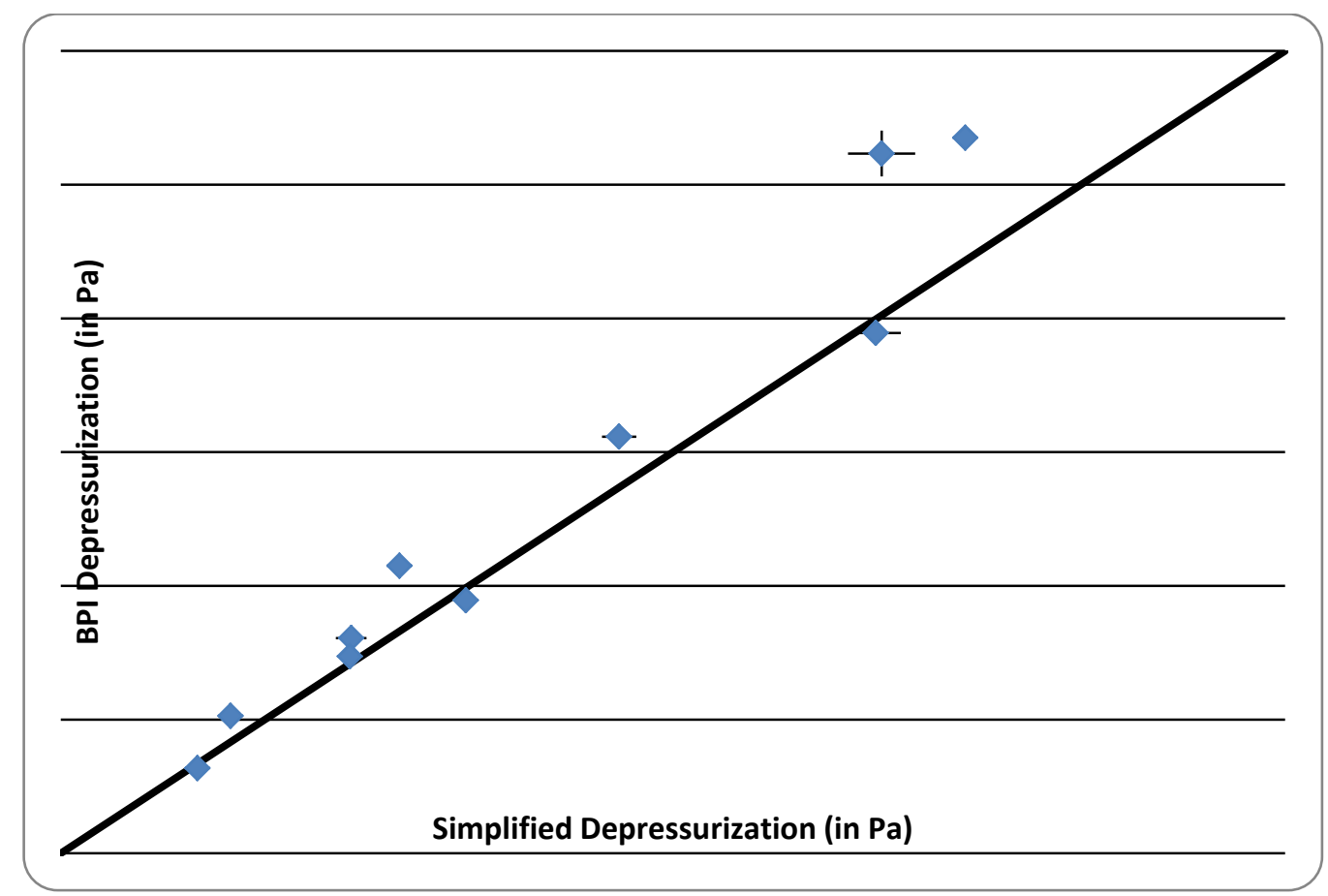

Figure 21. Comparison of the BPI protocol with the STP for measuring CAZ depressurization (in $\mathrm{Pa})$

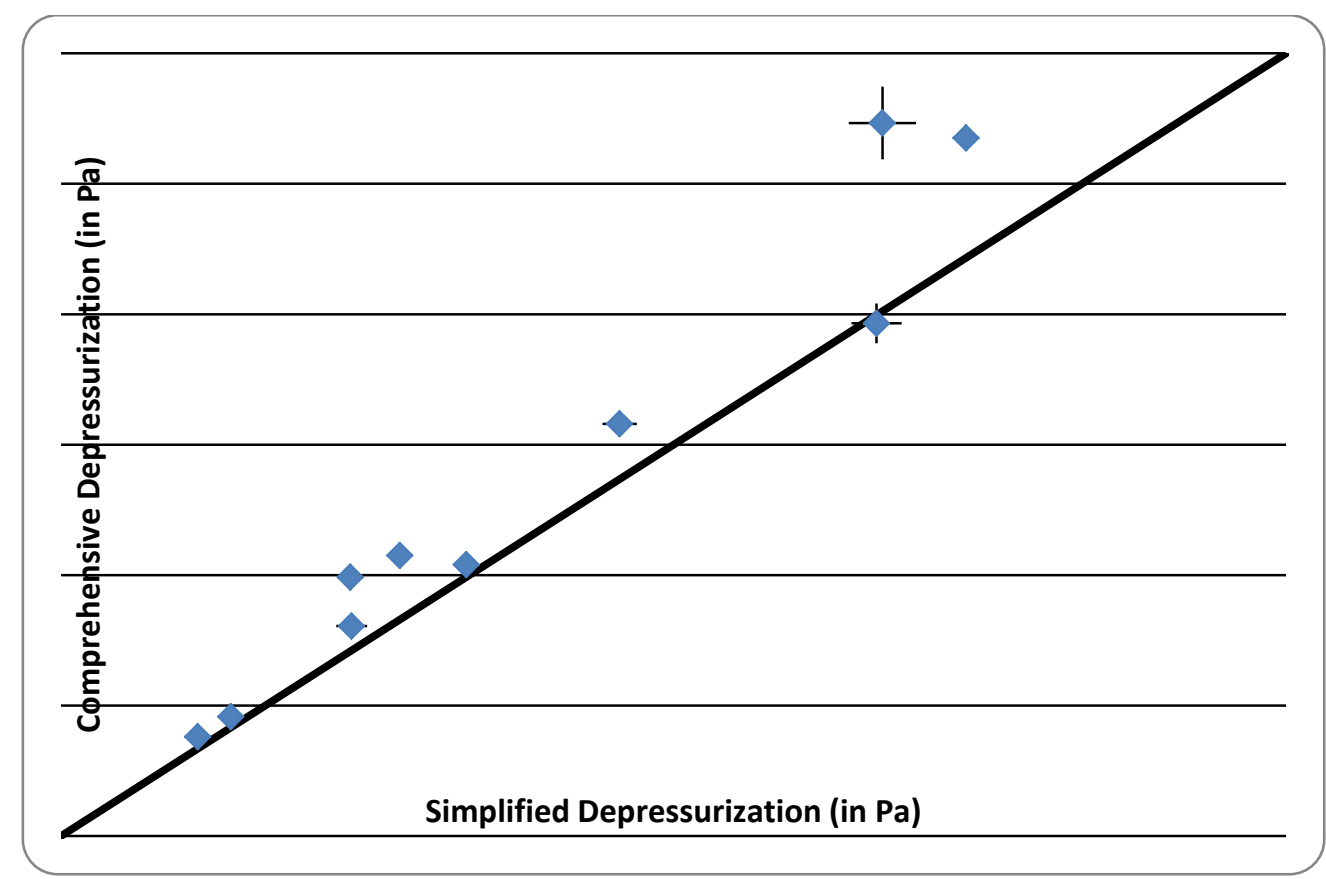

Figure 22. Comparison of the comprehensive protocol with the STP for measuring CAZ depressurization (in $\mathrm{Pa}$ ) 


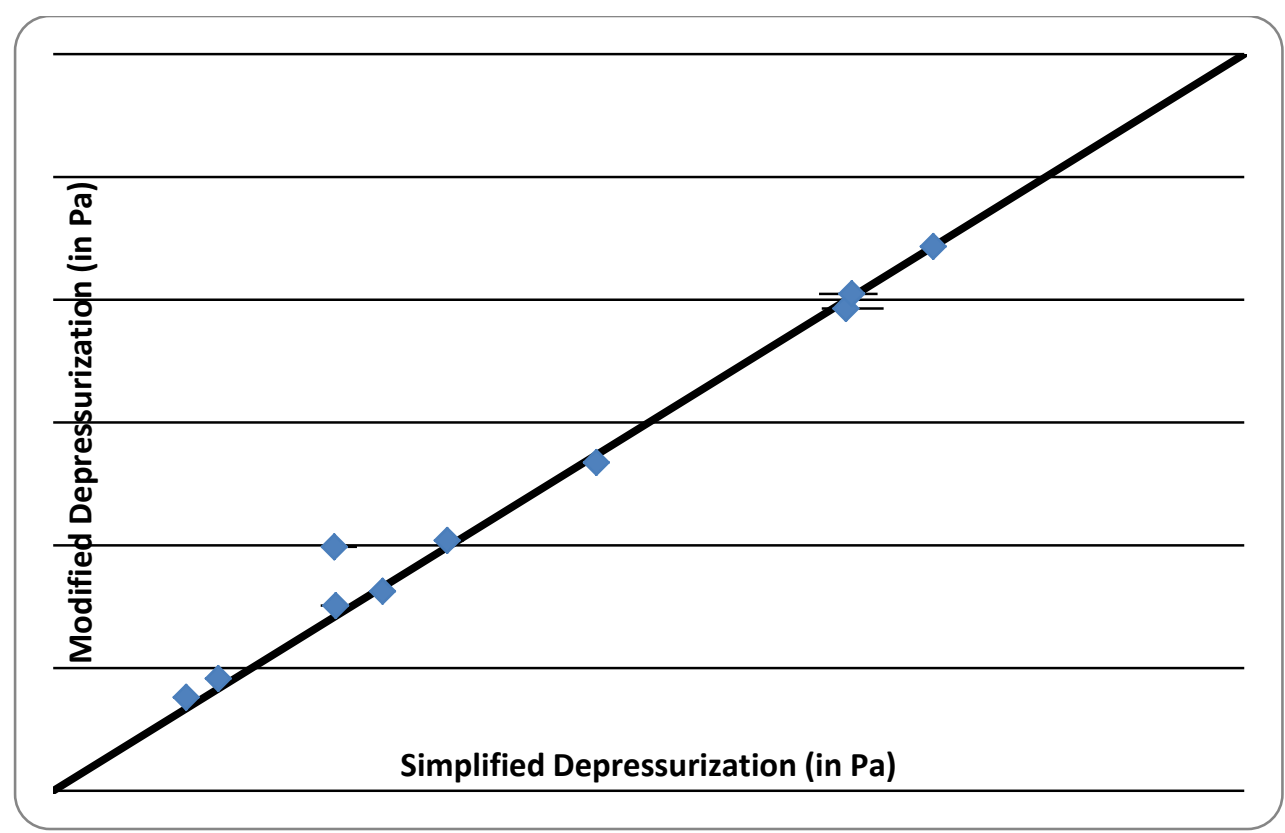

Figure 23. Comparison of the modified protocol with the STP for measuring CAZ depressurization (in $\mathrm{Pa}$ )

The results of the STP approach and the BPI protocol show good agreement with the exception of two houses: MN 06 and MN 07. The modified STP protocol did not have significantly different results than the STP protocol, suggesting that the prescribed door position approach is adequate. A final check on using the prescribed door position approach versus the pressure approach is provided by comparing the comprehensive protocol results with the BPI protocol measurements. Again the results agree well.

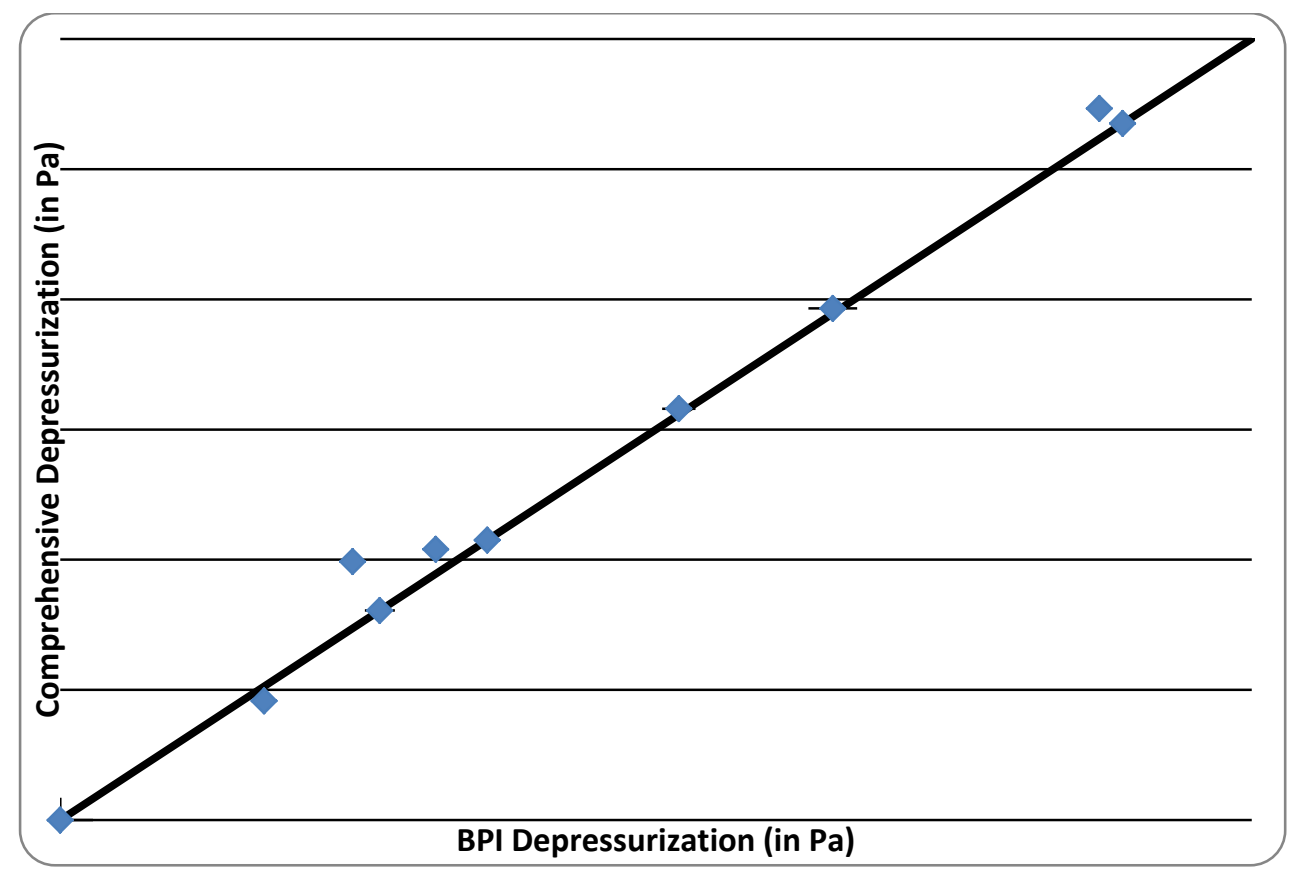

Figure 24. Comparison of the comprehensive protocol with the $\mathrm{BPI}$ protocol for measuring CAZ depressurization (in $\mathrm{Pa}$ ) 
Finally, testing was performed to measure the CVEP. The CEVP is the highest level of CAZ depressurization for which the appliance can overcome a cold stack and establish a draft up the flue. The CVEP test procedure is described in Appendix A. Table 17 lists the outdoor test conditions, the measured CVEP, and the measured CAZ depressurization using the STP. The CVEP varied widely with a low value of $-1.7 \mathrm{~Pa}$ and high of $-7.4 \mathrm{~Pa}$. This suggests that the appliance vent configuration and other factors may have significant impacts on the resistance to depressurization-induced spillage and that a single value for a depressurization guideline for safe venting may not be appropriate. Because these houses all failed spillage for the simplified depressurization conditions, the measured depressurization for the simplified protocol is expected to be lower than the CVEP. That was true for 7 of the 10 houses. Further work is necessary to better understand the repeatability and factors that influence the CVEP. House WI 01 continued to spill after the backdrafting was established during the test. All the other houses re-established a draft after the test was performed.

Table 17. House CVEP Measurements

\begin{tabular}{|c|c|c|c|c|c|}
\hline House & $\begin{array}{c}\text { Outside } \\
\text { Temperature } \\
\left(^{\circ} \mathrm{F}\right)\end{array}$ & $\begin{array}{c}\text { Wind Speed } \\
(\mathrm{mph})\end{array}$ & $\begin{array}{c}\text { CAZ Base } \\
\text { Pressure } \\
\text { (Pa) }\end{array}$ & $\begin{array}{c}\text { CVEP }^{\mathrm{a}} \\
(\triangle \mathrm{Pa})\end{array}$ & $\begin{array}{c}\text { Simplified } \\
\text { Depressurization } \\
(\mathbf{P a})\end{array}$ \\
\hline MN 01 & 35 & 23 & -2.3 & -4.4 & -3.6 \\
\hline MN 02 & 27 & 18 & -2.4 & -7.4 & -4.1 \\
\hline MN 03 & 56 & 7 & -1.3 & -2.6 & -6.8 \\
\hline MN 04 & 14 & 8 & -3.1 & -6.0 & -10.0 \\
\hline MN 05 & 37 & 10 & -2.3 & -3.4 & -3.5 \\
\hline MN 06 & 74 & 6 & -0.9 & -3.1 & -10.1 \\
\hline MN 07 & 46 & 15 & -0.8 & -4.9 & -11.1 \\
\hline MN 08 & 70 & 15 & -0.1 & -1.9 & -2.1 \\
\hline MN 09 & 54 & 16 & -1.4 & -6.1 & -5.0 \\
\hline MN 10 & 43 & 7 & -2.4 & -4.8 & N/A \\
\hline WI 01 & 80 & 11 & -0.2 & -1.7 & -1.9 \\
\hline
\end{tabular}

${ }^{a} \mathrm{CAZ}$ depressurization when appliance vent pressure transitions from positive to negative

\subsubsection{Long-Term Monitoring}

The project team gathered monitoring data starting January 16, 2015, and with changes in the monitoring system and software, began gathering usable data on February 9. Data collected through August 17 were used for the analysis in this report. Communication was lost with House MN 10 near the end of June; because of an extended absence by the homeowner, data after that date were not recovered in time to be included in the analysis Table 18 shows the sampling dates for each home. Houses in the upper Midwest may generally be closed up more tightly in the winter (and are thus more susceptible to depressurization from exhaust fan or air handler operation), draft force is reduced in warm weather, and data collection across a range of outdoor temperatures allows more complete characterization of spillage under normal operating conditions. 
Table 18. Data Collection Dates by House

\begin{tabular}{c|c|c|c}
\hline House & First Data Used & Last Data Used & $\begin{array}{c}\text { Number of Days } \\
\text { of Data Used }\end{array}$ \\
\hline MN 01 & $2 / 10 / 2015$ & $8 / 17 / 2005$ & 188 \\
MN 02 & $2 / 9 / 2015$ & $8 / 17 / 2005$ & 189 \\
MN 03 & $2 / 23 / 2015$ & $8 / 17 / 2005$ & 175 \\
\hline MN 04 & $2 / 27 / 2015$ & $8 / 17 / 2005$ & 171 \\
MN 05 & $4 / 9 / 2015$ & $8 / 17 / 2005$ & 130 \\
MN 06 & $4 / 17 / 2015$ & $8 / 17 / 2005$ & 122 \\
\hline MN 07 & $4 / 24 / 2015$ & $8 / 17 / 2005$ & 115 \\
\hline MN 08 & $5 / 7 / 2015$ & $8 / 17 / 2005$ & 102 \\
MN 09 & $5 / 12 / 2015$ & $8 / 17 / 2005$ & 97 \\
MN 10 & $5 / 19 / 2015$ & $6 / 29 / 2015$ & 41 \\
WI 01 & $2 / 18 / 2015$ & $8 / 17 / 2005$ & 180 \\
\hline
\end{tabular}

The monitoring system generally performed well. A limited number of spurious data points appeared in values coming from the onboard analog-to-digital converters and were filtered out of the data set. Additionally, several sensor-specific issues were identified:

- Outdoor temperature values showed large, unexpected variations over periods of minutes at several sites. The installation team used the clothes dryer exhaust duct as a conduit for the outdoor sensor wire and tubing, and exposure to heated air from the dryers is the likely cause of the problem. The team ultimately chose to use airport weather data for Minneapolis and Madison as a replacement for on-site temperature data.

- Zone pressure measurements sometimes exhibited very high variability from one second to the next, much larger than would be expected from indoor-outdoor measurements averaged over 1 second or longer. CARB and NorthernSTAR concluded this is due to the influence of wind pressure on the outdoor termination of the pressure measurement system in combination with the responsiveness of the pressure sensor and lack of any damping in the measurement system. High variability in measured zone pressure correlated well with wind speed (from airport weather data). The team could not tell with certainty whether the wind-induced scatter introduced a significant bias and decided to filter out pressure readings that showed more than $11 \mathrm{~Pa}$ variation over a 1-minute period and to record these periods as "windy." This affected about $11 \%$ of zone pressure data and less than $0.3 \%$ of water-heater-vent pressure data. The zone pressure data values used in this report represent the outdoor pressure relative to the indoor (CAZ) pressure, so a depressurized CAZ has a positive value.

- Fan status data from wireless modules proved spotty in some cases, and data from several devices were unusable. Wireless sensor modules were dislodged from the intended mounting position in at least three cases, with an extended loss of data from a kitchen exhaust fan in one case.

- A single atmospherically vented furnace with a draft diverter was included in the study (at House MN 04). This furnace was a convection design (lacking a blower) and had an unusually large-diameter concentric draft diverter. Clearly well out of the mainstream of 
current technology, it was excluded from analysis. The water heater at this house is included in the results.

\subsubsection{Monitoring Results-Characteristic System Operation}

\subsection{Water Heater Operation}

The water heaters in the houses studied went through 2 to 5 cycles in a typical day, with the exception of House MN 08, which saw only 1.1 cycles per day on average (Figure 25). Water heater burner operation nearly always lasted for 5 minutes or longer, but characteristic runtimes varied greatly across houses (Figure 26). House MN 04 had a particularly large fraction of cycles that lasted more than 30 minutes.

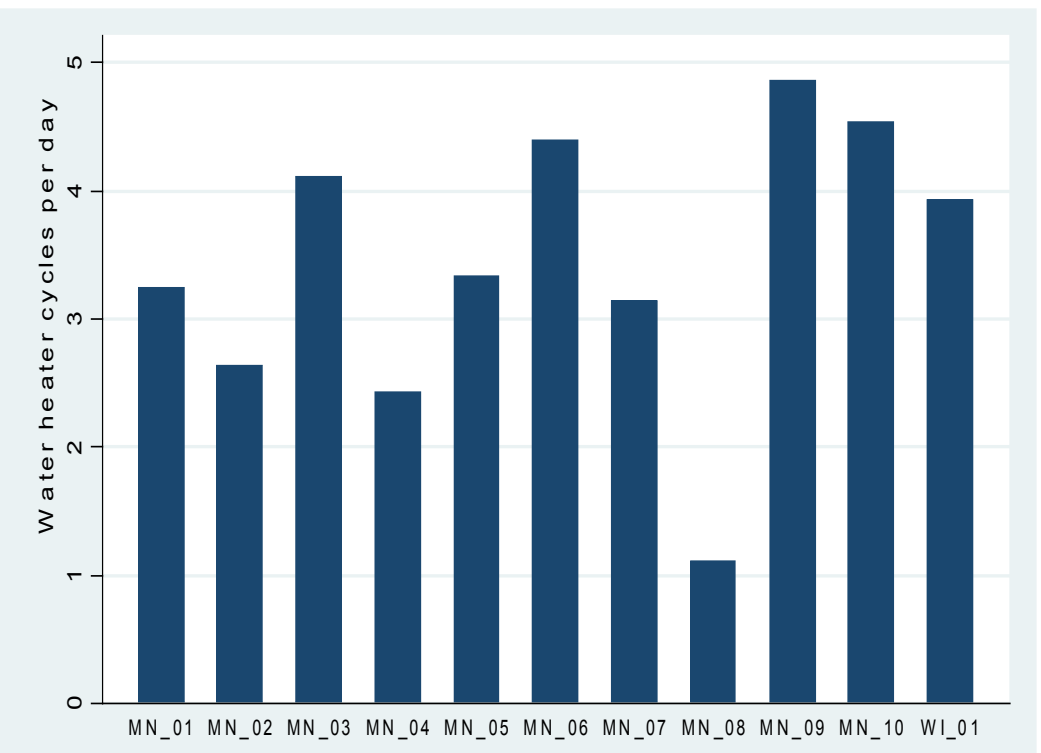

Figure 25. Average number of water heater burner cycles per day, by house

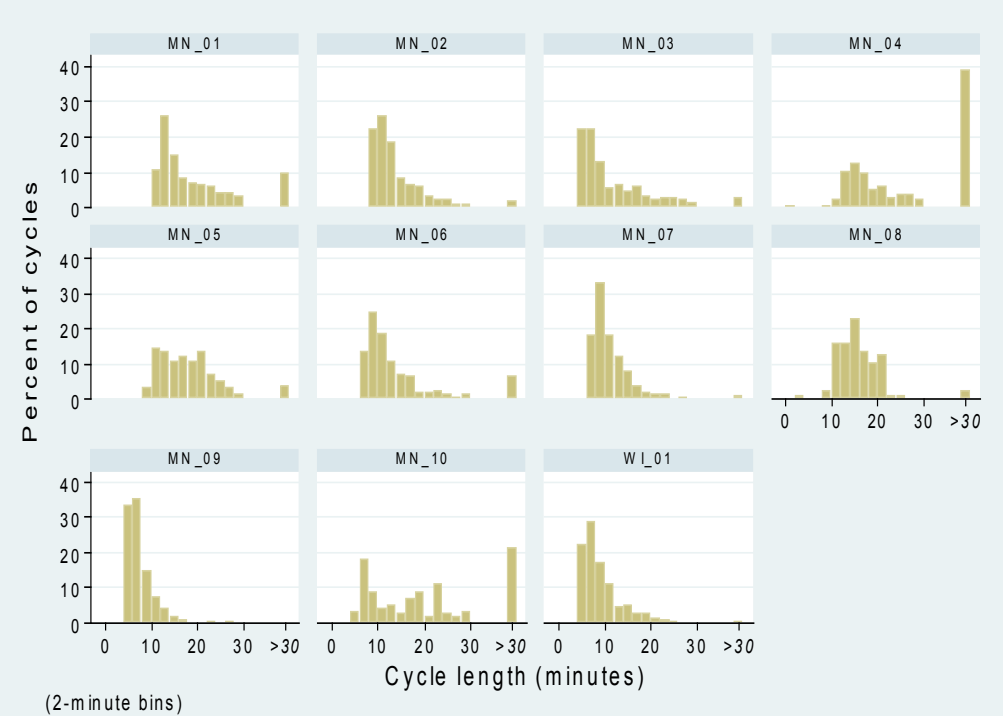

Figure 26. Water heater burner runtime distribution, by house 
Burners in conventional residential gas water heaters operate when a thermostat senses a water temperature lower than a threshold setting and opens the main gas valve. The gas is ignited by a standing pilot, and combustion products begin to flow up the internal flue, transferring heat to the water through the burner compartment and flue wall. In normal operation, the combustion products begin to flow across the draft hood gap (though some spillage of combustion products often occurs), then mix with additional air introduced at the draft hood and flow into the venting system and vertical chimney. Heating of the vent system increases draft and flow rate until a quasi-steady-state condition is reached. When the burner is off, the flue temperature and vent temperature typically remain elevated much higher than room temperature, heated by the pilot light and warm storage tank. Figure 27 shows measured conditions during a typical burner cycle.
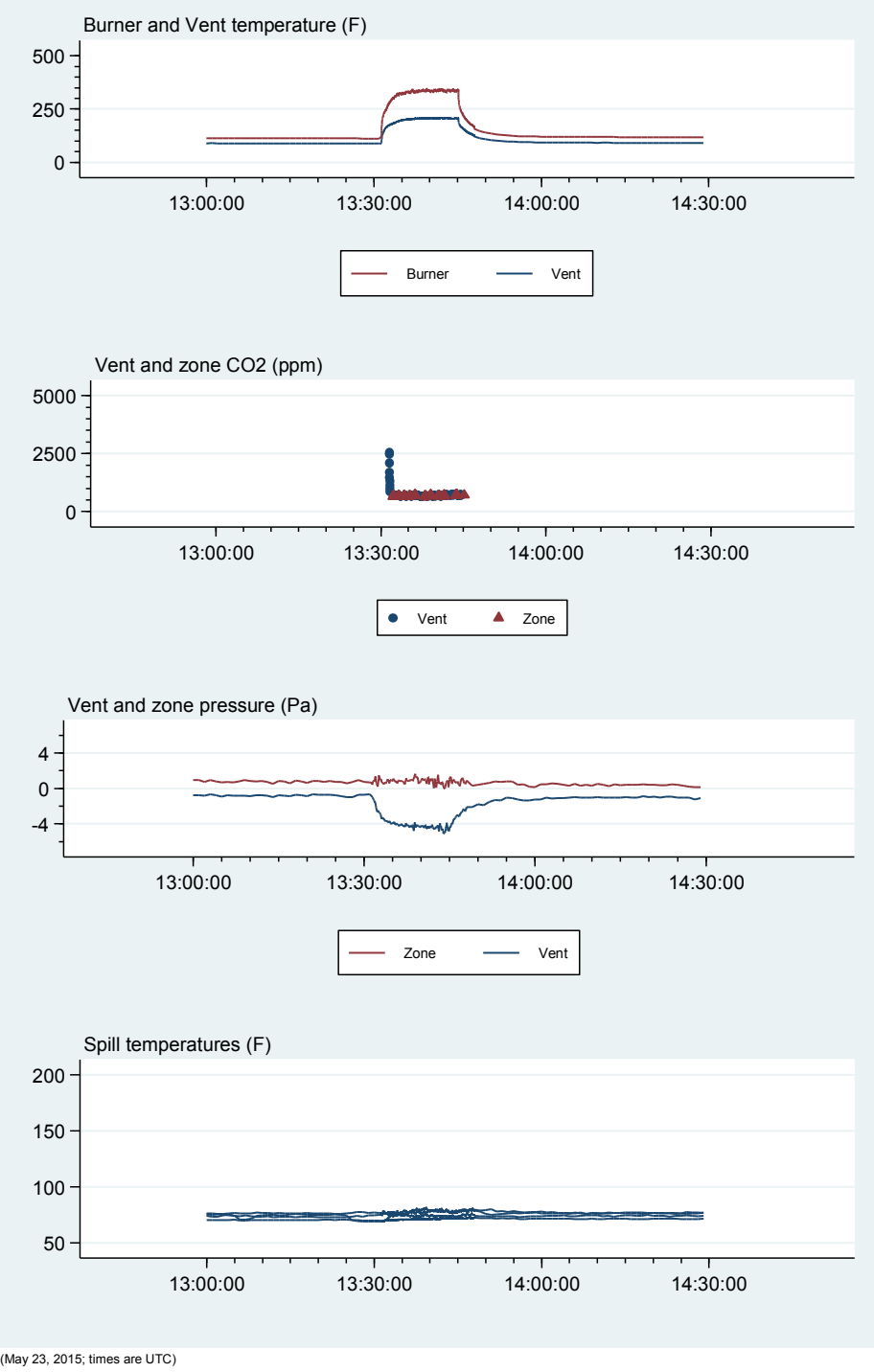

Figure 27. Conditions during characteristic water heater burner cycle, House MN 01. Time shown in hours, minutes, and seconds. A brief increase in $\mathrm{CO}_{2}$ concentration at the start of the cycle is evidence of spillage, but the four spillage temperatures in the bottom panel show no discernable rise. 
Vent pressure is typically very slightly positive during the off cycle (about $-0.7 \mathrm{~Pa}$ in the case shown), and drops (to about $-5 \mathrm{~Pa}$ in this case) as the venting system heats up and flow increases. The zone pressure is influenced by many factors and may run positive or negative during firing cycles.

\subsection{Fan Operation}

Table 19 summarizes the monitoring of devices expected to affect CAZ depressurization and spillage.

Table 19. Summary of Air Handlers, Exhaust Devices, and CAZ Door Monitoring

\begin{tabular}{|c|c|c|c|c|c|c|}
\hline House & $\begin{array}{c}\text { Air } \\
\text { Handler }\end{array}$ & Dryer & $\begin{array}{l}\text { Kitchen } \\
\text { Exhaust }\end{array}$ & Bath Fan 1 & Bath Fan 2 & CAZ Door \\
\hline MN 01 & $\begin{array}{c}\text { Not } \\
\text { present }^{\mathrm{a}}\end{array}$ & $\mathrm{Y}$ & $\mathrm{Y}$ & No data ${ }^{b}$ & $-^{\mathrm{c}}$ & $\mathrm{Y}$ \\
\hline MN 02 & Y & Y & No data & $\mathrm{Y}$ & $\mathrm{Y}$ & Y \\
\hline MN 03 & Y & Y & Y & $\mathrm{Y}$ & $\mathrm{Y}$ & Not present \\
\hline MN 04 & $\begin{array}{c}\text { Not } \\
\text { present }\end{array}$ & $\mathrm{Y}$ & Y & $\begin{array}{l}\text { No data, } \\
\text { probably } \\
\text { used rarely }\end{array}$ & - & No data \\
\hline MN 05 & $\mathrm{Y}$ & Y & Y & $\mathrm{Y}$ & - & $\mathrm{Y}$ \\
\hline MN 06 & Y & $\mathrm{Y}$ & $\mathrm{Y}$ & $\mathrm{Y}$ & - & $\mathrm{Y}$ \\
\hline MN 07 & Y & $\mathrm{Y}$ & $\mathrm{Y}$ & $\mathrm{Y}$ & - & $\mathrm{Y}$ \\
\hline MN 08 & Y & $\mathrm{Y}$ & $\mathrm{Y}$ & No data & - & $\mathrm{Y}$ \\
\hline MN 09 & Y & $\mathrm{Y}$ & $\mathrm{Y}$ & No data & Y & $\mathrm{Y}$ \\
\hline MN 10 & No data & Y & Y & Y & $\begin{array}{l}\text { No data, } \\
\text { probably } \\
\text { used rarely }\end{array}$ & Not present \\
\hline WI 01 & $\mathrm{Y}$ & Y & Not present & $\mathrm{Y}$ & Not present & Y \\
\hline
\end{tabular}

${ }^{a}$ Not present means the item did not exist in that house.

${ }^{a}$ No data means the item was monitored but the data were unusable.

c "_" means the item was either not present or not monitored.

The observed operating status of air handlers, exhaust fans, and CAZ doors is summarized in Figure 28 (N/A means fan does not exist or data are unusable). The secondary red shading on each bar indicates the average number of minutes per day during which the device operated (or door was closed) with the water heater burner operating simultaneously. 


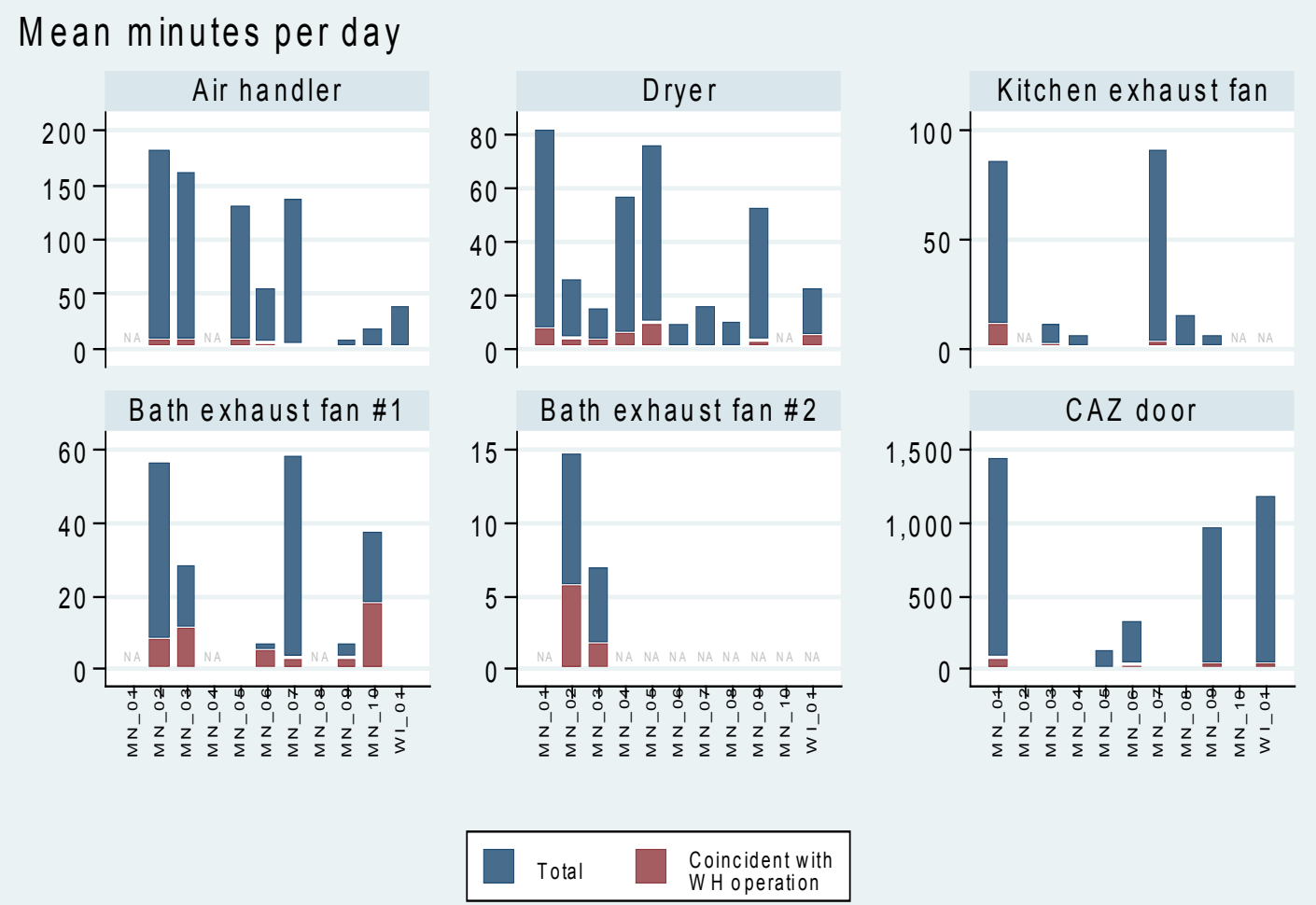

Figure 28. Fan runtime and CAZ door closed time, by house

\subsubsection{Monitoring Results-Spillage}

\subsection{Identifying Spillage}

The monitoring system design included two methods for identifying spillage: temperature sensing around the draft hood and $\mathrm{CO}_{2}$ sampling above the draft hood. Review of data collected makes it clear that $\mathrm{CO}_{2}$ measurement is a far more sensitive and robust means of identifying spillage.

When spillage is significant and lasts much longer than 1 minute, the $\mathrm{CO}_{2}$ signal and the spill temperature sensor rise are usually large and unambiguous, and either could be used to identify such spillage. Brief spillage episodes on startup present a very different picture, however. $\mathrm{CO}_{2}$ spikes were frequently found during the first 20 seconds of water heater burner operation, which disappear before the end of the first minute, demonstrating brief spillage on startup. This phenomenon is apparent in Figure 27). The temperature rise around the draft hood during these brief spillage episodes, however, is frequently small and very uneven; one or more temperatures fall while one or more rise. Spill temperature sensor data are further complicated by a tendency for the temperatures to rise later in each burner cycle, after spillage has ended, likely driven by radiation from the heated flue. The result is that spill temperatures present a complicated picture and would be difficult to interpret reliably.

$\mathrm{A} \mathrm{CO}_{2}$ elevation of $500 \mathrm{ppm}$ higher than the $\mathrm{CAZ}$ background level was used as an indicator of spillage. Background $\mathrm{CO}_{2}$ levels can vary, especially during prolonged spillage episodes and 
occasionally at other times for unknown reasons; thus, the increase over the background concentration is a more robust indicator than any fixed level. ${ }^{1}$

As discussed earlier, $\mathrm{CO}_{2}$ measurements were made sequentially at the water heater draft hood, furnace draft hood, ${ }^{2}$ and room background on a 20 -second cycle, with 10 usable values recorded in each cycle. This results in an effective resolution of water heater spillage data of 40 to 60 seconds. In this report, spillage data are summarized in terms of the number of minutes the spillage lasted.

Figure 29 shows a typical pattern associated with a persistent spillage episode. Observed $\mathrm{CO}_{2}$ concentrations start near 5,000 ppm and slowly dropped to near CAZ background level, indicating an end of spillage about the time the burner cycle ends. Vent pressure is negative throughout the period displayed (consistent with normal flow up the vent) and drops slightly during burner operation, indicating developing draft. The four spillage temperatures spaced around the draft hood show a distinct rise, confirming spillage early in the burner cycle, followed by a drop indicating the end of spillage.

\footnotetext{
${ }^{1}$ The team arrived at $500 \mathrm{ppm}$ by informally examining $\mathrm{CO}_{2}$ concentrations, spillage temperatures, and vent pressures across a number of burner cycles and confirmed this value as a useful indicator of a change point by inspecting the distribution of $\mathrm{CO}_{2}$ elevation higher than background levels, which exhibited a "knee" at around 500 ppm elevation. $\mathrm{CO}_{2}$ concentration, however, was often observed at around 4,500-5,000 ppm during spillage on startup and generally recovered quickly to very near the room background level when spillage ended. The identification of spillage is not particularly sensitive to the parts per million elevation selected.

${ }^{2}$ The extra measurement was required at the one house with a furnace but included at some other houses.
} 

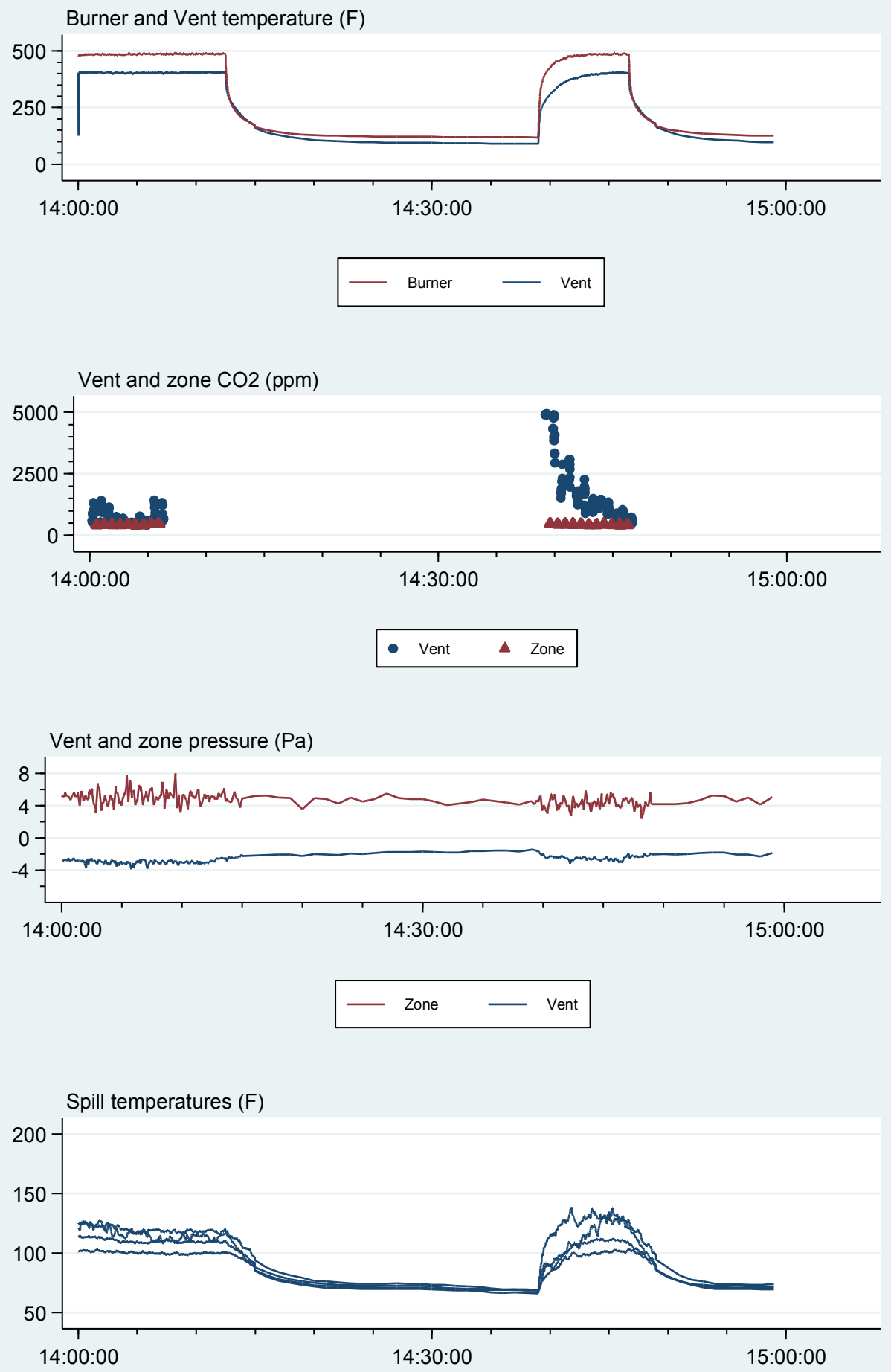

(Feb 20, 2015; times are UTC)

Figure 29. Conditions during long-lasting spillage episode, House WI 01 . Time shown in hours, minutes, and seconds. A sustained elevation of $\mathrm{CO}_{2}$ concentration and obvious rise in all four spillage temperatures (bottom panel) provide evidence of prolonged spillage. 


\subsection{Spillage Observed by House}

The number and duration of spillage episodes varied dramatically across the houses studied. Houses MN 04 and WI 01 showed a far higher total time and percent of operating time in spillage than the other houses (Table 20).

Table 20. Water Heater Spillage Time by House

\begin{tabular}{|c|c|c|c}
\hline House & $\begin{array}{c}\text { Total Hours Burner } \\
\text { Operating Time }\end{array}$ & $\begin{array}{c}\text { Hours of } \\
\text { Spillage }\end{array}$ & $\begin{array}{c}\text { Percent of Operating } \\
\text { Time in Spillage }\end{array}$ \\
\hline MN 01 & 243.6 & 4.1 & 1.7 \\
MN 02 & 134.7 & 0.7 & 0.5 \\
MN 03 & 203.2 & 9.9 & 4.9 \\
MN 04 & 226.6 & 105.5 & 46.6 \\
MN 05 & 189.6 & 1.4 & 0.7 \\
MN 06 & 176.2 & 0.5 & 0.6 \\
MN 07 & 117.1 & 0.4 & 0.4 \\
MN 08 & 34.7 & 0.3 & 1.1 \\
MN 09 & 100.7 & 0.2 & 0.3 \\
\hline MN 10 & 39.0 & 112.6 & 0.6 \\
\hline WI 01 & 123.1 & 91.4 \\
\hline
\end{tabular}

Except for the two spillage-prone houses, most of spillage identified occurred in the first minute of operation. This first-minute effect was especially pronounced at Houses MN 01 and MN 03 (see Figure 30, with highlighting showing the number of cycles in which spillage was observed).

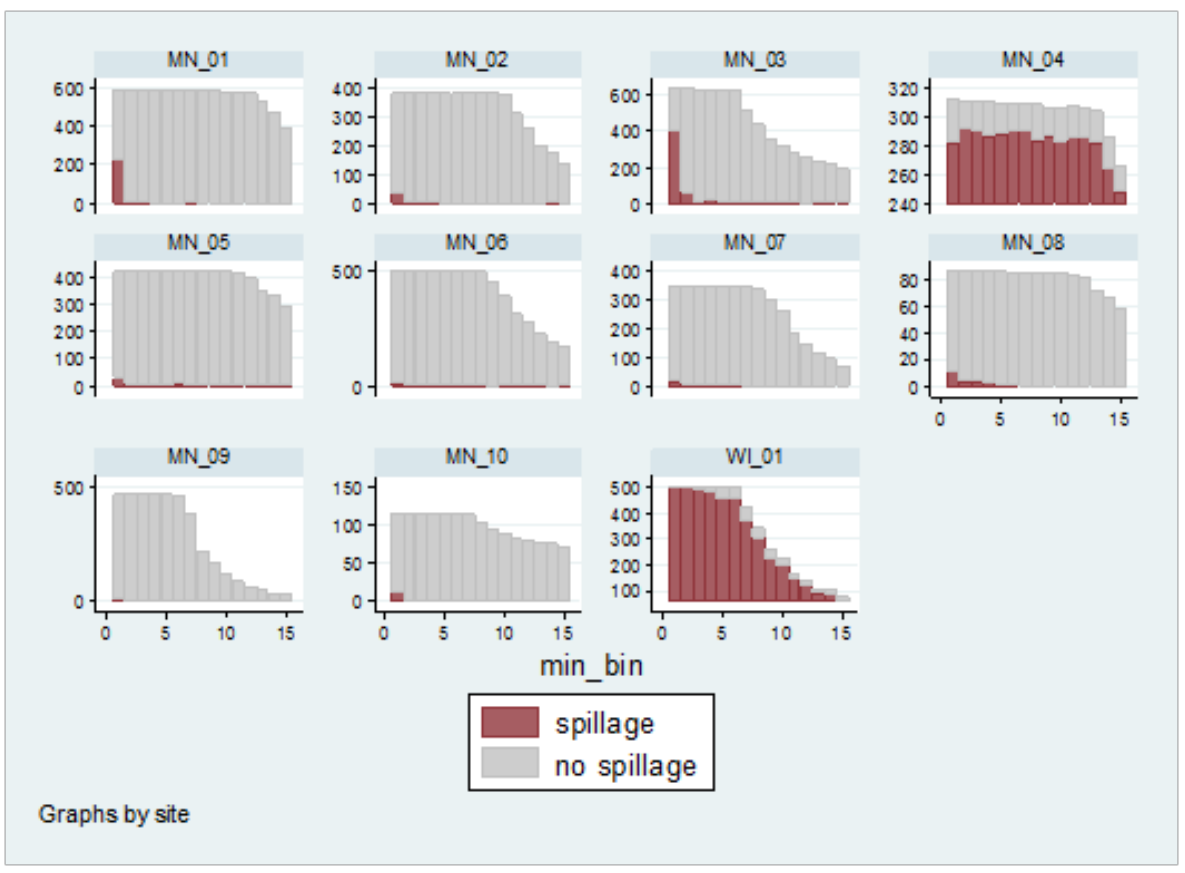

Figure 30. Number of water heater cycles lasting at least as long as time displayed, in 2-minute bins. Cycles with spillage are differentiated by color. 


\subsubsection{Monitoring Results-Predictors of Spillage}

The reasons for the far higher incidence of spillage at two houses are clear. House MN 04 had a vent system that was undersized for the capacity of the water heater, and WI 01 had a major venting defect in the form of a 5-in. connector that had once been the common vent attachment point for a furnace that was incompletely closed off.

Inspection of the data suggests that some of the suspected drivers of spillage do indeed influence its frequency. To investigate the causal factors quantitatively, we used logistic regression to model the probability of spillage as a function of factors thought to contribute to it. ${ }^{3}$ These factors include:

- Time into the firing cycle: As discussed, many water heaters spill on initial startup, before full draft is established. The project team created a binary indicator to represent the first minute of operation in each firing cycle to capture this phenomenon.

- Outdoor temperature: A spillage is more likely when the outside temperature is warm - and the stack effect is thus weak - than when the outside temperature is cold and stack forces are higher.

- $\mathbf{C A Z}$ depressurization: The more the $\mathrm{CAZ}$ is depressurized relative to the outside, the more likely the water heater is to spill.

- Operation of exhaust devices: Exhaust fans and clothes dryers depressurize the house when operated and thus can contribute to spillage. Air handler operation may depressurize the CAZ in specific houses.

- Closure of the door to the CAZ: Isolating the CAZ may lead to additional depressurization that could contribute to spillage.

The last two factors manifested as an increase in CAZ depressurization. The project team therefore examined two models of spillage: (1) a model that used CAZ pressure directly as a predictor of spillage and (2) a model that substituted binary indicators of operation of various devices in place of the direct CAZ-depressurization measurements.

Table 21 summarizes the results of the first model, which examines how the first three factors above contribute to spillage. ${ }^{4}$ The fitted coefficients are expressed in terms of odds ratios: an odds ratio greater than unity indicates that an increase in the factor tends to increase the likelihood of spillage, and an odds ratio below unity means that in increase in the factor tends to decrease the likelihood of spillage.

As Table 22 shows, the coefficients are almost all greater than unity and highly significant, which indicates that, as expected, these factors tend to increase the likelihood of spillage.

\footnotetext{
${ }^{3}$ Logistic regression considers the probability of a binary outcome (spillage or no spillage) as a function of the possible causal factors. The team used a multiple regression method that models the effects of all independent parameters ("causal factors") simultaneously, assigning each a coefficient that represents its contribution to increased spillage.

${ }^{4}$ Appendix E includes complete descriptions of the model specifications and output.
} 
Table 21. Summary of Coefficients (odds ratio) from Logistic Regression Predictors for Spillage (Model 1)

\begin{tabular}{|c|c|c|c|c|c|c|}
\hline \multirow{2}{*}{$\begin{array}{l}\text { House } \\
\text { MN } 01\end{array}$} & \multicolumn{2}{|c|}{$\begin{array}{c}\mathbf{1}^{\text {st }} \text { Minute of } \\
\text { Operation } \\
\text { (Binary) }\end{array}$} & \multicolumn{2}{|c|}{$\begin{array}{c}\text { Outdoor } \\
\text { Temperature } \\
\left({ }^{\circ} \mathbf{F}\right)\end{array}$} & \multicolumn{2}{|c|}{$\begin{array}{c}\text { CAZ } \\
\text { Depressurization } \\
\text { Relative to } \\
\text { Outside } \\
(\mathrm{Pa})^{\S}\end{array}$} \\
\hline & $1,005.01$ & $* * *$ & 1.10 & $* * *$ & 1.46 & $* * *$ \\
\hline MN 02 & 213.78 & $* * *$ & 1.23 & $* * *$ & 4.29 & $* * *$ \\
\hline MN 03 & 171.39 & $* * *$ & 1.07 & $* * *$ & 1.65 & $* * *$ \\
\hline MN 04 & 0.65 & $*$ & 1.10 & $* * *$ & 1.21 & $*$ \\
\hline MN 05 & 15.61 & $* * *$ & 1.06 & $* * *$ & 2.36 & $* * *$ \\
\hline MN 06 & 3.69 & $* * *$ & 1.10 & $* * *$ & 1.39 & $* * *$ \\
\hline MN 07 & 31.48 & $* * *$ & 1.03 & & 2.32 & $* * *$ \\
\hline MN 08 & 244.16 & $* * *$ & 1.27 & $* * *$ & $\mathrm{~N} / \mathrm{A} \dagger$ & \\
\hline MN 09 & 13.81 & $* * *$ & 1.09 & $*$ & 2.79 & $* * *$ \\
\hline MN 10 & 396.99 & $* * *$ & 1.13 & $* *$ & 2.74 & $* * *$ \\
\hline WI 01 & N/At & & 1.13 & $* * *$ & 1.07 & $*$ \\
\hline
\end{tabular}

Statistically significant at ***: a 99\% confidence level; **: a 95\% confidence level; *: a 90\% confidence level. †Omitted due to missing zone pressure data.

tOmitted because spillage occurred throughout the first minute for nearly every firing cycle.

$\S \mathrm{CAZ}$ pressures are defined here as outdoor pressure with respect to CAZ pressure, and a depressurized CAZ appears as a positive number.

Table 22. Summary of Coefficients (odds ratio) from Logistic Regression Predictors (binary indicators of device operation) for Water Heater Spillage (Model 2)

\begin{tabular}{l|c|c|c|c|c|c|c|c|c|c|c|c}
\hline House & \multicolumn{2}{|c|}{ Dryer } & \multicolumn{2}{|c|}{ Kitchen Fan } & \multicolumn{2}{|c|}{ Bath Fan 1 } & \multicolumn{2}{|c|}{ Bath Fan 2 } & \multicolumn{2}{|c|}{ Air Handler } & \multicolumn{2}{|c|}{ Door } \\
\hline MN 01 & $\mathbf{3 . 1 7 ^ { \mathrm { a } }}$ & $* * *$ & $\mathbf{2 . 9 1}$ & $* * *$ & ND & & ND & & ND & & NV & \\
MN 02 & $\mathbf{1 5 . 0 3}$ & $* * *$ & ND & & 1.78 & & $\mathbf{1 9 . 1 7}$ & $* * *$ & 1.93 & & NV & \\
MN 03 & $\mathbf{3 . 2 8}$ & $* *$ & $\mathbf{2 7 . 0 7}$ & $* * *$ & $\mathbf{2 . 4 0}$ & $* * *$ & 0.76 & & $\mathbf{2 . 3 7}$ & $* *$ & NV & \\
MN 04 & $\mathbf{1 . 9 0}$ & & AS & & ND & & ND & & ND & & NV & \\
MN 05 & $\mathbf{2 . 1 8}$ & $* *$ & NS & & NV & & ND & & 1.04 & & 1.95 & \\
MN 06 & NS & & NV & & 2.75 & $* *$ & ND & & 1.79 & & ND & \\
MN 07 & NS & & $\mathbf{1 3 . 1 0}$ & $* * *$ & NS & & ND & & $\mathbf{1 6 . 0 9}$ & $* *$ & NV & \\
MN 08 & NV & & NV & & ND & & ND & & NV & & NV & \\
MN 09 & 4.21 & & NS & & NS & & ND & & $\mathbf{9 . E}+\mathbf{0 4}$ & $* * *$ & $\mathbf{0 . 0 6}$ & $* *$ \\
\hline MN 10 & ND & & ND & & 0.55 & & ND & & NS & & NV & \\
WI 01 & 1.73 & & ND & & NV & & ND & & 0.91 & & 1.05 & \\
\hline
\end{tabular}

${ }^{a}$ Bold text indicates statistical significance at a $90 \%$ or higher level.

Statistically significant at ***: a 99\% confidence level; **: a 95\% confidence level; *: a $90 \%$ confidence level.

Key:

$$
\begin{aligned}
& \mathrm{ND}=\text { no data } \\
& \mathrm{NV}=\text { no variation (always on or always off) } \\
& \mathrm{AS}=\text { water heater always spilled when in operation } \\
& \mathrm{NS}=\text { water heater never spilled when in operation }
\end{aligned}
$$

The relative magnitudes of the odds ratios are also informative. The very large fitted odds ratios for some of the houses for the first minute of firing show that spillage is fairly common in the 
first minute of operation but rare later. For example, the odds of spillage in the first minute at House MN 01 are 1,000 times higher than those of spillage in any subsequent minute.

The seemingly more modest odds ratios observed for outdoor temperature and CAZ depressurization are a bit trickier to interpret, partly because they represent the increase in the likelihood of spillage per unit increase in the predictor. For example, for House MN 01, the fitted odds ratio for outdoor temperature is 1.10. This means that on average, each Fahrenheit degree increase in outdoor temperature is associated with a $10 \%$ increase in the odds of spillage Extending this to seasonal changes, if typical winter and summer temperatures are $25^{\circ} \mathrm{F}$ and $70^{\circ} \mathrm{F}$, respectively, the odds of spillage will be about 50 times higher in summer than in winter. The odds of spillage may thus increase significantly if one examines them across a wide temperature or zone-pressure span.

However, the regression results are in terms of an odds ratio. If the odds of spillage are very low to begin with, spillage may still be rare even in the presence of the factor, even if it is a statistically significant predictor. The individual elements of the logistic regression are directly additive in predicting the combined effects of multiple factors. For example, the odds ratio associated with first-minute operation at House MN 05 is 15.61, and a similar odds ratio can be associated with a change in CAZ depressurization (outdoor pressure with respect to CAZ pressure) of $6.6 \mathrm{~Pa}$ (because $15.61 / 2.36=6.6$ ). This implies that, all other conditions being equal, the system has similar odds of spillage in the first minute with a CAZ depressurization of zero compared to a second minute with a CAZ depressurization of 6.6 Pa.

Figure 31 shows the predicted probability of spillage with increasing outdoor temperature. Although temperature clearly has a significant effect, the overall probability of spillage at any time beyond the first minute remains extremely low for all houses except MN 04 and WI 01.

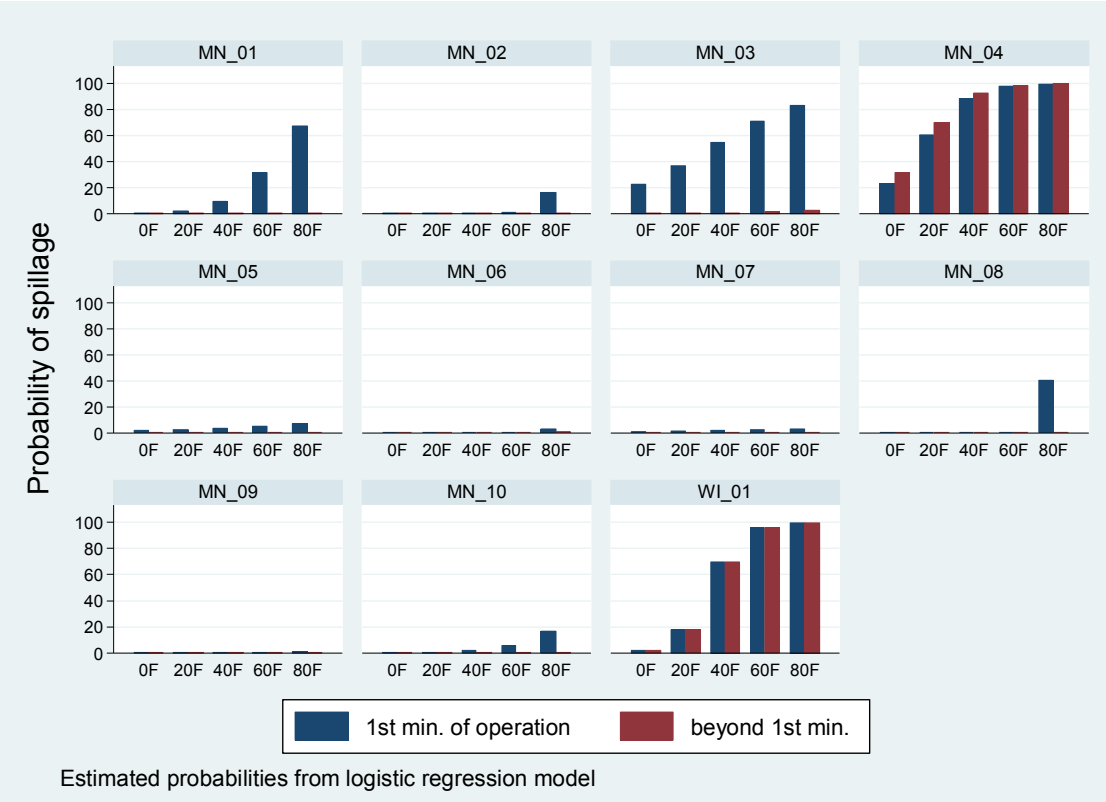

Figure 31. Logistic model fits for probability of spillage at selected outdoor temperatures and by time into firing cycle, by house 
Table 22 summarizes the device-related results for the model of spillage that includes binary indicators for device operation instead of CAZ pressure (Model 2). Some devices were not present in the homes, and others could not be included in the model because they were either always on or (more likely) always off over the course of the monitoring. But many of the remaining devices showed statistically significant indications of contributing to the likelihood of spillage. ${ }^{5}$ Clothes dryers significantly increased the probability of spillage in at least four houses, and kitchen exhaust fans and air handlers affected spillage in at least three houses. The CAZ door seemed to significantly reduced spillage when closed at house MN 09, perhaps a result of confounding between variables; e.g., if the door was more often open when the clothes dryer was running. Air handlers may affect spillage by directly pressurizing or depressurizing the CAZ, depending on the distribution of supply-side and return-side leakage in the CAZ, the rest of the home, and to outside the building envelope, and may also indirectly affect spillage through heating or cooling, which affects the overall building stack effect and pressure balances. Again, even though these results are statistically strong in many cases, the overall impact of, say, dryer operation in a specific home is generally to increase a very low probability of spillage to a greater, but still quite low, probability.

\subsubsection{Monitoring Results-Downdrafting}

Downdrafting is the term commonly used to describe full reversal of flow in the appliance venting system when the appliance is off (backdrafting is the term used for full reversal of flow when the appliance is operating). The team used a combination of positive vent pressure of at least $0.2 \mathrm{~Pa}$ and lower than typical vent temperature in the water heater vent as an indicator of downdrafting. ${ }^{6}$

The data summary by 1-minute periods includes about 2.04 million observations (about 1,400 days' worth). Of these, the team identified 5,377 minutes (about $0.03 \%$ ) with apparent downdrafting (Table 23). The median duration of downdrafting was 18 minutes; some episodes lasted as long as 6 hours.

Downdrafting often ends when a water heater burner fires, because some quantity of the hotter combustion products enters the vent system and starts to develop a normal draft. However, this is not always the case, and downdrafting can persist into or through burner cycles. Table 24 summarizes downdrafting that occurred during burner cycles in the test houses. Downdrafting during a burner operating cycle is characterized by a vent temperature that remains lower than normal, positive vent pressure, spillage zone temperatures that are elevated far above those seen during normal operation or modest spillage, and very high $\mathrm{CO}_{2}$ levels that last as long as both downdrafting occurs and burners operate (Figure 32).

\footnotetext{
${ }^{5}$ For computational reasons, devices whose operation is either always or never associated with spillage also cannot be included in the model. The kitchen fan at House MN 04 was the only case in which the water heater always spilled when a device operated. However, this fan only operated on three occasions, and the water heater for the site spilled much of the time, so it is difficult to assess how much the fan contributed to spillage.

${ }^{6}$ The specific rule selected for vent temperature indicating downdrafting during burner-off periods was at least $10^{\circ} \mathrm{F}$ lower than an average temperature calculated for daily periods using observations when the burner was off and had remained off for at least 2 minutes. For burner-on periods, a vent temperature of no more than $20^{\circ} \mathrm{F}$ higher than the same daily off-cycle average was used.
} 
Table 23. Incidence and Duration of Downdrafting by House

\begin{tabular}{|c|c|c|c|c|c|}
\hline House & $\begin{array}{c}\text { Number } \\
\text { of } \\
\text { Episodes }\end{array}$ & $\begin{array}{c}\text { Number of } \\
\text { Minutes in } \\
\text { Downdrafting }\end{array}$ & $\begin{array}{c}\text { Percent of } \\
\text { Operating Time in } \\
\text { Downdrafting }\end{array}$ & $\begin{array}{c}\text { Median } \\
\text { Duration }\end{array}$ & $\begin{array}{c}\text { Maximum } \\
\text { Duration }\end{array}$ \\
\hline MN 01 & 34 & 283 & $0.10 \%$ & 7 & 44 \\
\hline MN 02 & 27 & 140 & $0.06 \%$ & 6 & 63 \\
\hline MN 03 & 71 & 791 & $0.32 \%$ & 10 & 92 \\
\hline MN 04 & 48 & 1,038 & $0.42 \%$ & 96 & 383 \\
\hline MN 05 & 1 & 1 & $0.00 \%$ & 1 & 1 \\
\hline MN 07 & 0 & & $0.00 \%$ & & \\
MN 08 & 142 & 1,670 & $1.02 \%$ & 16 & 102 \\
\hline MN 09 & 1 & & $0.00 \%$ & & \\
MN 10 & 18 & 6 & $0.00 \%$ & 3.5 & 6 \\
\hline WI 01 & 105 & 1,042 & $0.70 \%$ & 28 & 137 \\
\hline Total & 447 & 5,377 & $0.54 \%$ & 24 & 211 \\
\hline
\end{tabular}

Table 24. Incidence and Duration of Downdrafting Episodes Coinciding with Water Heater Burner Operation

\begin{tabular}{c|c|c|c}
\hline House & $\begin{array}{c}\text { Number } \\
\text { of } \\
\text { Episodes }\end{array}$ & $\begin{array}{c}\text { Median } \\
\text { Duration } \\
\text { (min) }\end{array}$ & $\begin{array}{c}\text { Maximum } \\
\text { Duration } \\
\text { (min) }\end{array}$ \\
\hline MN 01 & 2 & 16.5 & 17 \\
\hline MN 02 & 3 & 6 & 7 \\
\hline MN 03 & 32 & 14.5 & 33 \\
\hline MN 04 & 4 & 6.5 & 8 \\
\hline MN 05 & 0 & - & - \\
\hline MN 06 & 0 & - & - \\
\hline MN 07 & 14 & 4.5 & 31 \\
\hline MN 08 & 0 & - & - \\
\hline MN 09 & 6 & 3.5 & 6 \\
\hline MN 10 & 1 & 9 & 9 \\
\hline WI 01 & 0 & - & - \\
\hline Total & 62 & 7 & 33 \\
\hline
\end{tabular}



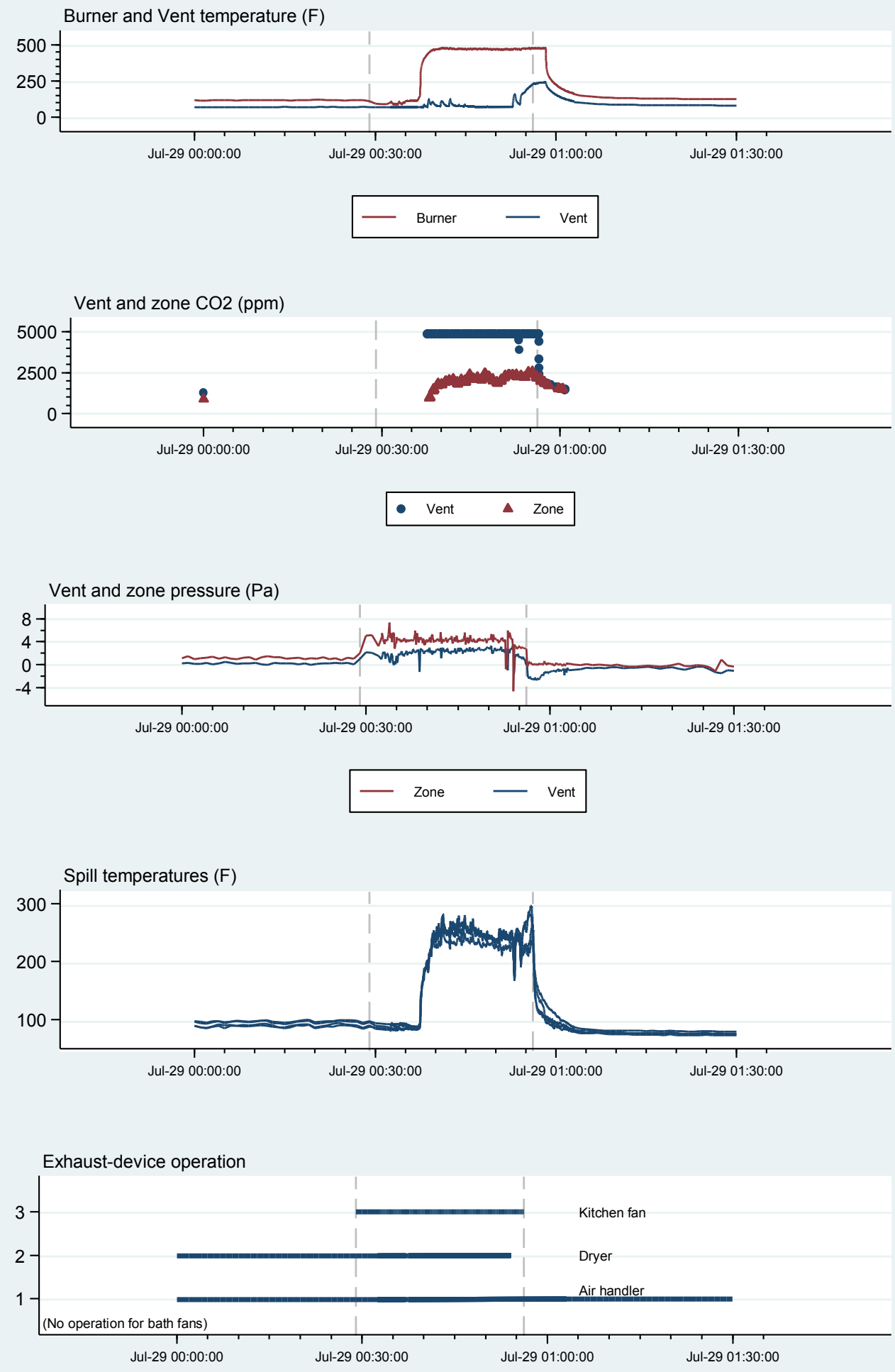

(Times are UTC)

Figure 32. Conditions during downdrafting episode, House MN 03 
In general, CAZ depressurization appears to be a factor in the development of downdrafting, as expected; the average zone pressure during downdrafting was $2.3 \mathrm{~Pa}$ lower than outdoor pressure across all houses, compared to $0.9 \mathrm{~Pa}$ higher than outdoors when downdrafting is not occurring. Downdrafting clearly depends on some confluence of factors including the temperature and density of air in the vent system, outdoor temperature, and CAZ depressurization. One general statement that can be made is that the column of air in the vent system during downdrafting is probably always cooler and denser than during normal operation, because heat from the pilot light and water tank is absent. Combined with a modest CAZ depressurization (e.g., through air handler operation, exhaust fan operation, or building stack effect), the downward flow of air, once established, may tend to be self-maintaining. This suggests that the start of a downdrafting episode is the key to understanding the phenomenon, and the further analysis focused on the first minute of each downdrafting episode.

Table 25 shows the difference in a number of measured parameters for the first minute of each downdrafting episode compared to all periods when downdrafting was absent. For outdoor temperature and CAZ pressure, the value shown is the difference in average measured values between downdrafting and nondowndrafting periods. For the variables that describe fan operation, the value shown is the difference in the average status across the periods. Results for the four houses that had zero or one downdrafting episode are excluded.

This analysis strongly supports the obvious idea that CAZ depressurization was a factor in development of downdrafting at all homes, with outdoor less CAZ pressure 0.55 to $1.74 \mathrm{~Pa}$ higher at the time of downdraft formation than at other times. The air handler and individual exhaust fans played a significant role in some houses. The incidence of air handler operation at House $\mathrm{MN} 02$, for example, was 50 percentage points higher during downdrafting episodes than at other times, and the incidence of kitchen fan operation at House MN 01 was 85 percentage points higher during downdrafting. As noted earlier, air handler operation may affect CAZ pressures directly due to unbalanced leakage and indirectly by introducing warmer or cooler air into the building, changing stack effect pressure balances.

CAZ door position, bathfan2, and wind speed were also considered but are not shown here. Average wind speed was about $2 \mathrm{mph}$ higher at the start of downdrafting than at other times at several houses and may be a factor. Windiness as indicated by CAZ pressure variation did not appear to be a factor at any house. 
Table 25. Explanatory Factors for Development of Downdrafting

\begin{tabular}{|c|c|c|c|c|c|c|c|c|}
\hline House & $\begin{array}{l}\text { Downdraft } \\
\text { Condition }\end{array}$ & $\begin{array}{c}\# \text { of } \\
\text { Observations }\end{array}$ & $\begin{array}{l}\text { Outdoor } \\
\text { Temp. (F) }\end{array}$ & $\begin{array}{c}\text { CAZ Pressure } \\
(\text { PA })^{\mathrm{a}}\end{array}$ & $\begin{array}{l}\text { Air Handler } \\
\text { Status }\end{array}$ & $\begin{array}{l}\text { Dryer } \\
\text { Status }\end{array}$ & $\begin{array}{c}\text { Kitchen Fan } \\
\text { Status }{ }^{\text {b }}\end{array}$ & $\begin{array}{l}\text { Bath Fan } \\
1 \text { Status }\end{array}$ \\
\hline \multirow{3}{*}{ MN 01} & No downdraft & 270,268 & 55 & 1.06 & Not present & 0.06 & 0.06 & ND \\
\hline & $1^{\text {st }}$ minute & 34 & 61 & 2.56 & & 0.35 & 0.91 & \\
\hline & increase & & 6 & 1.50 & & 0.30 & 0.85 & \\
\hline \multirow{3}{*}{ MN 02} & No downdraft & 221,400 & 61 & 0.70 & 0.13 & 0.02 & ND & 0.04 \\
\hline & $1^{\text {st }}$ minute & 27 & 81 & 1.25 & 0.63 & 1.00 & & 0.22 \\
\hline & increase & & 20 & 0.55 & 0.50 & 0.98 & & 0.18 \\
\hline \multirow{3}{*}{ MN 03} & No downdraft & 250,798 & 58 & 1.05 & 0.11 & 0.01 & 0.01 & 0.02 \\
\hline & $1^{\text {st }}$ minute & 71 & 76 & 1.72 & 0.45 & 0.23 & 0.35 & 0.43 \\
\hline & increase & & 18 & 0.67 & 0.34 & 0.22 & 0.35 & 0.41 \\
\hline \multirow{3}{*}{ MN 04} & No downdraft & 245,103 & 59 & 1.93 & Not present & 0.04 & 0.00 & ND \\
\hline & $1^{\text {st }}$ minute & 48 & 74 & 2.82 & & 0.54 & 0.10 & \\
\hline & increase & & 15 & 0.89 & & 0.50 & 0.10 & \\
\hline MN 05 & $\begin{array}{l}\text { No downdraft } \\
1^{\text {st }} \text { minute } \\
\text { increase }\end{array}$ & $\begin{array}{c}186,746 \\
1\end{array}$ & 66 & 0.53 & 0.09 & 0.05 & 0.000576 & 0.00 \\
\hline MN 06 & $\begin{array}{l}\text { No downdraft } \\
1^{\text {st }} \text { minute } \\
\text { increase }\end{array}$ & $\begin{array}{c}175,679 \\
0\end{array}$ & 67 & 0.49 & 0.04 & 0.01 & 0.00 & 0.00 \\
\hline \multirow{3}{*}{ MN 07} & No downdraft & 163,956 & 68 & 0.42 & 0.09 & 0.01 & 0.06 & 0.04 \\
\hline & $1^{\mathrm{st}}$ minute & 142 & 75 & 2.16 & 0.78 & 0.02 & 0.31 & 0.13 \\
\hline & increase & & 7 & 1.74 & 0.69 & 0.01 & 0.25 & 0.09 \\
\hline MN 08 & $\begin{array}{l}\text { No downdraft } \\
1^{\text {st }} \text { minute } \\
\text { increase }\end{array}$ & $\begin{array}{c}144,099 \\
0\end{array}$ & 69 & 0.02 & 0.00 & 0.01 & 0.01 & ND \\
\hline MN 09 & $\begin{array}{l}\text { No downdraft } \\
1^{\text {st }} \text { minute } \\
\text { increase }\end{array}$ & $\begin{array}{c}139,529 \\
1\end{array}$ & 70 & 0.41 & 0.01 & 0.04 & 0.00 & 0.00 \\
\hline MN 10 & $\begin{array}{l}\text { No downdraft } \\
1^{\text {st }} \text { minute } \\
\text { increase }\end{array}$ & $\begin{array}{c}58,294 \\
18\end{array}$ & $\begin{array}{c}67 \\
72 \\
5\end{array}$ & $\begin{array}{l}0.95 \\
2.16 \\
\mathbf{1 . 2 1}\end{array}$ & $\begin{array}{c}0.01 \\
0.00 \\
\mathbf{- 0 . 0 1}\end{array}$ & & & $\begin{array}{l}0.03 \\
0.11 \\
\mathbf{0 . 0 9}\end{array}$ \\
\hline
\end{tabular}




\begin{tabular}{|c|c|c|c|c|c|c|c|c|}
\hline House & $\begin{array}{l}\text { Downdraft } \\
\text { Condition }\end{array}$ & $\begin{array}{c}\text { \# of } \\
\text { Observations }\end{array}$ & $\begin{array}{c}\text { Outdoor } \\
\text { Temp. (F) }\end{array}$ & $\begin{array}{c}\text { CAZ Pressure } \\
(\text { (PA) })^{\mathrm{a}}\end{array}$ & $\begin{array}{c}\text { Air Handler } \\
\text { Status }\end{array}$ & $\begin{array}{l}\text { Dryer } \\
\text { Status }\end{array}$ & $\begin{array}{c}\text { Kitchen Fan } \\
\text { Status }\end{array}$ & $\begin{array}{l}\text { Bath Fan } \\
1 \text { Status }\end{array}$ \\
\hline WI 01 & $\begin{array}{l}\text { No downdraft } \\
1^{\text {st }} \text { minute } \\
\text { increase }\end{array}$ & $\begin{array}{c}191,383 \\
105\end{array}$ & $\begin{array}{l}63 \\
81 \\
\mathbf{1 9}\end{array}$ & $\begin{array}{l}0.85 \\
2.16 \\
\mathbf{1 . 3 1}\end{array}$ & $\begin{array}{l}0.02 \\
0.36 \\
\mathbf{0 . 3 3}\end{array}$ & $\begin{array}{l}0.01 \\
0.34 \\
\mathbf{0 . 3 3}\end{array}$ & Not present & $\begin{array}{l}0.00 \\
0.00 \\
\mathbf{0 . 0 0}\end{array}$ \\
\hline
\end{tabular}

${ }^{a} \mathrm{CAZ}$ pressure defined here as outdoor pressure relative to CAZ pressure. A depressurized CAZ shows a POSITIVE value.

${ }^{\mathrm{b}}$ Status means the fraction of observations when the device was operating.

ND: No data available.

Not present: Device not present in this house. 


\subsection{Carbon Monoxide Accumulation}

Observed CO levels remained low in all the houses studied; the maximum observed 1-minute average value across all houses was $7 \mathrm{ppm}$. Though downdrafting is thought to trigger $\mathrm{CO}$ production in some cases, the maximum values observed during downdrafting were the same as or lower than those observed during nondowndrafting conditions in the houses studied (Table 26). The modest elevated levels of $\mathrm{CO}$ observed did appear to be related to water heater combustion; no evidence of other sources was found.

Table 26. Observed CO Concentrations in CAZ Airspace by House

\begin{tabular}{|c|c|c|c}
\hline House & $\begin{array}{c}\text { Number of 1-Min } \\
\text { Avg Observations } \\
\text { Exceeding 3 ppm }\end{array}$ & $\begin{array}{c}\text { Max Observed 1-Min Avg } \\
\text { under Nondowndrafting } \\
\text { Conditions (ppm) }\end{array}$ & $\begin{array}{c}\text { Max Observed 1-Min } \\
\text { Avg under Downdrafting } \\
\text { Conditions (ppm) }\end{array}$ \\
\hline MN 01 & 0 & 1 & 1 \\
\hline MN 02 & 0 & 3 & 1 \\
\hline MN 03 & 20 & 7 & 5 \\
\hline MN 04 & 1,196 & 6 & 6 \\
\hline MN 06 & 17 & 1 & 1 \\
\hline MN 07 & 0 & 4 & 3 \\
\hline MN 08 & 0 & 3 & 1 \\
\hline MN 09 & 0 & 2 & 1 \\
\hline WI 01 & 24 & 3 & 1 \\
\hline
\end{tabular}

\subsubsection{Field Data Conclusions}

Of the water heaters evaluated, two spilled combustion products in a majority of burner cycles, often for prolonged periods. Each system also had significant venting defects (undersizing or an inappropriate opening), which could be easily identified by a trained technician using visual inspection and venting code information only. Screening of homes for combustion safety should explicitly include vent inspection and sizing evaluation.

Of the remaining nine systems, some demonstrated frequent spillage within the first minute of operation, but none showed a tendency toward frequent spillage beyond the first minute. For these nine systems, the maximum overall runtime spent in spillage was about $5 \%$, with most below $1 \%$.

The largest influence on water heater combustion spillage was the specific house (systems and installation); temporary operating conditions such as exhaust fan operation and outdoor temperature played a lesser role.

Considering the houses that did not have venting defects, operation of clothes dryers and individual exhaust fans had a statistically significant effect on the incidence of spillage in individual houses, though this generally appeared in the context of a low overall incidence of spillage; i.e., increasing the probability of spillage from one low number to another low number. Net CAZ depressurization and outdoor temperature also provide statistically significant predictors of spillages. 
Stable downdrafting is a real phenomenon and can persist through burner cycles. Downdrafting during burner operation in the houses studied represented a small fraction of overall spillage. However, because downdrafting may lead to $\mathrm{CO}$ formation and release into living space, the conditions leading to development of downdraft should be further explored, and tests for susceptibility to downdrafting should be further developed.

No significant accumulation of CO was found in any of the houses tested. 


\section{Survey Results from State Weatherization Agencies on Combustion Safety Field Data Collection}

As discussed previously, the recruitment of field-test houses was less successful than expected. States were willing to help but had a very difficult time finding eligible houses based on the screening criteria.

The difficulty in finding houses was surprising. The original work by Rapp et al. (2012) suggested that a significant frequency of homes failed combustion safety testing but were unlikely to have problems in practice, and these were the homes that this project was targeting. (The RAPP report was updated in 2015 [Rapp 2015].) Additionally, weatherization field staff had been reporting anecdotally that many homes failed combustion safety testing and needed to be addressed, especially once the WAP requirement for ASHRAE Standard 62.2 compliance was put into effect. This project targeted one type of potential failure: the result of nondryer exhausts. Failures due to dryers or air handlers were not included because dryer and air handler flow rates are not easily adjustable and were considered to be more likely to occur in practice.

The project team had assumed that locating suitable test homes would not be difficult. Given the challenge, the team sought additional sources that would support the notion that combustion safety failures due to exhaust-fan-induced depressurization was in fact known to be common. The first step was to inquire whether the National WAP Evaluation had this information. In that project, agencies across the country were asked to complete surveys detailing their operations. However, questions about combustion safety failure rates were not a part of these surveys. This lack of data indicated that it was not known whether these types of combustion safety failures were common, and a survey of this type was vital to understand the prevalence of combustion safety failures and to put the test home recruitment challenge into context.

\subsection{Development of the Survey Instrument}

A survey was developed in May 2015 to be sent out nationally. The aims were to understand states' methods for conducting WC depressurization tests, to quantify the prevalence of combustion safety failures, to understand the causes of these failures, and to assess the magnitude of resource allocation to measures implemented due to concerns of spillage from depressurization. Appendix D includes the National Weatherization Survey about Homes that Exceed Worst-Case Depressurization Limits and Fail Spillage.

PARR approached the National Association for State Community Services Programs to seek assistance in distributing the survey. This organization has strong connections with programs in every state and agreed to support these efforts. The survey was distributed in June 2015 to all state weatherization programs. Weatherization team leads or program managers were asked to complete the survey. Responses were requested to be submitted to ICRT via email or mail no later than mid-July.

The survey contained 16 questions divided into two sections. The first section included general questions about state weatherization program data: how many homes were weatherized within a program year, what is the primary fuel used in homes, etc. States were also asked to describe their WC draft testing and spillage testing procedure. The second section pertained to homes that fail spillage tests pre- and postweatherization, including questions that differentiate remediation 
from expected and observed spillage events, as well as spillage that occurs from air handler use versus from exhausts, including dryers.

These were differentiated because the PARR/NorthernSTAR study sought homes that failed spillage due to exhaust vents such as a bath or kitchen fan but not due to air handler operation.

ICRT received 19 survey responses from 16 states and Washington D.C. The majority of states responded at the state program manager level. Because the United States has about 900 local action agencies, the National Association for State Community Services Programs did not ask these agencies to reply.

Responses were received from Alaska, Arkansas, Colorado, Idaho, Illinois, Kansas, Minnesota, Missouri, New Hampshire, New Jersey, New Mexico, New York, Oregon, Texas, Virginia, Washington state and Washington D.C. Regionally, these responses covered the West, Northwest, Midwest, Southwest, Mid-Atlantic, and Northeastern states. No states from the hot and humid areas of the Southeast responded.

Of note, Arkansas referred its survey to local agencies, and three agency responses were submitted to ICRT. Alaska also consulted with one of its largest local agencies to provide additional data from Anchorage. Minnesota's response is based on a residential program sponsored by utilities, managed by CEE (a NorthernSTAR team member).

In this report some states are specifically referenced to provide clarification or to provide examples; however, the researchers looked to aggregate the responses to provide a higher-level review of the data.

For simplicity, in the discussion below Washington, D.C. is referred to as a state.

\subsection{Survey Part I-Overview of States Programs}

Survey Questions \#1, \#2, and \#3: Please specify the last program year you have data for, how many homes were weatherized in the last program year, and what percentage of homes weatherized use either natural gas or fuel oil as the primary heating fuel.

Eighteen respondents (including the three from Arkansas) provided data for 1 year and one state reported on 15 months. Nine states reported for the 2014-2015 fiscal year. Five states reported for the 2013-2014 fiscal year. Three states reported on calendar year 2014.

In total, the responses represent 30,385 homes or units in which an energy assessment and weatherization measures were completed. Of these 28,575 homes $(94 \%)$ were weatherized using federal DOE WAP funds; the remainder were from the non-WAP Minnesota program.

One state did not respond to any question after answering how many homes were weatherized. This means that only 30,172 homes were covered in the response to question \#3 about the prevalence of natural gas or fuel oil. Of these, 23,442 homes (78\%) were reported to use natural gas, fuel oil, or propane as their primary heating fuel. Natural gas was the most commonly reported fuel followed by fuel oil and propane. 
Survey Questions \#4 and \#5: What percentage of homes have natural draft appliances within the pressure boundary of the home? What percentage of homes have natural draft appliances outside the pressure boundaries?

Seven of 17 states responded that they either do not track this information in their databases or do not collect this information. Fewer than half of homes, 44\% (14,395 of 30,385), are therefore excluded from this question.

Of the remaining 10 states, 6 provided only an estimate for the number of natural draft appliances in the pressure boundary. These 6 states estimated that of 3,448 homes with natural gas or fuel oil, 1,415(41\%) have natural draft appliances within the pressure boundaries.

The remaining four states provided exact numbers. One state reported separately for water heaters and furnaces, with 4,382 natural gas water heaters $(85.5 \%)$ and 1,883 (36.8\%) furnaces located within the pressure boundary of 5,124 homes that have natural gas or fuel oil as their primary heating source. Given that most homes with natural draft furnaces also have natural draft water heaters, the $85.5 \%$ value is likely a good approximation of the total percentage of homes that have natural draft appliances within the pressure boundaries. With this assumption, the four states with exact numbers reported 6,952 homes had natural draft appliances within the pressure boundary of 8,588 homes that had natural gas, propane, or fuel oil $(81 \%)$. One of these four states was the state that reported only on a non-WAP program.

Alaska's response was unique. It does not track these numbers in its database but explained that all the homes encountered by the weatherization program have space heating and water heaters inside the thermal boundaries. However, some are within the conditioned garage spaces, which may have combustion air inlets, so these would be considered outside the pressure boundaries.

Survey Questions \#6, \#7, and \#8: What is the test procedure your state uses to address combustion safety? Does spillage testing occur when a house exceeds WC depressurization limits? At how many minutes does the weatherization retrofit $(\mathrm{Wx})$ assessor check for spillage under WC depressurization conditions?

One of 17 states responded that it does not collect this information pertaining to all three questions. All the remaining states provided information for each question.

The majority of states use BPI Building Analyst procedures. One state indicated that it is using the draft BPI-1200 test procedure with one exception on the limit for sealed combustion appliances. The state allows negative pressure of only $-20 \mathrm{~Pa}$ rather than $-50 \mathrm{~Pa}$ due to impact on heating systems. The final BPI-1200 test procedure does not include depressurization limits.

Two states reported that they are currently using BPI Technical Standards for Building Analyst Professional but anticipate alignment with the ANSI/BPI-1200 procedures in PY 2015 or PY 2016. One of those states indicated that it was using the BPI Technical Standards for the Building Analyst Professional Version 2/20/05mda. Two states indicated they are using BPI Building Analyst Standards. Three states reported that they use BPI technical standards for the Building Analyst Professional Version 1/4/12. Another three states reported they use BPI test procedures, BPI/QCI standards, or BPI combustion safety procedure for vented appliances; these states did not report a version. 
Illinois, Oregon, and Kansas reported that their standards and procedures could be found in their state field guides or procedure manuals. Two states described their combustion safety test procedures within their survey responses without referring to a guide or to BPI standards.

In terms of spillage testing, 2 of 17 states responded that they do not collect this information or the information is unknown. Fifteen of 17 states responded that they complete spillage testing on natural draft appliances. One of the Arkansas agencies responded that it "almost never" conducts spillage testing. Kansas reported that it tested spillage at natural conditions but was not testing WC depressurization limits. Effective July 1, 2015, Kansas began testing spillage at WC but would allow a 2-minute spillage test.

The majority of respondents (11) checked for spillage at 1 minute, which was the requirement of the BPI standards until 2015. Three states tested at 2 minutes and two states tested at 3 minutes.

Question \#9 asked about how assessors test for spillage when the CAZ has insufficient space for the assessor to be in the space with the door closed. This was an open-ended question that elicited a range of responses. The responses were split about evenly between states that would test with the door partially open and states that would use other means (e.g., measure CAZ pressure or leave a mirror by the draft diverter) to estimate spillage without the need to be in the CAZ.

\subsection{Survey Part II-Homes that Fail Spillage Tests}

Questions \#10-\#16 are about spillage test outcomes from the applicable homes. For these questions, eight states reported that they do not collect the data, the data are not tracked, or the data are not applicable. These eight states represent $66 \%(20,171$ of 30,385$)$ of homes reported on in the study.

Of the remaining nine states, four provided data using precise numbers, and five states provided estimated data. For the four states that provided precise numbers, 5.6\% of homes reported $(1,707$ of 30,385$)$ are represented. For the five states that provided estimated data, $28 \%$ of homes $(8,507$ of 30,385$)$ reported are represented.

Estimated data and precise data are discussed separately below.

Survey Question \#10: How many homes in the last program year received any remediation measures to alleviate expected post-Wx spillage due to approaching or exceeding WC depressurization limits during pre-Wx assessments?

Four states provided precise data when answering question \#10. They reported that $4.3 \%$ (74 of $1,707)$ homes received remediation to alleviate expected post-Wx spillage.

Five states provided estimated data that indicated about $6 \%$ (about 513 of 8,507 ) homes received remediation measures due to expected spillage. In this group, one state reported that it did not track the data but estimated very few. No value was assigned to "very few" to calculate the estimated number reported. 
The non-WAP Minnesota program reported that it expected 436 of 1,800 homes to receive measures due to expected post-Wx spillage. This figure was not accounted in either group because the Minnesota program does not complete combustion safety measures through its retrofit program. The homeowners are ultimately responsible for addressing combustion safety issues in their homes. It is unknown why such a large percentage of these homes were expected to have spillage problems relative to the WAP homes. Perhaps the Minnesota program tends to achieve greater airtightness than is typical in the WAP program.

Survey Question \#11: How many homes in the last program year received any remediation measures to alleviate observed spillage due to depressurization (e.g., not from a blocked flue)?

Four states provided precise data for question \#11 and reported that 5.4\% of homes (about 92 of 1,707) homes received remediation measures due to observed spillage during a weatherization post-test.

Five states provided estimated data that indicated about $16 \%(1,351$ of 8,507$)$ homes received remediation measures to alleviate observed spillage. In this group, one state reported that it did not track the data but estimated very few of 1,186 weatherized homes. No value was assigned to "very few" in calculating the estimated number.

A second state in this group reported that the observed spillage occurred approximately $3 \%$ of the time, and that state's agencies report that most spillage is due to improper flue sizing or a crushed roof cap, not an exhaust fan or air handler. This resulted in approximately 10 homes for the state of 839 weatherized homes. These 10 homes were included in the estimate data.

In this group, Alaska reported that $40 \%-50 \%$ of homes with either natural gas or fuel oil as a primary heat source were remediated due to observed spillage. On average, 810 of 2,000 weatherized homes were estimated to have received remediation due to this condition.

The non-WAP Minnesota program reported that 111 of 1,488 water heaters failed WC testing and 43 of 1,076 gas furnaces failed WC testing. Within these failures, 33 homes had both appliances fail WC testing.

Survey Question \#12: For homes that failed a spillage test, how many of those homes failed due to operation of the air handler (i.e., air handler return leaks)?

Four states provided precise data for question \#12 and reported that 4\% (about 73 homes of $1,707)$ homes failed spillage tests due to operation of an air handler.

Four states provided estimated data that indicated 6.5\% (374 homes of 5,757) weatherized failed spillage due to operation of an air handler.

Survey Question \#13: When homes failed a spillage test, how many of those homes failed due to operation of appliances that exhaust air (i.e., kitchen or bath ventilation, dryers)?

Three states provided precise data for question \#13. Of 967 homes weatherized in this group, 39 (4\%) failed due to operation of appliances that exhaust air. 
Four states estimated spillage failure due to exhaust and reported that 1,043 of 5,757 weatherized homes $(18 \%)$ failed spillage due to exhaust appliances. Of these states, the numbers of failures reported were 260, 196, 585, and one. Alaska reported 585 failures due to appliances that exhaust air, but stated that half of these are failures mostly occurring from dryers. With Alaska removed, the rate of failures due to exhaust from states that provided estimated values dropped to $12 \%$.

Survey Question \#14: How many homes receiving remediation for expected or observed spillage post-Wx had a new appliance installed?

Three states reported precisely that 31 of 967 weatherized units had new appliances installed $(3.2 \%)$.

Excluding Alaska, four states estimated that 150 of 6,507 total remediated homes had new appliances installed $(2.3 \%)$.

Based on reported figures, Alaska estimated $60 \%$ of homes that were remediated due to spillage received new appliances (702 of 1,170 remediated homes).

Survey Question \#15: How many homes receiving remediation for expected or observed spillage post-Wx had a power vent kit installed?

Four states estimated that 17 out of 4,987 weatherized homes received power vent kits. Three states reported that no power vent kits were installed in 4,131 weatherized homes.

Survey Question \#16: How many homes did not receive weatherization services (or were deferred) due to combustion safety failures?

Six states responded that no homes were deferred due to combustion safety failures. One state indicated that it does not defer homes due to combustion safety failures except for cracked heat exchangers. One Arkansas agency reported that six homes were deferred due to combustion safety failures. These were the only deferrals reported.

\subsection{Discussion and Conclusion}

The survey revealed a number of important findings. The most striking result is how few respondents actually had precise data about combustion safety failures. Of 17 states, only four had precise data of this type, and these four states represented fewer than $6 \%$ of the homes in the sample. Of the remaining 13 states, it would have been fair to simply state that none collect this information; however, the team tried to summarize estimated values when available.

A second important finding is that of the homes that failed spillage tests in the four states that reported precise numbers, the failures were split about evenly between being due to exhausts and being due to air handler operation (about 4\% each). This is critical, because failures due to air handler operation are not the type that the field-testing for the STP project was intended to address. Further, although clearly some failures reported were due to exhausts, the survey did not attempt to distinguish between failures due to dryers or other exhausts. However, some states did volunteer that many failures due to exhausts were from dryers, meaning that the homes with 
failures of a type that would have qualified for the field-testing would have been noticeably fewer than $4 \%$.

It is also of interest that the states that did not track this information but attempted to provide estimates indicated higher failure rates than those states with precise numbers. Given how few states reported precise numbers, they cannot be considered to constitute a representative sample, so other states may well have higher failure rates, but clearly this is speculative. In the absence of states recording these data, a survey targeting individual agencies would be required to improve the team's detailed understanding of this issue. However, given the difficulty of finding eligible homes for field-testing, it may be considered sufficient that the few data that are available tend to concur with the conclusion that relatively few homes that fail for the reasons targeted by the project.

The primary takeaway is that little actual evidence shows that combustion safety failures due to spillage from nondryer exhaust are common. This is counter to the anecdotal opinions and assumptions that were made by a number of entities before the field-testing project was conducted. The few hard data that detail actual failures suggest that only a very small number of homes are subject to these failures; therefore, the actual cost to programs for correcting these failures is also expected to be low. 


\section{Conclusions}

The conclusions of this project cover a wide array of topics related to combustion safety: state weatherization team reporting of combustion safety events, the development of an STP, evaluation of the procedure in the field compared to other methods in use, and field-test data and analysis.

Survey results from 17 state weatherization agencies are presented. These agencies do not generally track combustion safety failures. The data from those that do suggest that little actual evidence shows that combustion safety failures due to spillage from nondryer exhaust are common and that only a very small number of homes are subject to the failures.

Field evaluations of the STP and the traditional and comprehensive BPI test procedures produced similar results - the same houses failed both tests. The authors conclude that the STP is appropriate for combustion safety assessment; that is, it is as effective at identifying problem houses as the WC procedures in use.

According to the field data from 11 houses monitored for 7 months, the 2 houses that failed the STP and showed significant persistent flue gas spillage events also had vent systems that violated the NFGC sizing guidelines. This finding suggests that energy auditors and any personnel charged with combustion safety evaluation should be trained to perform inspections specifically to identify violations of the current venting standards. The fact that only homes with clear venting code violations experienced significant spillage in normal operation also suggests that correcting venting system defects may prevent excessive spillage and avoid the need for higher cost system replacement in many cases.

None of the remaining houses (i.e., the houses with code-compliant vent systems) in the field study experienced significant spillage beyond the first minute of operation, yet all failed the STP, suggesting that this procedure (as well as traditional procedures) is conservative; i.e., it creates false positive spillage test results that do not correlate with spillage under normal operating conditions. A lower exhaust fan level is likely more appropriate for the test, though this was not evaluated.

In the houses with code-compliant venting, field data show that the operation of clothes dryers and exhaust fans (especially kitchen fans) is often statistically associated with spillage. The low incidence of spillage after the first minute of operation means, however, that the effect of fan operation is generally to increase the probability of spillage from one very low number to a higher but still low number. Test data show that kitchen fan airflow rates in the houses studied are on the same order of magnitude as dryer airflow, and kitchen fans are probably as likely as dryers to be triggers for spillage (although dryer operation appears more likely to overlap with burner cycling than kitchen fan operation).

An investigation into whether exhaust fan (dryer, range hood) operation in proximity to an atmospheric water heater is a hazard or is a method of exhausting spilled flue gases is appropriate, especially in light of the fact that no elevated $\mathrm{CO}$ readings were recorded. If the fan is the cause for the spillage, once the fan stops the root cause for the spillage is removed. 
When CAZ net depressurization is considered (instead of the operation of individual fans) as a predictor of spillage, it showed a clear and statistically significant effect in most of the houses tested. A higher level of depressurization (defined here as CAZ pressure with respect to outdoor pressure) always correlated with a higher probability of spillage.

Backdrafting (or persistent reversal of flow in the vent system) occurred in some homes, indicating that the buoyancy of the flue gases was insufficient to overcome the flow of cold air down the vent. Similar to spillage in general, the start of a backdrafting episode appears to be much more likely when exhaust fans are operating and when the CAZ is under greater depressurization. Backdrafting may be associated with $\mathrm{CO}$ production, and although the team did not find elevated $\mathrm{CO}$ levels, this fact suggests a need for more investigation into the causes and effects of backdrafting.

Elevated CO levels at the Underwriters Laboratories alarm limit of $70 \mathrm{ppm}$ were not detected in the test, even during spillage events. Appliance $\mathrm{CO}$ levels that exceeded the ANSI certification limit in the NFGC were also not detected, and CO levels observed during normal operation remained low in all homes.

Finally, a primary conclusion related to audit practices is that the main cause of persistent failures in this project was improperly sized vents. Auditors should be trained in the proper sizing of vent systems to be able to resolve the failures that relate to serious and persistent combustion safety issues. From the weatherization survey results, another root cause of the failures is most commonly related to depressurization associated with poorly sealed ductwork that should be resolved during the upgrade. Appliances should be replaced only if a failure occurs at test-out, or if the flue gas CO reading exceeds the requirement in the NFGC. The STP in this report should provide an easier route to performing the test. Because the BPI-1200-2015 standard was developed based on input from the authors, the combustion safety provisions in that standard are recommended as the STP until further research can be done.

Responses to research questions:

Q1: Does the STP accurately predict combustion safety hazards as determined by long-term monitoring? Does it predict hazards more accurately than the conventional protocol used by weatherization agencies?

A1: The STP was demonstrated to be as effective as the WC methods using trial and error to select door positions. Long-term monitoring revealed that houses that fail the STP either show a pattern of persistent failures or show no pattern of failures. Persistent failures would have been detected by a careful inspection of the vent sizing in the small number of samples in this study.

Q2: Is the STP practical for field implementation, and can it be improved?

A2: The team was able to train field weatherization agencies on the STP with little difficulty. The results of the field test show that if a vent inspection and remediation are done before the STP, the exhaust fan levels in the STP could be lowered.

Q3: What is the incidence of spillage and combustion safety failures based on feedback from weatherization agencies and other field experience? 
A3: State weatherization agencies do not generally track combustion safety failures. The data from those that do suggest that little actual evidence shows that combustion safety failures due to spillage from nondryer exhaust are common and that only a very small number of homes are subject to the failures. In the field study, 2 of the 11 houses that failed the STP had persistent spillage that required remediation. 


\section{References}

Brand, L. 2014. Combustion Safety for Natural Draft Appliances Using Indoor Air (Subcontract Report, NREL/SR-5500-61326). Golden, CO: National Renewable Energy Laboratory. Accessed October 19, 2015: www.nrel.gov/docs/fy14osti/61326.pdf?gathStatIcon=true.

Cautley, D., J. Viner, M. Lord, and M. Pearce. 2012. Test Methods and Protocols for Environmental and Safety Hazards Associated with Home Energy Retrofits (Subcontract Report, DOE/GO-102012-3752). Golden, CO: National Renewable Energy Laboratory, http://apps1.eere.energy.gov/buildings/publications/pdfs/building_america/test_methods_and_pr otocols.pdf

Fitzgerald, J., and D. Bohac. 2014. Combustion Safety for Natural Draft Appliances through Appliance Zone Isolation (Subcontract Report, NREL/SR-5500-61295). Golden, CO: National Renewable Energy Laboratory. Accessed October 19, 2015: www.nrel.gov/docs/fy14osti/61295.pdf?gathStatIcon=true.

IFGC. 2013. International Fuel Gas Code, International Code Council

NREL. 2013. "Standard Work Specifications for Home Energy Upgrades." Accessed October 19, 2015: www.nrel.gov/tech_deployment/buildings_sws.html.

NFPA 54. 2012. National Fuel Gas Code. Boston, MA: National Fire Protection Association, American Gas Association.

Rapp, V.H., B.C. Singer, J.C. Stratton, and C.P. Wray. 2012. Assessment of Literature Related to Combustion Appliance Venting Systems. Berkeley, CA: Lawrence Berkeley National Laboratory, Berkeley, CA. June 2012. LBNL-5798E.

Rapp, V.H., B.D. Less, B.C. Singer, J.C. Stratton, and C.P. Wray. 2015. Assessment of Literature Related to Combustion Appliance Venting Systems. Berkeley, CA: Lawrence Berkeley National Laboratory, LBNL-176805. 


\section{Bibliography}

ASTM. 1998. "Standard Guide for Assessing Depressurization-Induced Backdrafting and Spillage from Vented Combustion Appliances."

BPI 1200 Basic Analysis of Buildings. 2012.Building Performance Institute, Malta New York.

Brand, L., D. Cautley, and D. Bohac. 2014. Test Plan: Combustion Safety. Golden, CO: National Renewable Energy Laboratory.

Building Performance Institute. 2015. "Standard Practice for Basic Analysis of Buildings", ANSI/BPI-1200-S-2015.

Cummings, J., and C. Withers. 2008. "Problems Related to Air Handler Leakage." ASHRAE Journal, January 2008. American Society of Heating, Refrigerating and Air-Conditioning Engineers, Inc.,

DOE. n.d. "Venting Issues I Gas-Fired Water

Heaters." www1.eere.energy.gov/buildings/appliance_standards/residential/pdfs/d-3.pdf.

Grimsrud, D T., M.D. Koontz, and N.L. Nagda. 1996. Field Protocol for Determining Depressurization-Induced Backdrafting and Spillage from Vented Residential Gas Appliances, Technical Report 96/0303. Chicago, IL: Gas Research Institute.

Hnatov, M. 2012. "Non-Fire Carbon Monoxide Deaths Associated with the Use of Consumer Products 2009 Annual Estimates.” U.S. Consumer Products Safety Commission.

IRC. 2013. International Residential Code for One and Two Family Dwellings. International Code Council.

Koontz, M.D., and N.L. Nagda. 2002. "Depressurization-Induced Backdrafting and Spillage: Implications of Results from North American Field Studies." ASHRAE Transactions, 108.

NFPA 211. 2012. Standard for Chimneys, Fireplaces, Vents, and Solid Fuel-Burning Appliances. National Fire Protection Association.

Proctor, J., R. Chitwood, and B.A. Wilcox. 2011. "Efficiency Characteristics and Opportunities for New California Homes." California Energy Commission. Publication number: CEC 5002012-062.

RESNET. 2010. Interim Guidelines for Combustion Appliance Testing and Writing Work Scope. www.resnet.us/standards/RESNET_interim_guidelines_for_combustion_safety_scope_of work.pdf.

U.S. Census Bureau. Characteristics of New Single-Family Houses Completed, Type of Foundation. www.census.gov/construction/chars/completed.html. 


\section{Appendix A. Overview of Short-Term Testing Protocol}

Record the outdoor temperature, wind speed, and wind direction reported by the nearest weather station.

1. Measure the house air leakage by performing a multipoint envelope air leakage test in accordance with ASTM E779. Close all exterior doors, windows, and fireplace dampers. Conduct only the depressurization section of the test (do not perform the pressurization test). The minimum induced pressure difference shall be no greater than $10 \mathrm{~Pa}$.

2. Measure the flow rate of all exhaust fans, heat recovery ventilators, energy recovery ventilators, dryer vents, and any other appliance that moves air into or out of the house.

3. Measure the change in pressure as a result of appliances (including appliance air handlers). For each CAZ within the pressure boundary of the house, use an appropriate application (e.g., The Energy Conservatory's Teclog3) to record the house pressure at the CAZ with respect to outside at 1-second intervals.

4. To gauge the accuracy of the pressure measurements, record the results for three 30second measurement periods for the baseline conditions and for three 30 -second periods under the test or other conditions. Each period is alternated so each baseline measurement period is followed by a test condition, as shown below:
A. Baseline
B. Test condition (e.g., fan on)
C. Baseline
D. Test condition
E. Baseline
F. Test condition.

5. The first series of pressure test conditions examines the impact of the individual exhaust appliances. Depending on the number of multispeed fans in the house, as many as 10 tests will be performed. With all the interior doors open, the exhaust fans are tested in the following order; the last test is conducted with all the fans on:
A. Kitchen fan low
B. Kitchen fan high
C. Bath fan 1 low
D. Bath fan 1 high
E. Bath fan 2 low
F. Bath fan 2 high
G. Dryer

H. Dryer, with CAZ door closed (this can be the door of the mechanical room or the basement door if the combustion appliances are in an open basement)

I. Any other fan high 
J. All fans on high speed (do not need to wait 30 seconds between fans).

The second series of test conditions investigates the impact of the air handler operation (if applicable) and the position of the CAZ door. For this series of tests, the baseline condition has the air handler off and doors and fans in the specified state for each defined test condition shown below. The air handler is on for the test condition. Below are the four conditions for this series of tests:

1. Air handler on/off. All interior doors open, all exhaust fans off.

2. Air handler on/off. CAZ door closed, other interior doors open, all exhaust fans off.

3. Air handler on/off. CAZ door closed, other interior doors closed EXCEPT rooms with an exhaust fan or air handler return (BPI protocol), ALL exhaust fans on.

4. CAZ door closed/open. Select air handler on or off, whichever gave more negative pressure in previous condition, other interior doors closed EXCEPT rooms with an exhaust fan or air handler return (BPI protocol), ALL exhaust fans on.

The final series of pressure conditions investigates the test conditions of various combustion safety test protocols. For these tests, measure the pressure differences for the following four fan, door, and air handler combinations:

1. BPI: All exhaust fans on; other interior doors as per BPI protocol, air handler on/off based on which produces most negative CAZ pressure (CAZ door closed); CAZ door open/closed based on which produces most negative $\mathrm{CAZ}$ pressure

2. Comprehensive WC: All exhaust fans on, interior doors (including CAZ) set to WC conditions as indicated by smoke movement or pressure across door, air handler on or off depending on which condition produces most negative $\mathrm{CAZ}$ pressure

3. STP: Dryer, kitchen fan high, next largest fan high; CAZ door closed, other interior doors as per BPI protocol, air handler on/off based on whichever produces most negative CAZ pressure

4. Modified STP: Dryer, kitchen fan high, next-largest fan high; interior doors (including CAZ) set to WC conditions as indicated by smoke movement or pressure across door, air handler on or off depending on which condition produces most negative CAZ pressure (same as comprehensive WC except only dryer, kitchen and next largest exhaust fans)

5. Visually inspect the venting system for proper size and horizontal pitch and determine that there is no blockage, restriction, leakage, corrosion, or other deficiencies that could cause an unsafe condition (NFPA 54 Chapter 13; IFGC 2013, Chapter 5). For masonry chimneys determine if it has a metal liner, if required. Take and record the following basic measurements and check them against the tables in the NFGC and International Fuel Gas Code to determine whether the vent system is properly sized:

A. Type of vent connector and common vent materials

B. The vertical common vent/chimney diameter and approximate height, noting offsets 
C. The common vent manifold diameter and horizontal length (if any)

D. Each appliance vent connector diameter, rise, length, and number of elbows.

6. Visually inspect any combustion air $\operatorname{duct}(\mathrm{s})$. Ducts that have been fully or partially blocked by the occupant should be unblocked. Ducts that are fully or partially blocked due to deterioration or debris should be left as-is. Record information on the combustion air and include number of openings, location of openings, type of duct, duct area, duct length, and elbows. Check the combustion air configuration against NFGC and International Fuel Gas Code requirements to determine whether the system is properly sized.

7. Ensure that the termination of the indoor pressure reference is in the space where the vented combustion appliances are located. Use an appropriate application to record the house pressure with respect to the outside at 1 -second intervals. Continue the measurements while the house is being placed in the first test condition. Wait a minimum of 15 seconds after each change in the house configuration and document the average house pressure difference for each configuration.

8. Install a static pressure (or draft) sensor in the appliance vent approximately $1-2 \mathrm{ft}$ downstream of the appliance draft diverter. The sensor will be used to reference the area in which the appliance is located. Use an appropriate application to record the house pressure and draft pressure at 1-second intervals

9. Conduct short-term testing under the must-fail condition and the must-pass condition.

10. Place the appliance being inspected in operation. Follow lighting instructions for each appliance. Adjust the thermostat so the appliance will operate continuously.

11. Measure CO levels in the appliance flue. Measured air-free $\mathrm{CO}$ levels should not exceed the ANSI certification requirement for the type of appliance.

12. Test for spillage at the draft hood relief opening. Use chemical smoke as an indicator of spillage. Note the duration of time required after the burner is ignited until there is no visible spillage up to 5 minutes. Evaluate the spillage after 1, 2, and 5 minutes of burner operation.

13. Record the draft pressure after 1,2, and 5 minutes of burner operation.

14. Turn on all other fuel-gas-burning appliances within the same room so they operate at their full inputs. Follow lighting instructions for each appliance.

15. Repeat the spillage test for any additional appliances being inspected.

The CEVP is the highest level of CAZ depressurization for which the appliance can overcome a cold stack and establish a draft up the flue. The CVEP is measured using the blower door to vary the CAZ depressurization. Use an appropriate application (e.g. The Energy Conservatory's Teclog3) to record the house pressure, draft pressure, and blower door fan flow at 1-second intervals. Install the termination of the indoor pressure reference to the space where the vented combustion appliances are located. Open all interior doors. The outdoor pressure reference will be an average of measurements at each side of the house. Test atmospherically vented appliances only. Do not test appliances having an interlocked spill sensing switch. 
1. Install a static pressure (or draft) sensor in the appliance vent approximately $1-2 \mathrm{ft}$ downstream of the appliance draft diverter. The sensor will be used to reference the area in which the appliance is located.

2. Reference the blower door fan pressure to house pressure. Install the smallest fan ring to attain the needed CAZ depressurization.

3. Place all appliances to be tested in standby mode. If testing the water heater, run hot water to ensure the appliance will continue to fire during the duration of test. Test only one appliance at a time and keep the additional appliances on standby.

4. Begin TECLOG3.

5. Record a 2-minute period of record baseline.

6. Referencing the previous must-fail test pressure, use the blower door fan to increase the CAZ depressurization by an additional $5 \mathrm{~Pa}$.

7. Fire the appliance to be tested.

8. Measure and record the air-free $\mathrm{CO}$ at the appliance flue and continue to monitor the $\mathrm{CO}$ for the duration of test.

9. Reduce $\mathrm{CAZ}$ to outside depressurization by $0.5 \mathrm{~Pa}$, holding the $\mathrm{CAZ}$ at that pressure for 30 seconds.

10. Repeat step 9 until the vent establishes negative pressure. Record the CAZ pressure and fan flow when the vent negative pressure is achieved.

11. Record a 2-minute period of record baseline

12. Repeat for additional commonly vented appliances allowing the blower door fan to run at the start of additional tests to adequately cool the flue.

13. When possible, use the gas utility meter to "clock" or measure the maximum burner input rate for each appliance tested.

14. Return doors, windows, exhaust fans, fireplace dampers, and all fuel-gas-burning appliances to their "as found" conditions of use. 


\section{Appendix B. Monitoring System Parts}

\begin{tabular}{|c|c|c|}
\hline Sensor & $\begin{array}{l}\text { Number } \\
\text { Used }\end{array}$ & Manufacturer and Model \\
\hline $\begin{array}{c}\text { K Type Thermocouples in Flue } \\
\text { and Vent }\end{array}$ & 2 & $\begin{array}{c}\text { Fabricated by project team using } 24 \text { American } \\
\text { wire gauge fiberglass-insulated } \mathrm{K} \text { type solid } \\
\text { thermocouple grade wire }\end{array}$ \\
\hline $\begin{array}{c}\text { K Type Thermocouples at } \\
\text { Draft Hood, in CAZ, and } \\
\text { Outdoors }\end{array}$ & 4 & $\begin{array}{l}\text { Fabricated by project team using } 24 \text { American } \\
\text { wire gauge perfluoroalkoxy alkane insulated } \mathrm{K} \\
\text { type solid thermocouple grade wire }\end{array}$ \\
\hline $\begin{array}{c}\text { K Type Thermocouples in } \\
\text { CAZ, and Outdoors }\end{array}$ & 3 & Same as above \\
\hline $\begin{array}{c}\text { Differential Pressure } \\
\text { Transducer, Digital Output }\end{array}$ & 1 & $\begin{array}{c}\text { All Sensors DLVR I2C digital output } \\
\text { differential pressure sensor, } \pm 1 \text { in. water column } \\
\text { range }\end{array}$ \\
\hline $\begin{array}{l}\text { Nondispersive Infrared } \mathrm{CO}_{2} \\
\text { Sensor, Analog Output }\end{array}$ & 1 & Digital Control Systems 305E \\
\hline Electrochemical CO Sensor & 1 & $\begin{array}{c}\text { Figaro TGS5042 with amplifier conditioned } \\
\text { output current }\end{array}$ \\
\hline $\begin{array}{c}\text { 20A Current Transducer, } \\
\text { Analog Output }\end{array}$ & $1-2$ & Onset Computer CTV-A 20A current transducer \\
\hline $\begin{array}{l}\text { Custom Wireless Sensor } \\
\text { Module, Transceiver with A to } \\
\text { D Converter }\end{array}$ & Up to 3 & Digi Xbee Pro S2B module, Zigbee protocol \\
\hline $\begin{array}{l}\text { Custom Wireless Sensor } \\
\text { Module, Pressure Sensor }\end{array}$ & $\begin{array}{l}1 \text { per } \\
\text { module }\end{array}$ & $\begin{array}{c}\text { All Sensors BLV analog (bridge) output } \\
\text { differential pressure sensor, } \pm 1 \text { in. water column } \\
\text { range }\end{array}$ \\
\hline
\end{tabular}




\section{Appendix C. House Data Sample Photos}

$\mathrm{MN} 01$

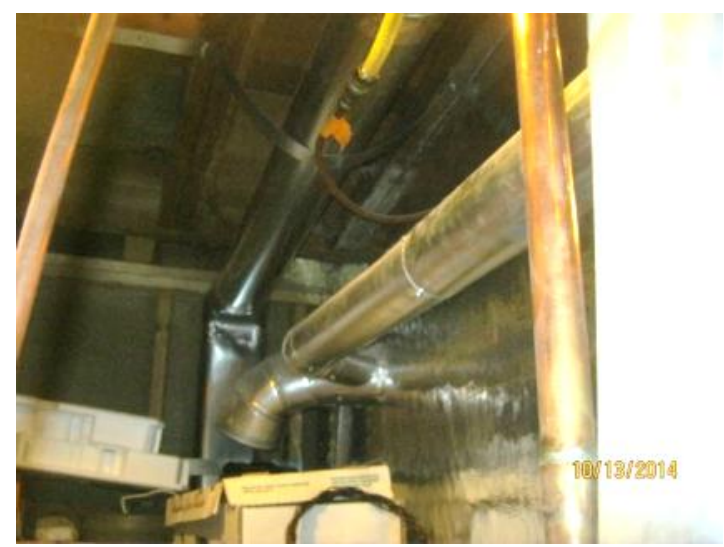

MN 02

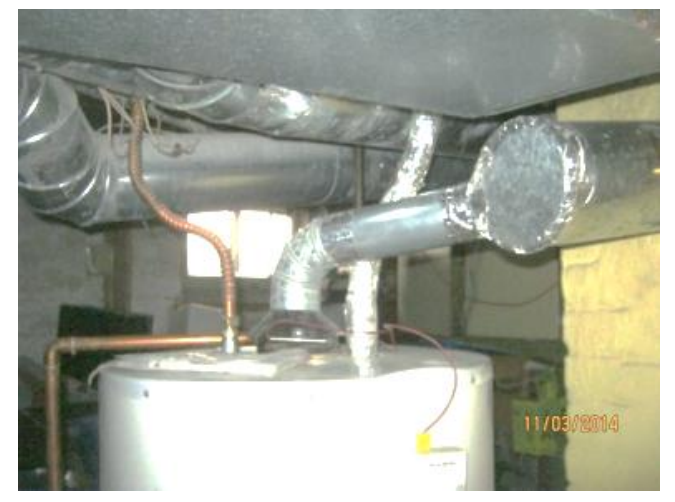

MN 03

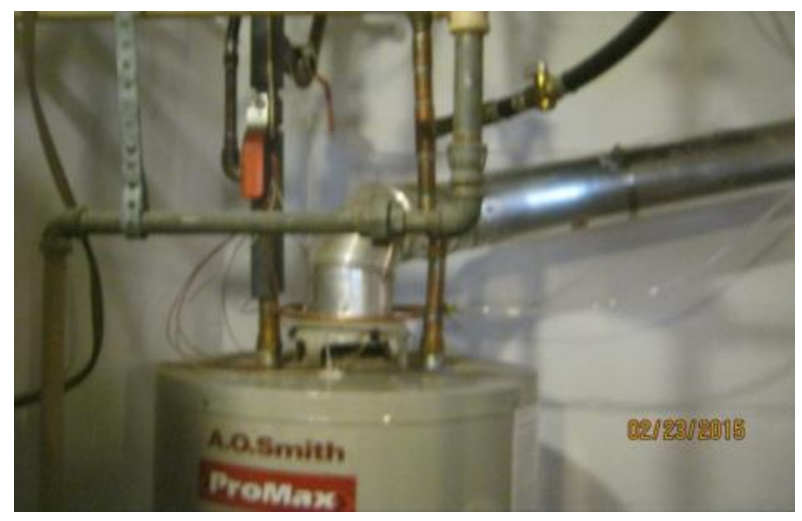

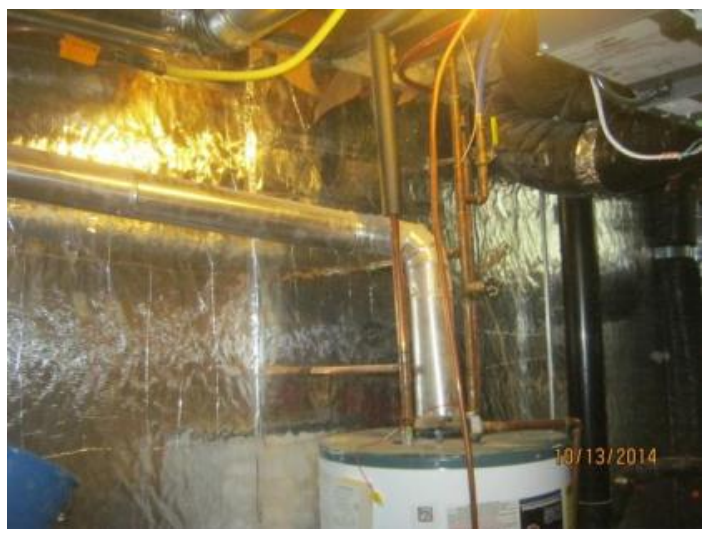

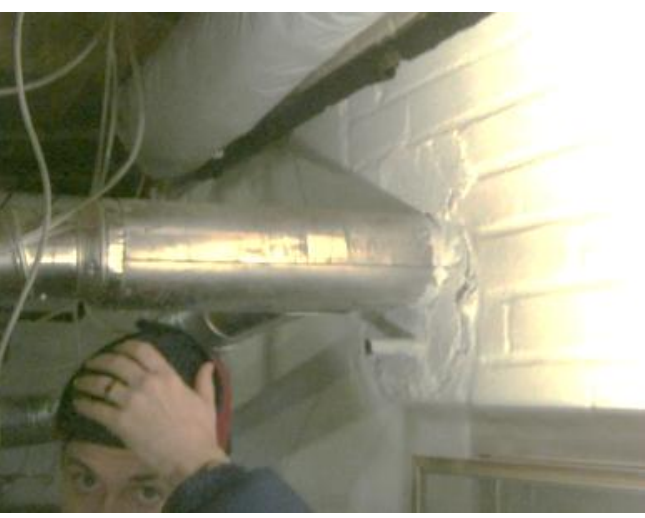


\begin{tabular}{l|l} 
u.s. Department of & Energy Efficiency \& \\
Renewable Energy
\end{tabular}

MN 04

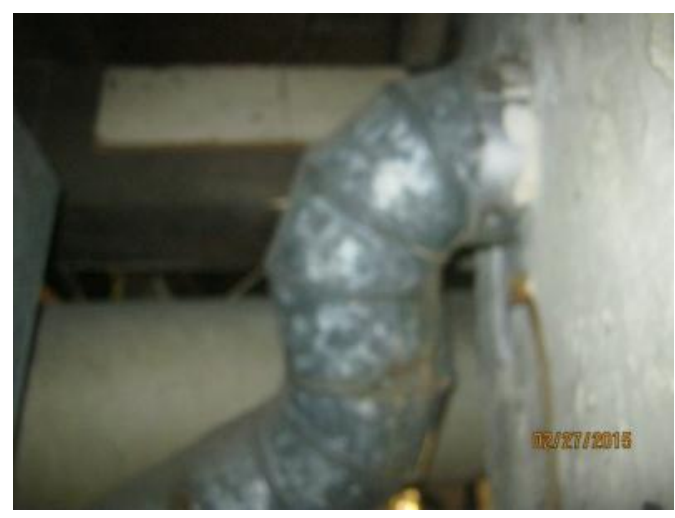

MN 05

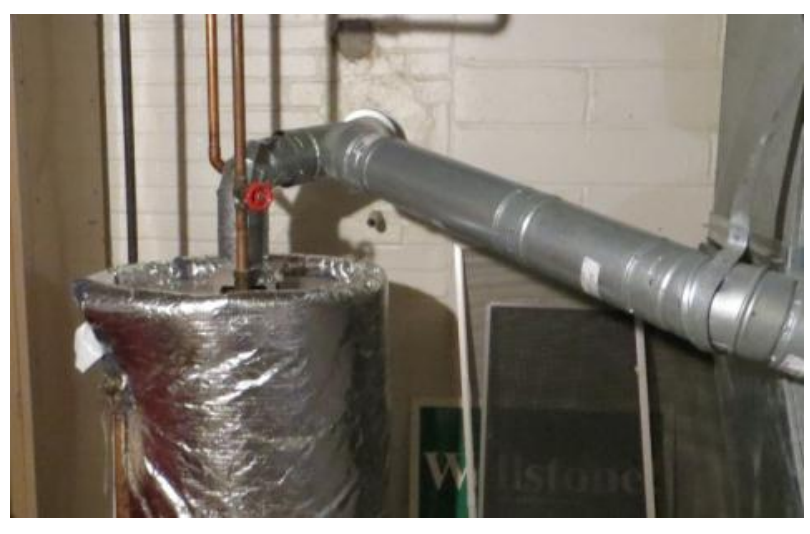

MN 06

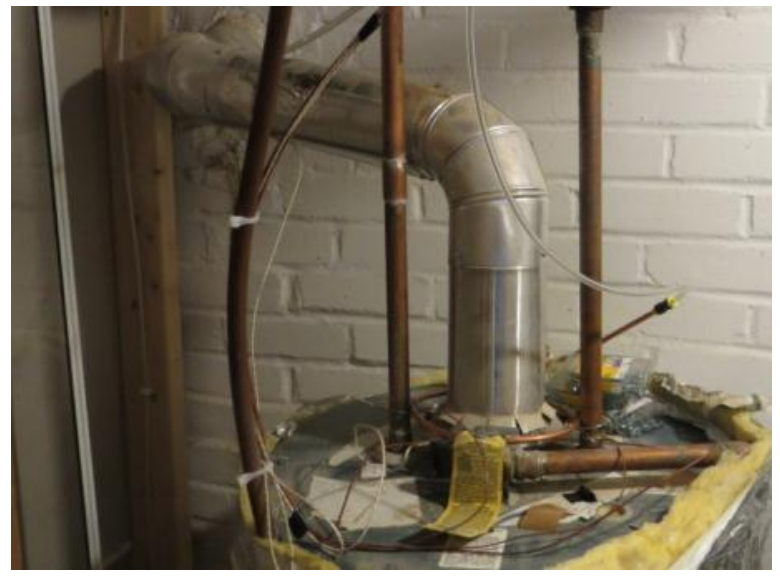

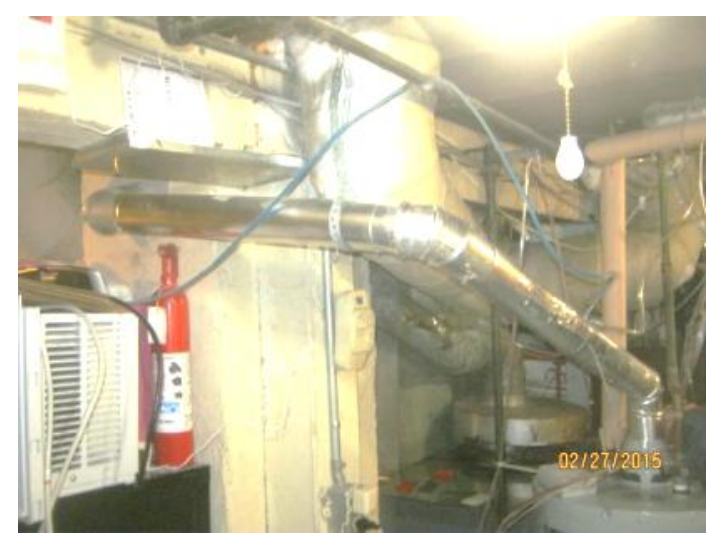

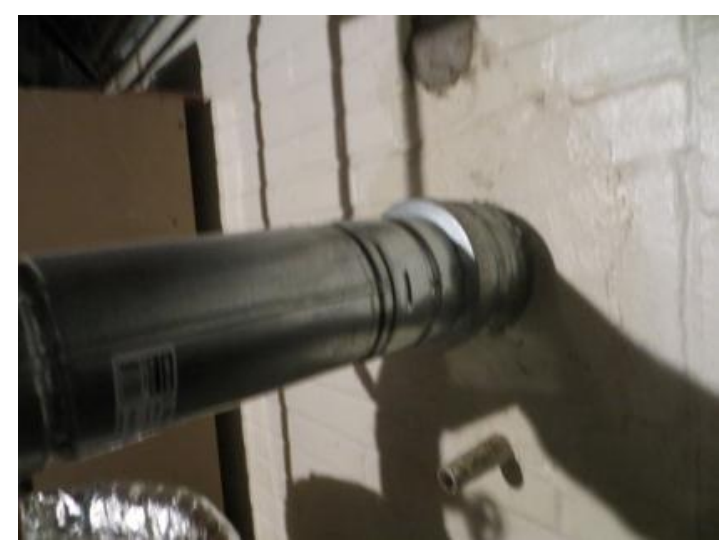


\begin{tabular}{l|l} 
u.s. Department of & Energy Efficiency \& \\
ENERewable Energy
\end{tabular}

MN 07

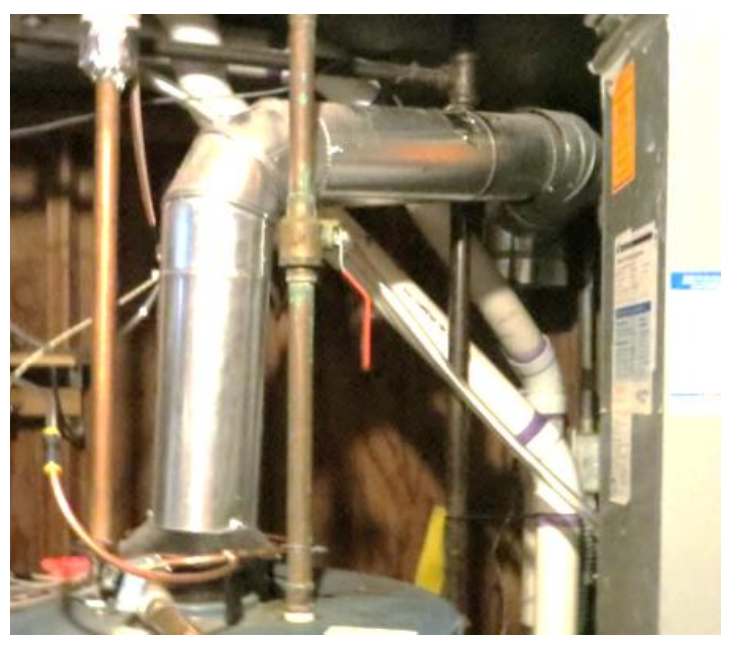

MN 08
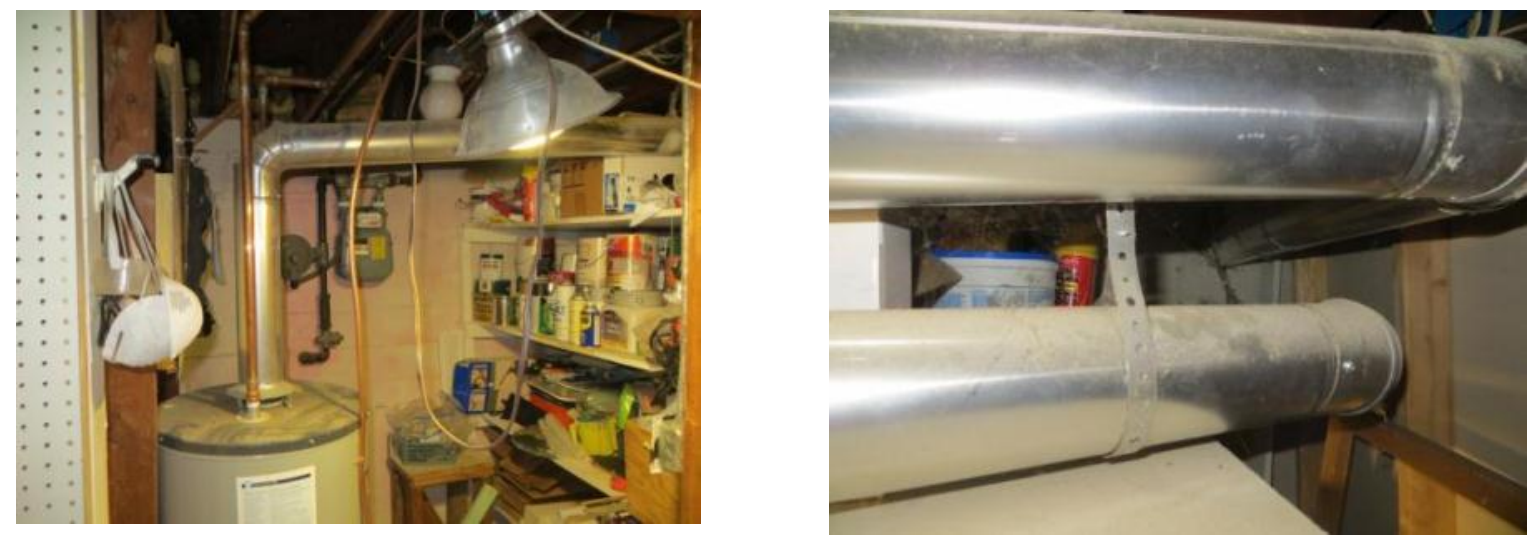

MN09

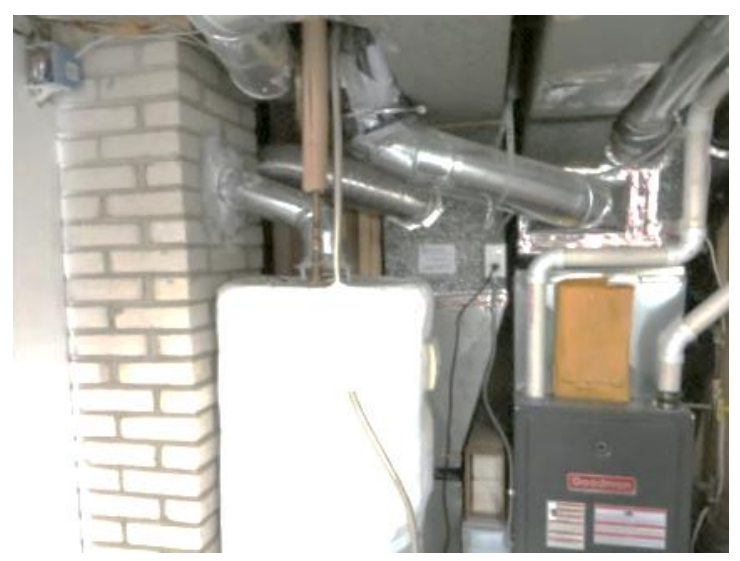


\begin{tabular}{l|l} 
u.s. DEPARTMENT OF & Energy Efficiency \& \\
ENEnewable Energy
\end{tabular}

MN 10

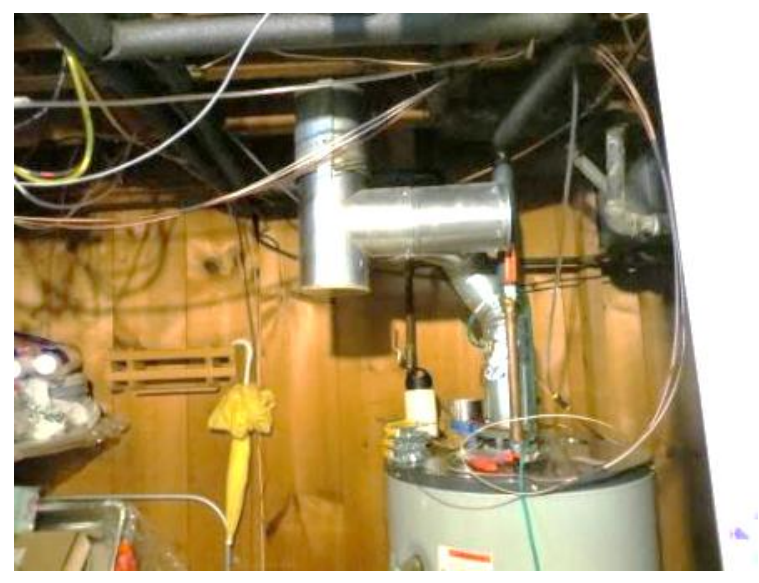

WI 01
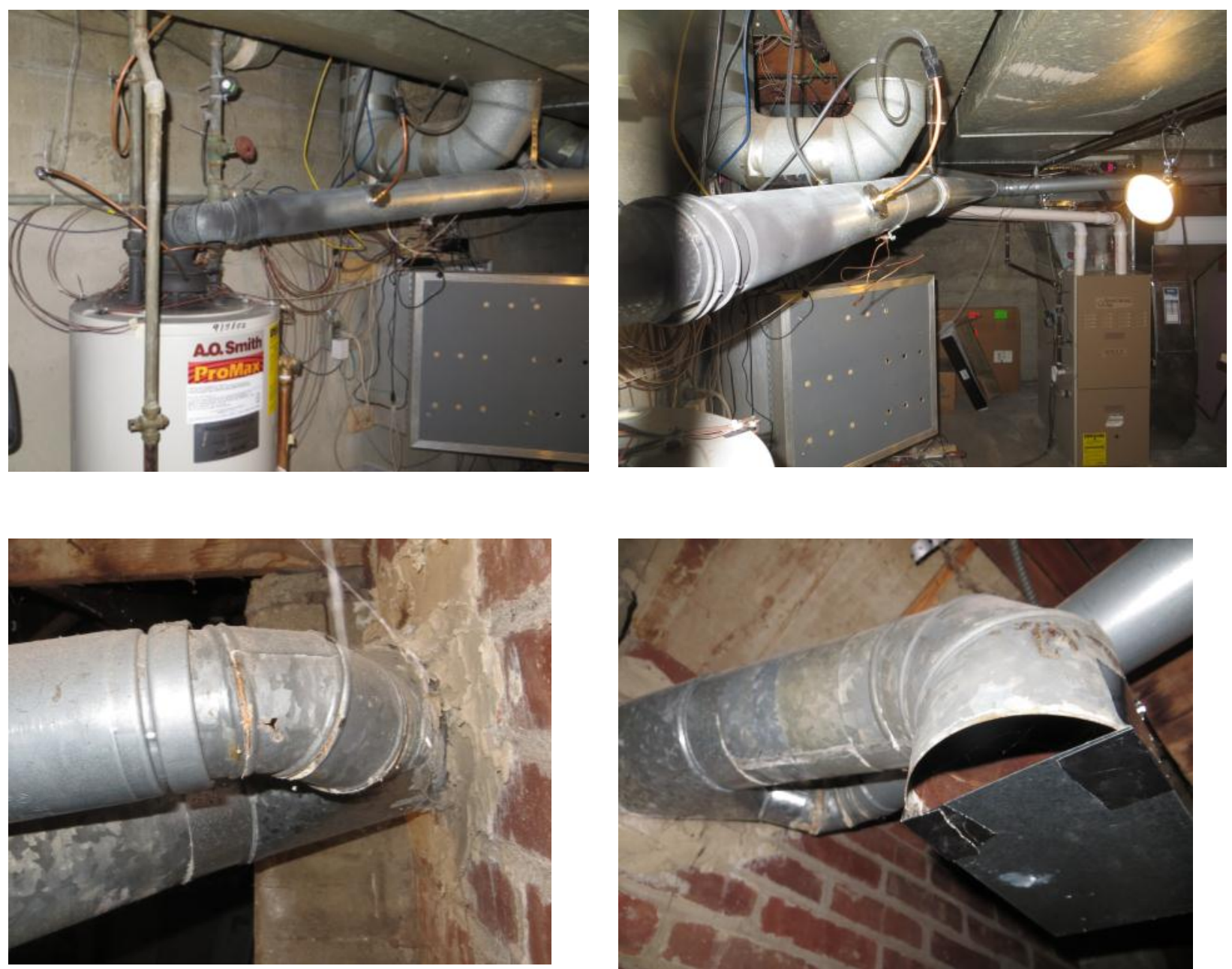

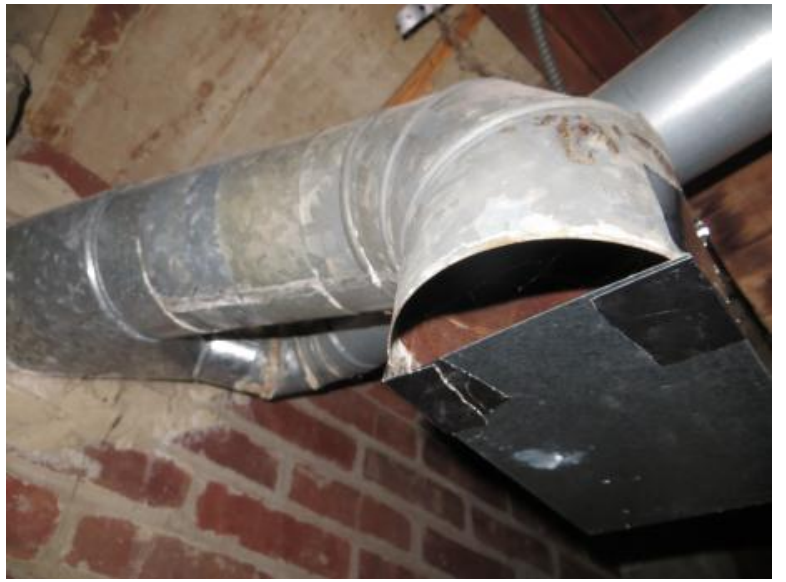




\section{Appendix D. Combustion Safety Survey

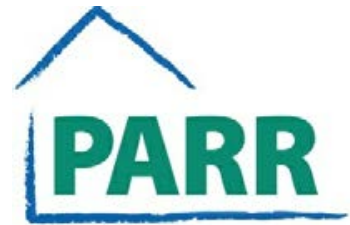 NATIONAL WEATHERIZATION SURVEY ABOUT HOMES THAT EXCEED WORST-CASE DEPRESSURIZATION LIMITS AND FAIL SPILLAGE}

The Partnership for Advanced Residential Retrofit research team is conducting a Building America research project designed to increase understanding of combustion appliance spillage test results among the housing stock weatherized by DOE Weatherization Assistance Programs nationally.

The primary purpose of this survey is to understand states' methods for conducting the worst-case depressurization test and identify the number of homes per state that received measures due to concerns of spillage from depressurization (i.e., not spillage from a plugged flue).

This survey should be completed by weatherization team leads or program managers.

Please submit your responses by mail or by e-mail by $7 / 15 / 2015$ to:

Stacy Gloss, research specialist

2111 S. Oak St. Suite 106

Champaign, IL 61820

sgloss@illinois.edu

\section{SURVEY QUESTIONS:}

Please provide information about the respondent:

Name:

Title:

Street Address:

State:

Phone number:

E-mail address:

May we contact you to follow up on your responses?

Answer the following questions to the best of your knowledge about your state's program. Be as specific as possible.

1. Please specify the last program year that you have data for (e.g., $7.2013-6.2014$ or $1.2014-$ 12.2014)

2. How many homes were weatherized in your state in the last program year?

3. What percentage of homes weatherized use either natural gas or fuel oil as the primary heating fuel? 
4. What percentage of homes have natural draft appliances (e.g., a natural draft water heater) within the pressure boundary of the home? These appliances would have a draft hood or draft diverter. Inside the pressure boundary means in the living space or a room that doesn't have a duct or wall penetration opening to an area outside the living space.

5. What percentage of homes have natural draft appliances outside the pressure boundary of the home? For example, vented closets, garages, crawl spaces, attics.

6. What is the test procedure your state uses to address combustion safety? If your state uses a BPI procedure please simply state which version. If your state uses another procedure and you can share a document or link, please do.

7. Does spillage testing occur when a house exceeds worst-case depressurization limits? $\mathrm{Y} / \mathrm{N}$

8. At how many minutes does the Wx assessor check for spillage under WCD conditions?

9. In homes where the combustion appliance is in a small closet and the assessor cannot be in the CAZ with the door closed, how is spillage assessed?

This next section pertains to homes in your program that fail spillage tests. Read each question carefully. If you have any questions about this section, or if you need clarification on a question please contact sgloss@illinois.edu.

10. How many homes in the last program year received any remediation measures to alleviate expected post-Wx spillage due to approaching or exceeding worst-case depressurization limits during pre-Wx assessments?

11. How many homes in the last program year received any remediation measures to alleviate observed spillage due to depressurization (i.e. not from a blocked flue, etc.)?

12. When homes failed a spillage test, how many of those homes failed due to operation of the air handler (i.e. air handler return leaks)?

13. When homes failed a spillage test, how many of those homes failed due to operation of appliances that exhaust air (i.e. kitchen or bath ventilation, dryers)?

14. How many homes receiving remediation for expected or observed spillage post-Wx had a new appliance installed?

15. How many homes receiving remediation for expected or observed spillage post-Wx had a power vent kit installed?

16. How many homes did not receive weatherization services (or were deferred) due to combustion safety failures? 


\section{Appendix E Logistic Model Definition and Detailed Output}

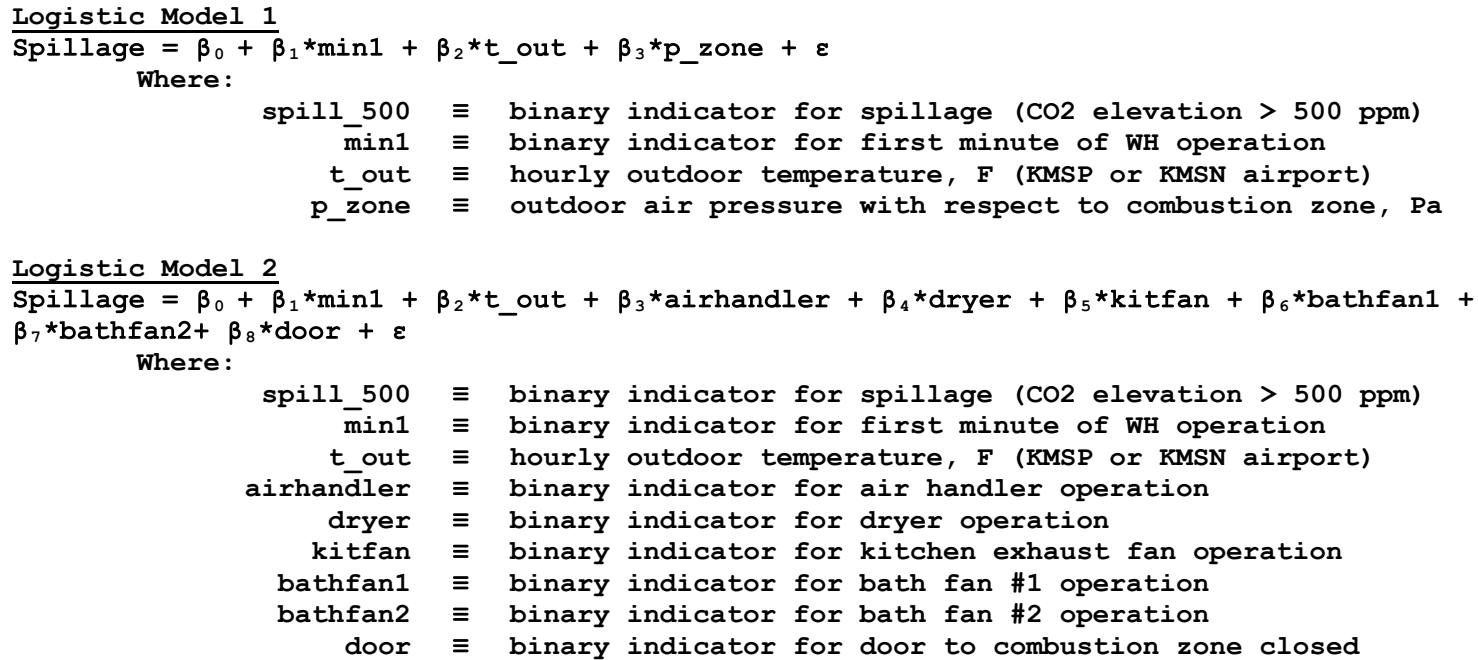

MODEL 1 OUTPUT

MN_01

Logistic regression Number of obs $=9840$

Wald $\operatorname{chi} 2(3)=219.15$

Prob $>$ chi2 $=0.0000$

Log pseudolikelihood $=-380.79947$ Pseudo $\mathrm{R} 2=0.6603$

(Std. Err. adjusted for 594 clusters in wh_cycle)

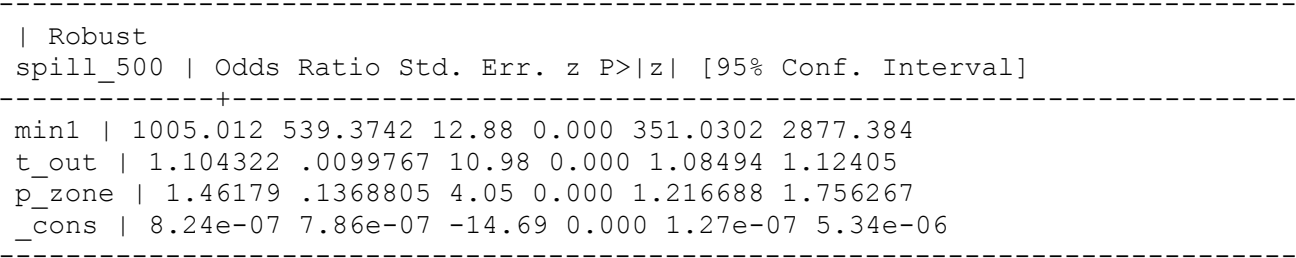

MN_02

Logistic regression Number of obs $=7169$

Wald $\operatorname{chi} 2(3)=85.42$

Prob $>$ chi2 $=0.0000$

Log pseudolikelihood $=-116.69931$ Pseudo $\mathrm{R} 2=0.5182$

(Std. Err. adjusted for 383 clusters in wh_cycle)

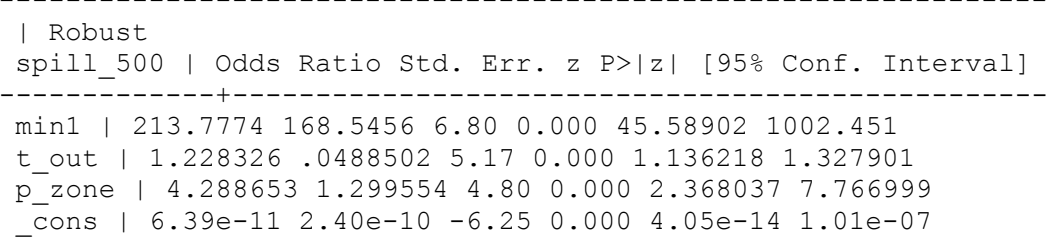

Note: 2 failures and 0 successes completely determined. 
MN_03

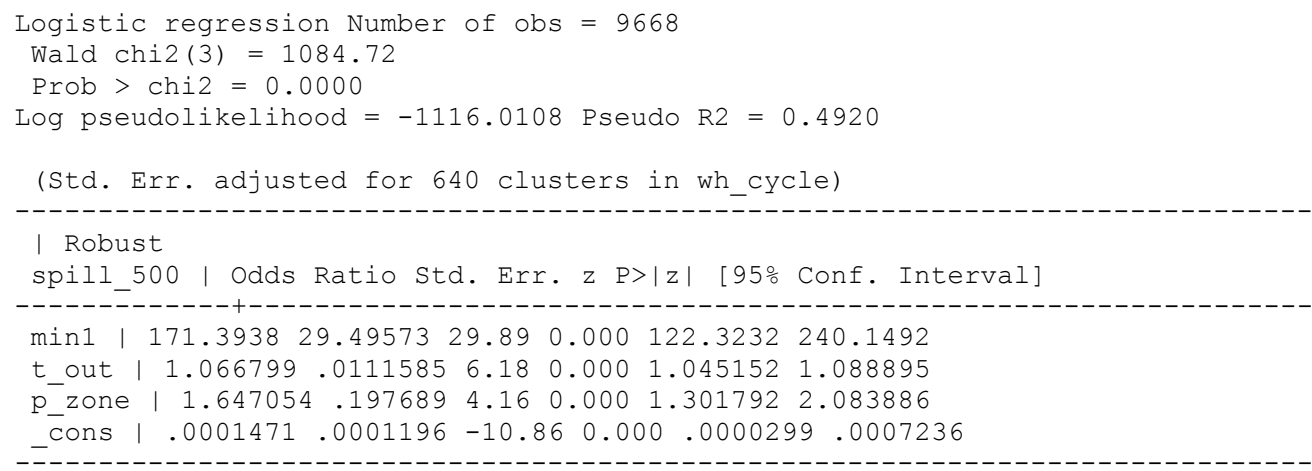

\section{MN_04}

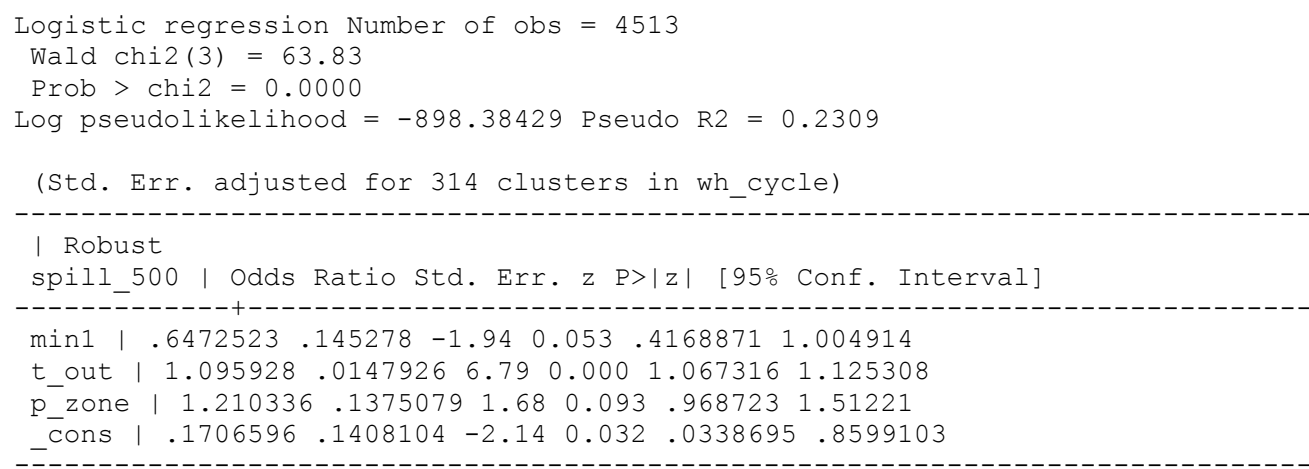

\section{MN_05}

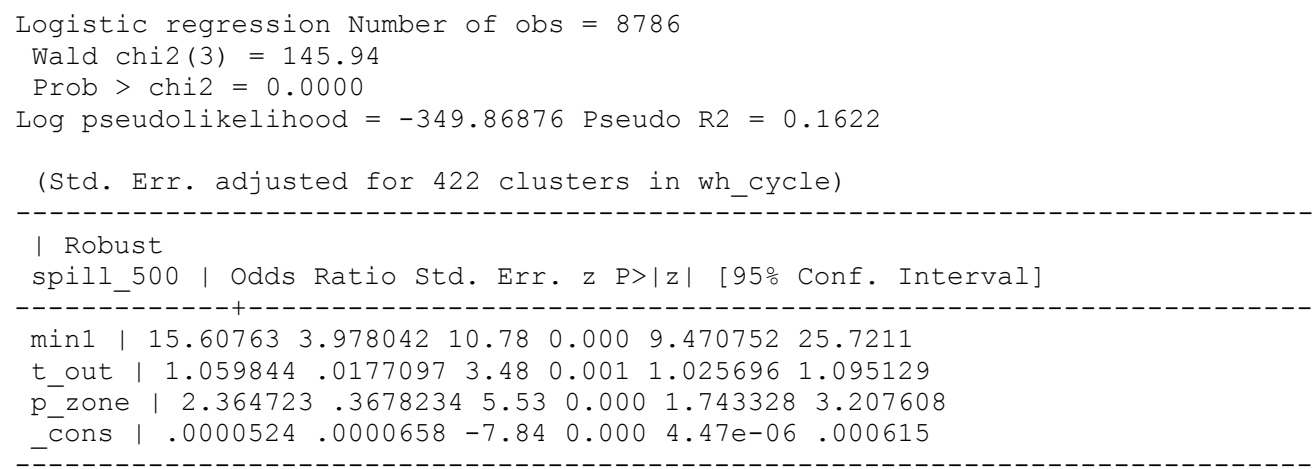


MN_06

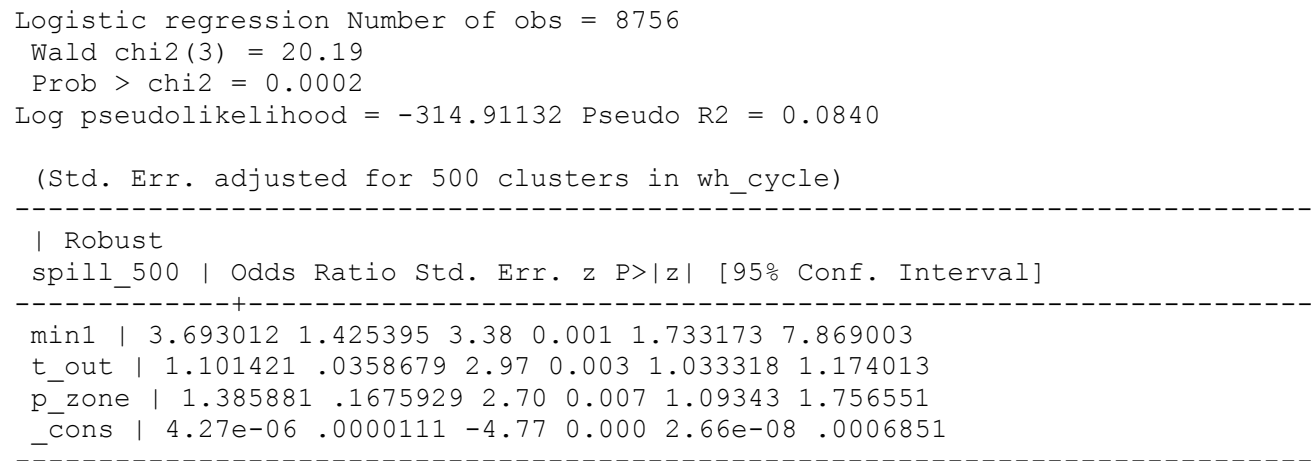

MN_07

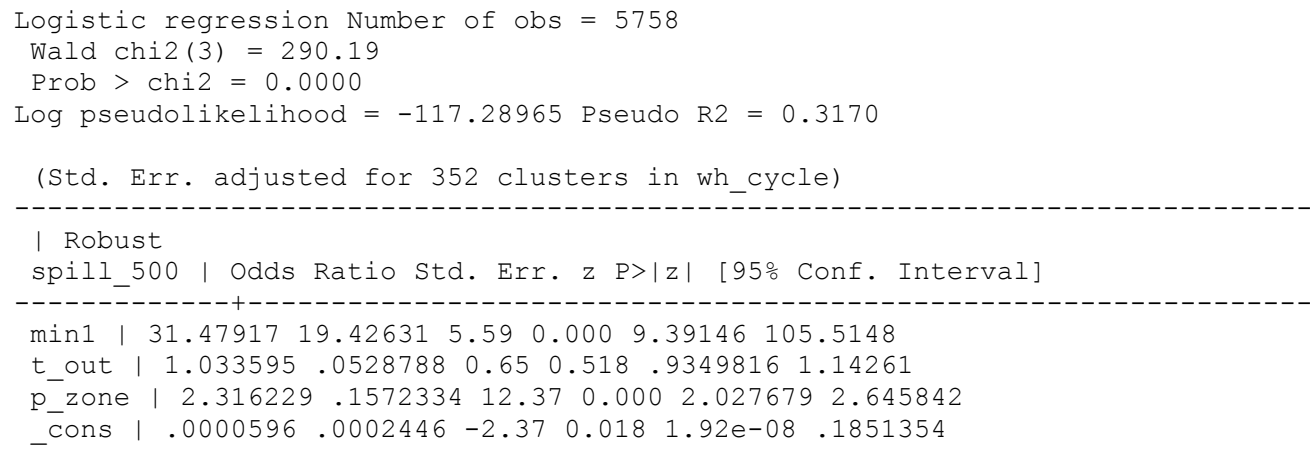

\section{MN_08}

[p_zone removed as a predictor due to missing data]

Logistic regression Number of obs $=1734$

Wald $\operatorname{chi} 2(2)=46.76$

Prob > chi2 $=0.0000$

Log pseudolikelihood $=-22.655858$ Pseudo $R 2=0.5559$

(Std. Err. adjusted for 82 clusters in wh cycle)

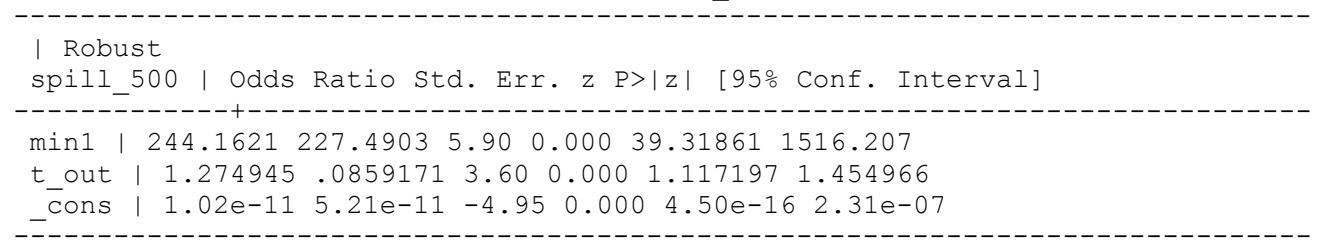


MN_09

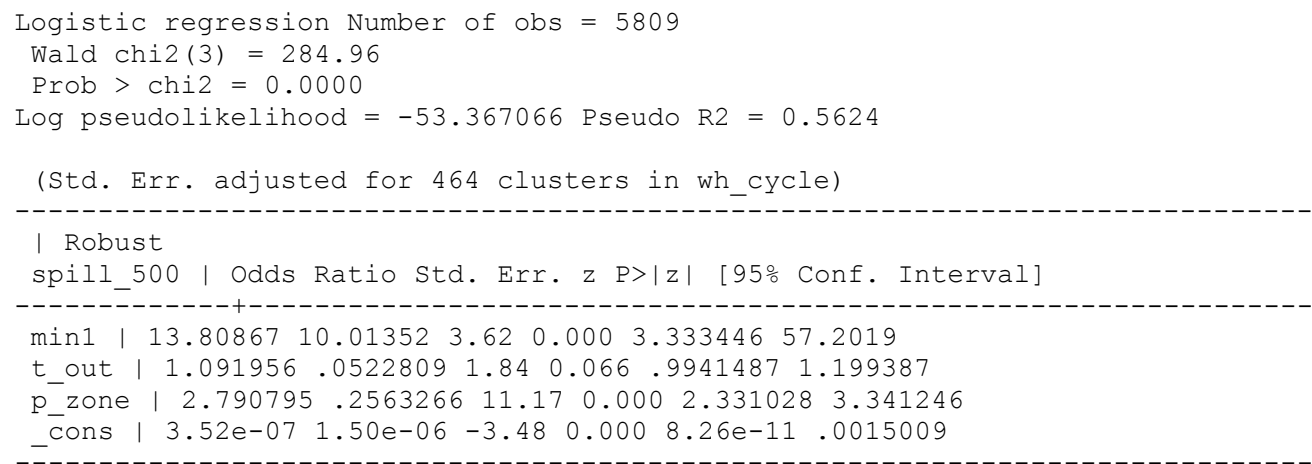

MN_10

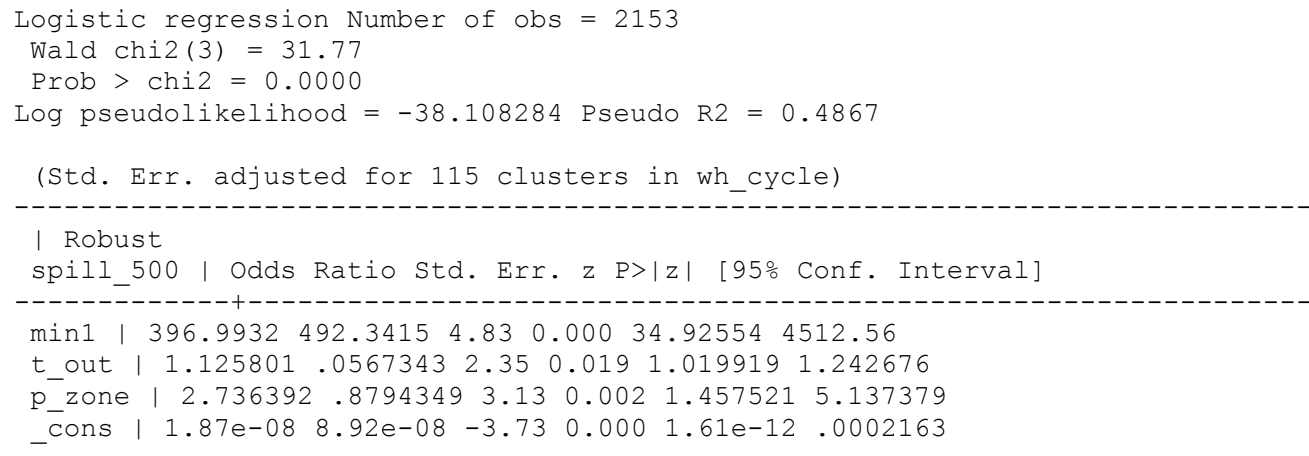

\section{WI_01}

[min1 removed as a predictor due to near coincidence with observed spillage]

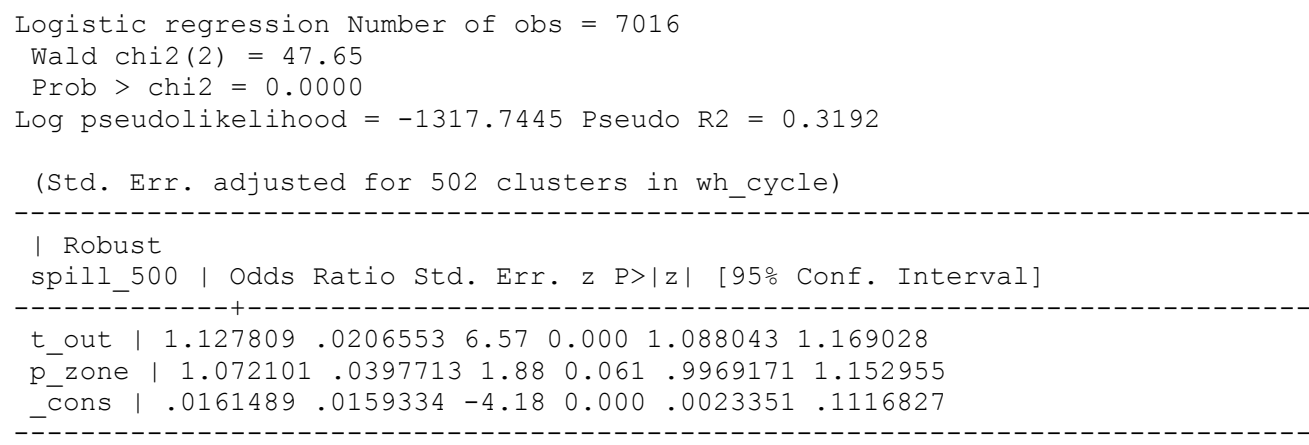


MODEL 2 OUTPUT

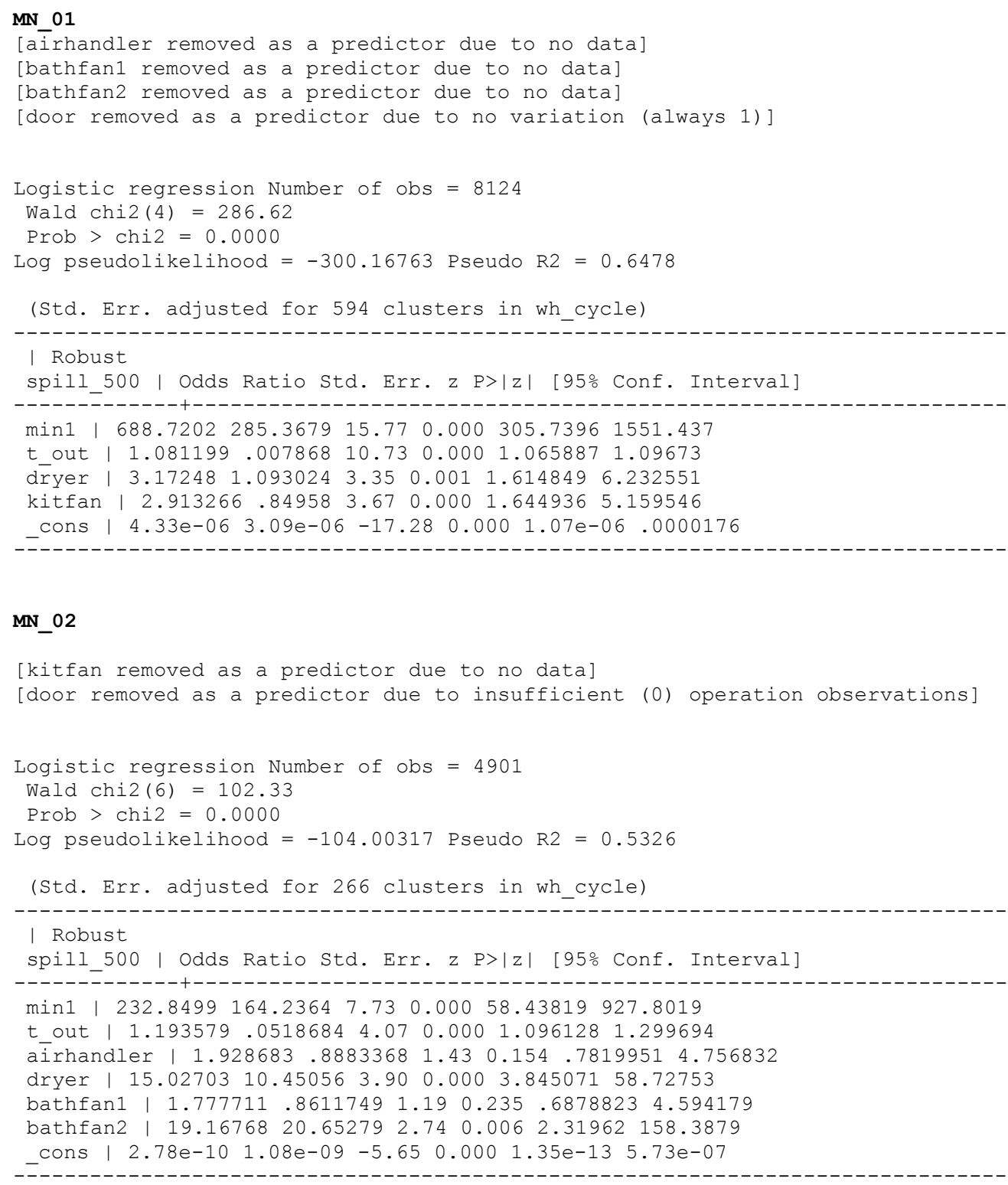


MN_03

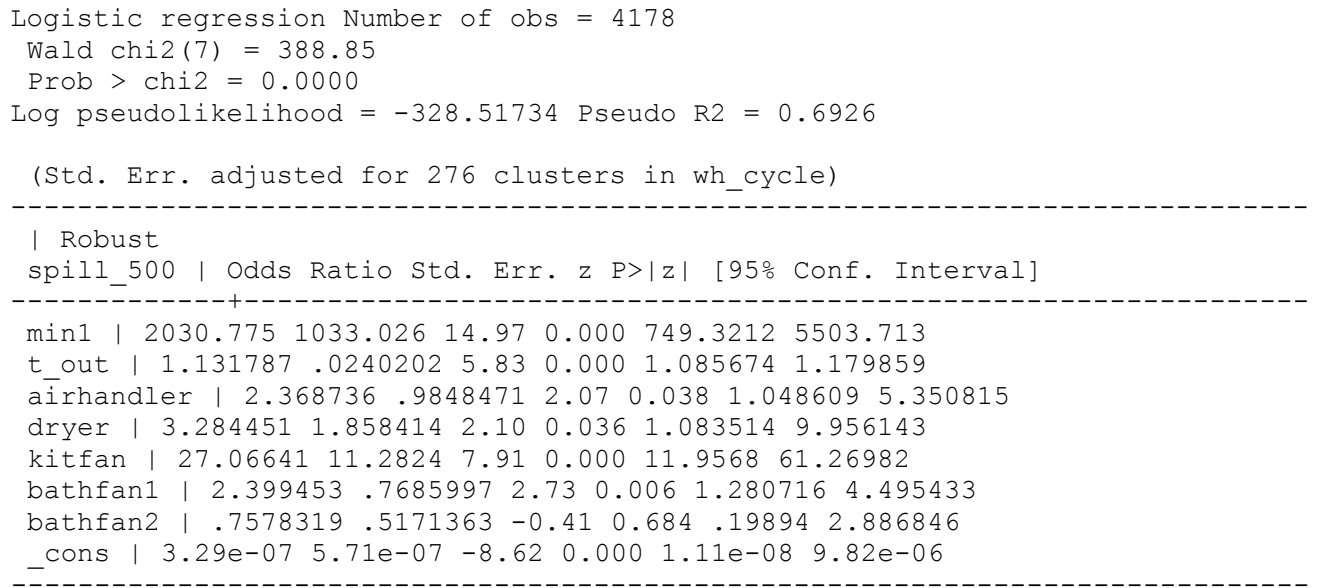

\section{MN_04}

[airhandler removed as a predictor due to no data]

[kitfan removed as a predictor due to spillage always occurring during operation]

[bathfan1 removed as a predictor due to no data]

[bathfan2 removed as a predictor due to no data]

[door removed as a predictor due to insufficient (0) operation observations]

Logistic regression Number of obs $=4586$

Wald $\operatorname{chi} 2(3)=70.64$

Prob $>$ chi2 $=0.0000$

Log pseudolikelihood $=-913.36726$ Pseudo $\mathrm{R} 2=0.2267$

(Std. Err. adjusted for 314 clusters in wh cycle)

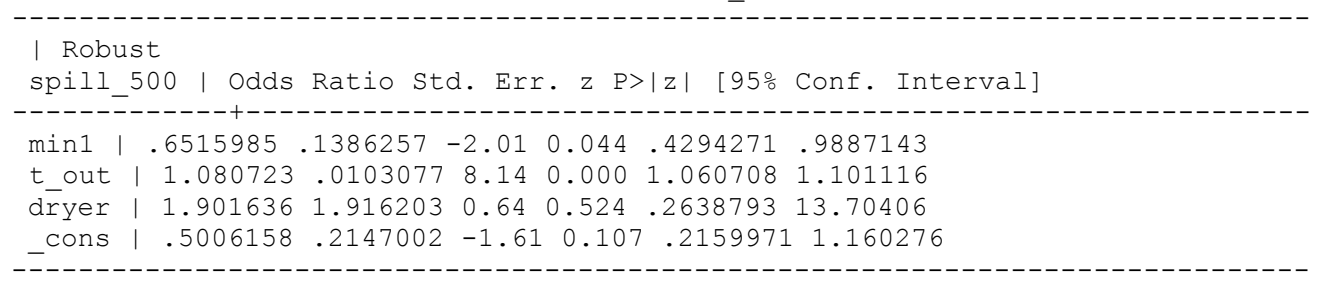


MN_05

[kitfan removed as a predictor due to spillage never occurring during operation] [bathfan1 removed as a predictor due to insufficient (0) operation observations] [bathfan2 removed as a predictor due to no data]

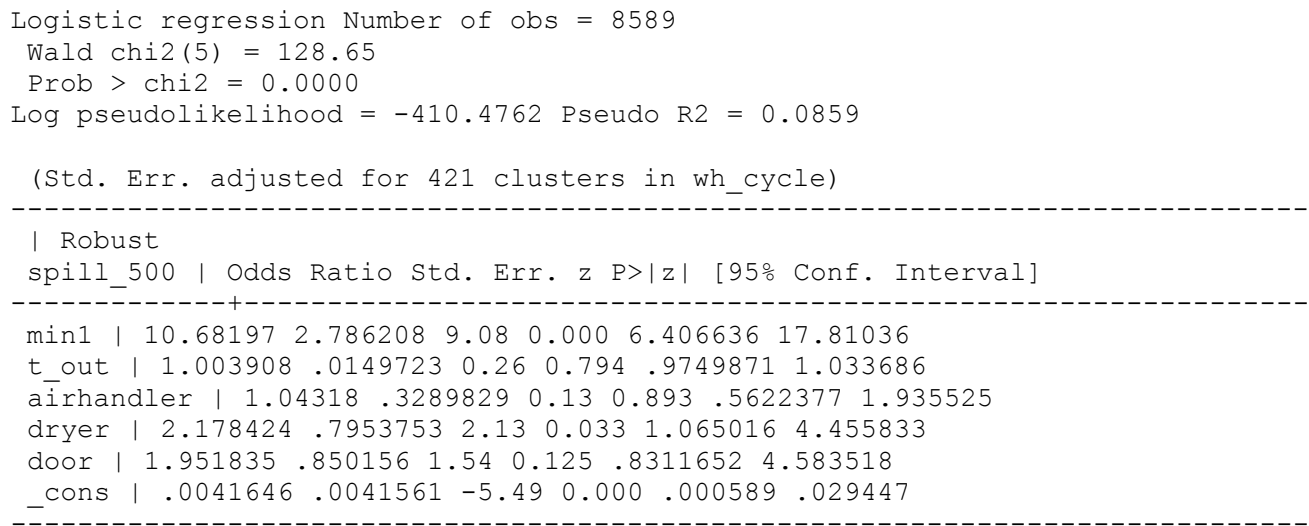

\section{MN_06}

[dryer removed as a predictor due to spillage never occurring during operation] [kitfan removed as a predictor due to insufficient (0) operation observations] [bathfan2 removed as a predictor due to no data] [door removed as a predictor due to suspect data]

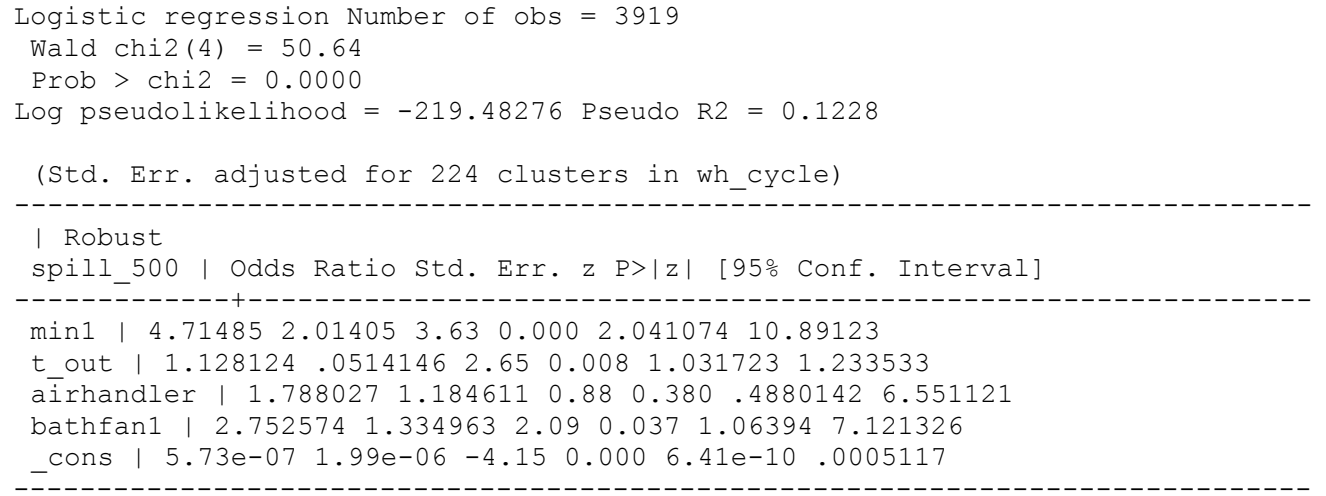


MN_07

[dryer removed as a predictor due to spillage never occurring during operation] [bathfanl removed as a predictor due to spillage never occurring during operation] [bathfan2 removed as a predictor due to no data]

[door removed as a predictor due to insufficient (0) operation observations]

Logistic regression Number of obs $=2609$

Wald $\operatorname{chi} 2(4)=127.34$

Prob > chi2 $=0.0000$

Log pseudolikelihood $=-47.881658$ Pseudo $\mathrm{R} 2=0.4506$

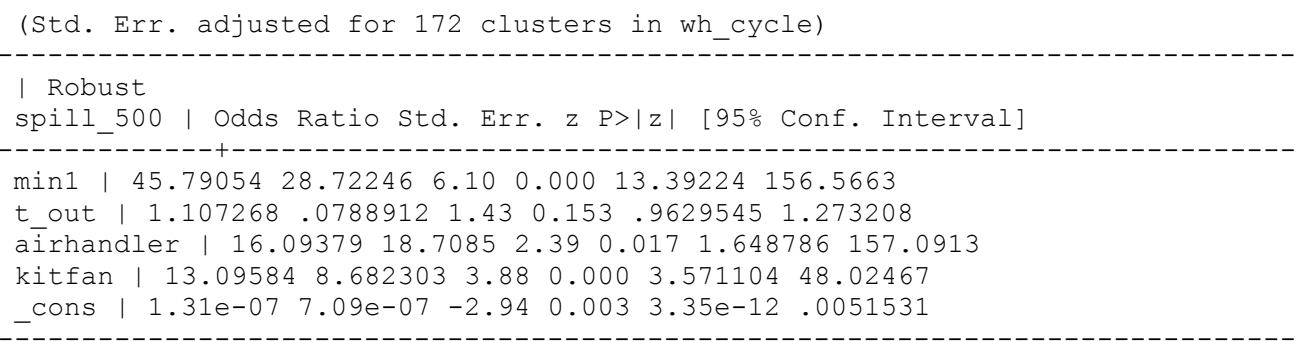

MN_08

[airhandler removed as a predictor due to insufficient (0) operation observations] [dryer removed as a predictor due to insufficient (0) operation observations] [kitfan removed as a predictor due to insufficient ( 0 ) operation observations] [bathfan1 removed as a predictor due to no data] [bathfan2 removed as a predictor due to no data] [door removed as a predictor due to insufficient (0) operation observations]

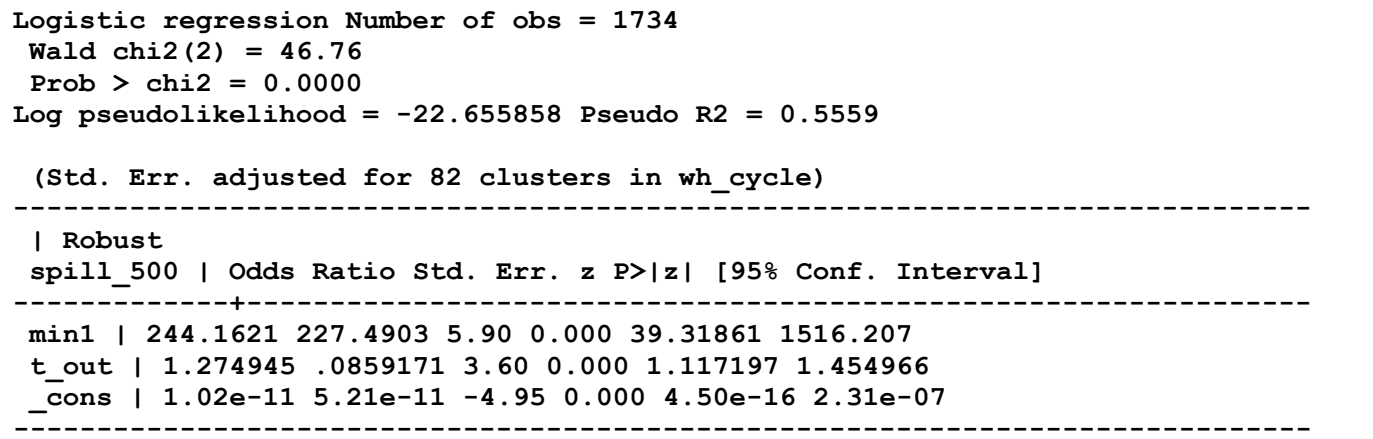


MN_09

[kitfan removed as a predictor due to spillage never occurring during operation] [bathfanl removed as a predictor due to spillage never occurring during operation] [bathfan2 removed as a predictor due to no data]

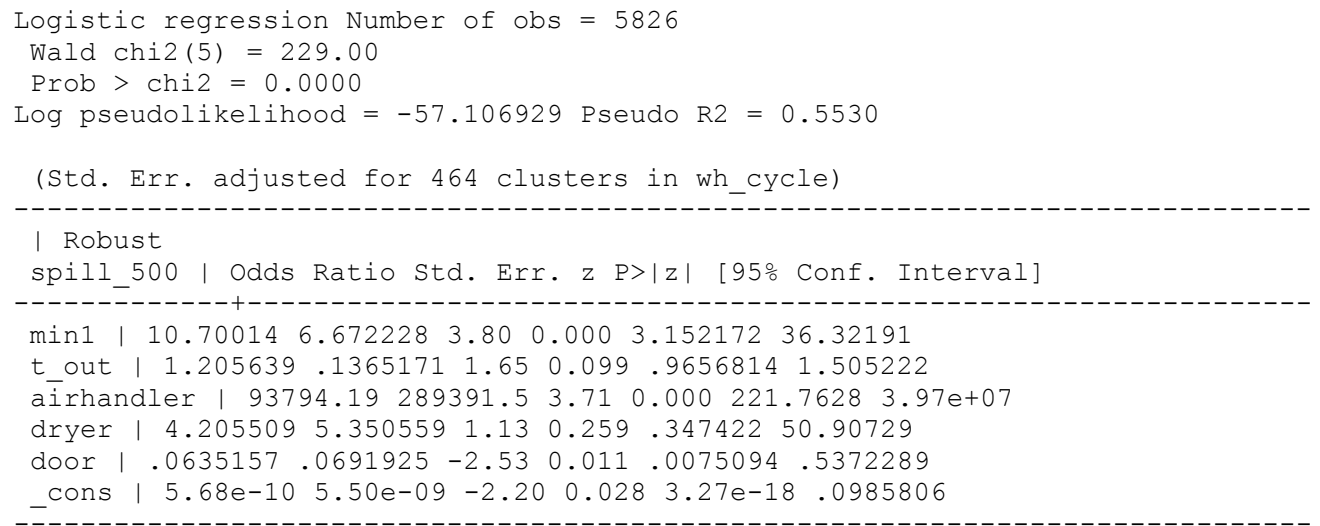

\section{MN_10}

[airhandler removed as a predictor due to spillage never occurring during operation] [dryer removed as a predictor due to no data] [kitfan removed as a predictor due to no data] [bathfan2 removed as a predictor due to no data] [door removed as a predictor due to insufficient (0) operation observations]

Logistic regression Number of obs $=2157$

Wald $\operatorname{chi} 2(3)=48.40$

Prob $>$ chi2 $=0.0000$

Log pseudolikelihood $=-49.817469$ Pseudo $\mathrm{R} 2=0.3727$

(Std. Err. adjusted for 115 clusters in wh cycle)

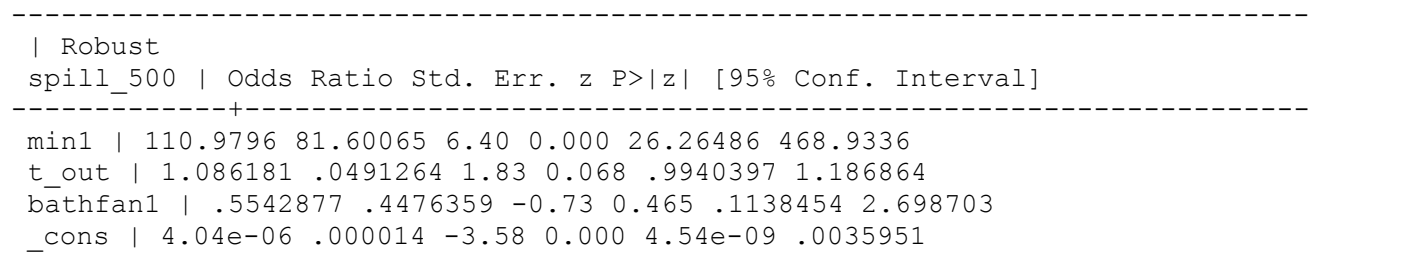




\section{u.s. Department of | Energy Efficiency \& ENERCY Renewable Energy}

\section{WI_01}

[min1 removed as a predictor due to spillage always occurring in Minute 1] [kitfan removed as a predictor due to no data]

[bathfan1 removed as a predictor due to insufficient (3) operation observations]

[bathfan2 removed as a predictor due to no data]

Logistic regression Number of obs $=6147$

Wald $\operatorname{chi} 2(4)=357.10$

Prob > chi2 $=0.0000$

Log pseudolikelihood $=-890.71423$ Pseudo R2 $=0.4953$

(Std. Err. adjusted for 446 clusters in wh_cycle)

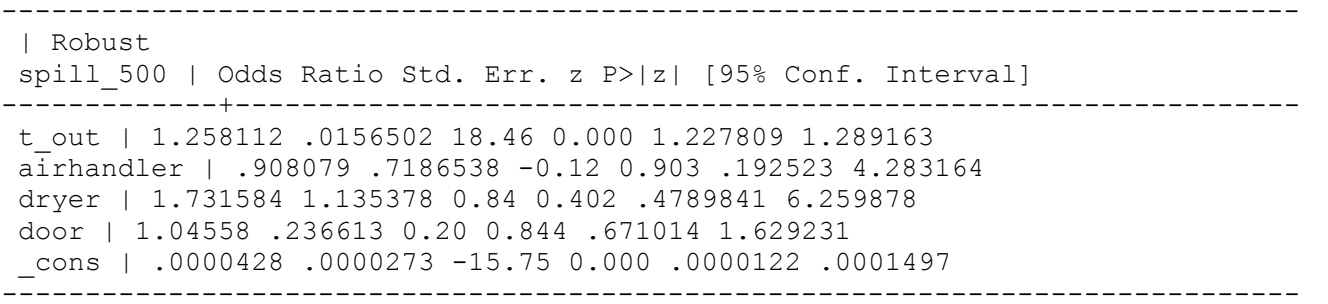


